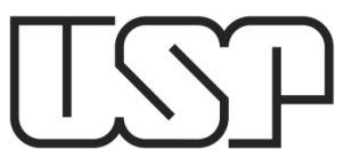

UNIVERSIDADE DE SÃO PAULO

ESCOLA DE EDUCAÇÃO FÍSICA E ESPORTE

PEDAGOGIA DO MOVIMENTO HUMANO

PROGRAMA DE PÓS-GRADUAÇÃO

DANIEL DONADIO DE MELLO

\title{
A REDUÇÃO DO ESTADO DE ANSIEDADE DOS COBRADORES DE PÊNALTI NO FUTEBOL
}

TESE DE DOUTORADO

São Paulo 


\section{A REDUÇÃO DO ESTADO DE ANSIEDADE DOS COBRADORES DE PÊNALTI NO FUTEBOL}

Tese de Doutorado apresentada à Escola de Educação Física e Esporte da Universidade de São Paulo, como requisito parcial para obtenção do grau de Doutor em Educação Física - Área de Concentração: Pedagogia do Movimento Humano

Orientador: Antônio Carlos Simões

São Paulo 


\section{AGRADECIMENTOS}

Á minha mãe Vera Lucia Donadio e meu pai Jorge Luiz di Lorenzo Midões de Mello por todo carinho, amor e suporte ao longo de toda a minha vida. Sinceros agradecimentos ao meu querido professor Dr. Antonio Carlos Simões pela orientação e oportunidade. Muito obrigado a Eliane Yumi Kimura por toda força durante todo o processo. Agradeço ao Marcos Rodrigues Maximino por toda a paciência, boa vontade e apoio. 


\section{Resumo}

Mello, Daniel Donadio de. A Redução do estado de ansiedade dos cobradores de pênalti no futebol. 2017. Tese (Doutorado em Pedagogia do Movimento Humano) Escola de Educação Física e Esporte, Universidade de São Paulo, São Paulo. 2017.

O futebol é um esporte coletivo, em que desempenhos individuais podem definir o resultado de um jogo ou de um campeonato. Especialmente em cobranças de pênalti, o destino da partida encontra-se nos pés do cobrador. A ansiedade no momento das cobranças de pênalti em jogos de futebol de campo é um dos motivos que podem fazer com que um jogador de futebol não converta a cobrança em gol. Neste estudo experimental controlado foi testado um protocolo de biofeedback e psicologia cognitivo-comportamental com o objetivo de reduzir o estado de ansiedade em atletas de futebol amadores de futebol de campo de 15 e 16 anos de idade. Os participantes do grupo experimental foram avaliados antes de duas competições de pênaltis, que aconteceram antes e depois de quatro encontros de intervenção com o protocolo de biofeedback e psicologia cognitivocomportamental para a redução de ansiedade dos jogadores de futebol que participaram do grupo ativo, em relação ao grupo controle.

Palavras-chave: biofeedback, ansiedade, futebol, pênalti, psicologia do esporte. 


\begin{abstract}
Mello, Daniel Donadio de. The Reduction of state anxiety in penalty kickers in soccer. 2017. Tese (Doctor in Pedagogy of Human Movement) School of Physical Education and Sports, University of Sao Paulo, Sao Paulo. 2017.

Soccer is a collective sport in which individual performances can define the outcome of a game or a championship. Especially at penalties shootouts, the destination of the match is at the feet of the penalty taker. Anxiety at the time of penalty kicks at soccer matches is one of the reasons why a soccer player may not score the goal. In this controlled experimental study, a protocol of biofeedback and cognitive-behavioral psychology was tested with the objective of reducing the state anxiety in 15 and 16 year old amateur soccer athletes. Participants in the experimental group were assessed before two penalty shoot-outs, which took place before and after four intervention sessions with a biofeedback and cognitivebehavioral psychology protocol. The results showed that the protocol was efficient as a method and effective in reducing the anxiety state of soccer players who participated in the experimental group, in comparison to the control group.
\end{abstract}

Keywords: Biofeedback, soccer, football, anxiety, penalty, sports psychology, cognitivebehavioral therapy. 


\section{LISTA DE FIGURAS}

Figura 1 - Relação das cobranças realizadas (CR), cobranças convertidas em

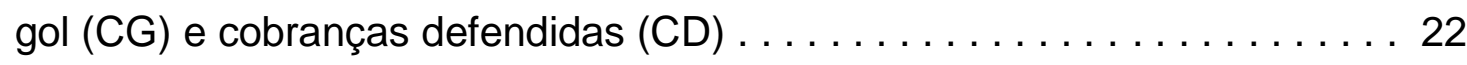

Figura 2 - Teoria do $U$ Invertido $\ldots \ldots \ldots \ldots \ldots \ldots \ldots \ldots \ldots \ldots \ldots \ldots \ldots \ldots \ldots \ldots \ldots$

Figura 3 - Flecha Descendente $\ldots \ldots \ldots \ldots \ldots \ldots \ldots \ldots \ldots \ldots \ldots \ldots$

Figura 4 - Glândulas Sudoríparas. As 0 "ligadas" e as "desligadas". . . . . . . . . . .44

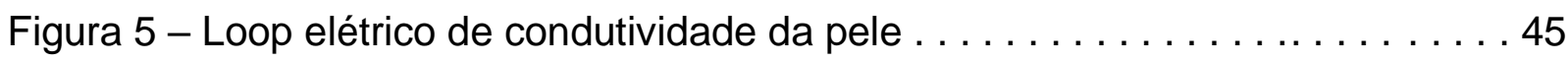

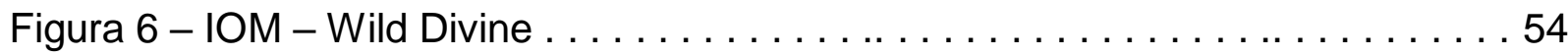

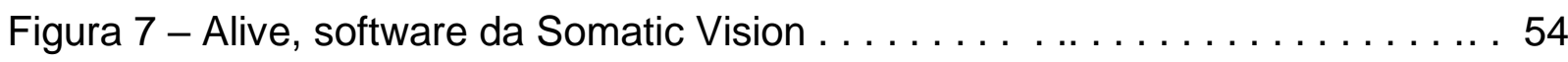

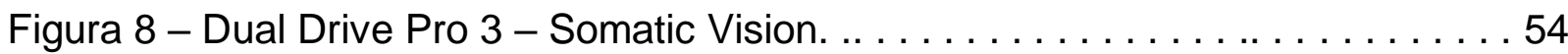

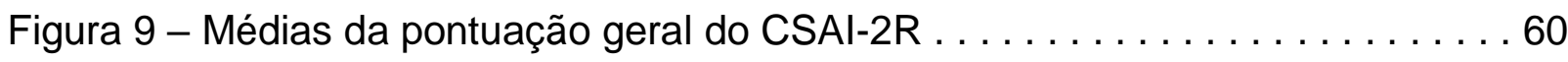

Figura 10 - Médias do sub item Ansiedade Somática do CSAI-2R. . . . . . . . 61

Figura 11 - Médias do sub item Ansiedade Cognitiva do CSAI-2R. . . . . . . 62

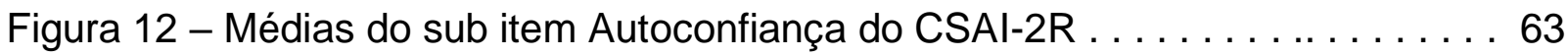

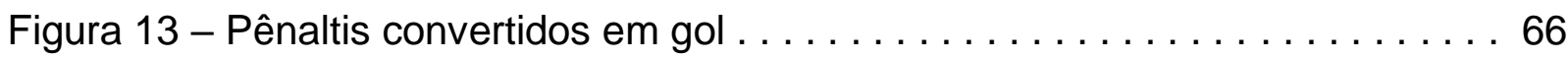




\section{LISTA DE QUADROS}

Quadro 1 - Desenho do estudo . 


\section{LISTA DE TABELAS}

Tabela 1 - Registro de pensamentos disfuncionais - RPD. . . . . . . . 41

Tabela 2 - Média entre grupos pré e pós intervenção . . . . . . . . . . 61

Tabela 3 - Tabela de comparações múltiplas das médias: Contrastes de

Tukey com as médias das diferenças e seus respectivos intervalos de

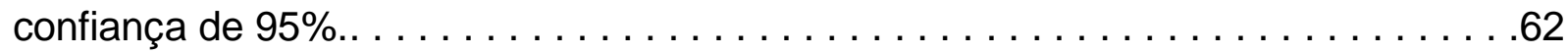




\section{Lista de abreviaturas e siglas}

$\begin{array}{ll}\text { ARS } & \text { Arritmia Sinusal Respiratória } \\ \text { CSAI-2R } & \text { Revised Competitive State Anxiety Inventory-2 } \\ \text { EDR } & \text { Resposta eletro dérmica (electrodermal response) } \\ \text { EEG } & \text { Eletroencefalograma } \\ \text { GSR } & \text { Biofeedback de Resposta Galvânica da pele (galvanic skin response) } \\ \text { HRV } & \text { Biofeedback de Variabilidade Cardíaca (heart rate variability) } \\ \text { RPD } & \text { Registro de Pensamentos Disfuncionais } \\ \text { SRL } & \text { Biofeedback de Resistência da pele (skin resistence level) } \\ \text { TCC } & \text { Terapia Cognitivo-Comportamental }\end{array}$




\section{Sumário}

1 INTRODUÇÃO

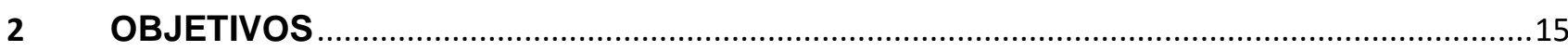

2.1 Geral:

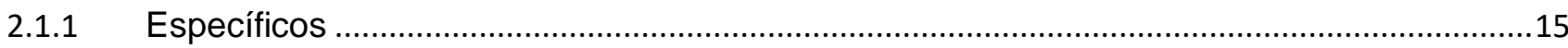

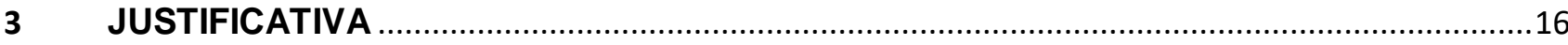

4 DELIMITAÇÃO DO ESTUDO

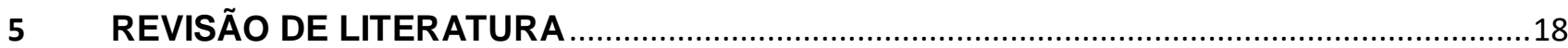

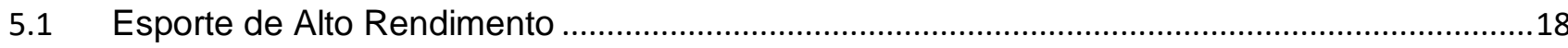

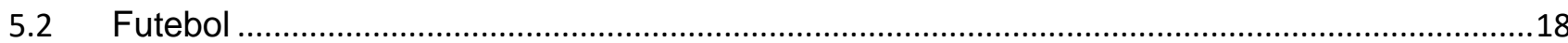

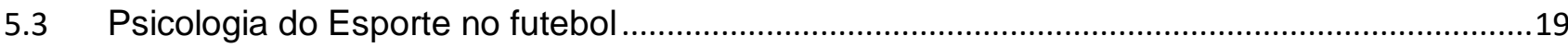

5.4 Cobranças de Pênaltis e Fatores Gerais Envolvidos ...........................................................21

5.5 Cobranças de Pênaltis e Ansiedade .......................................................................................23

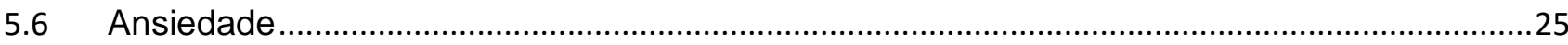

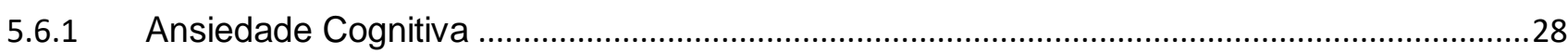

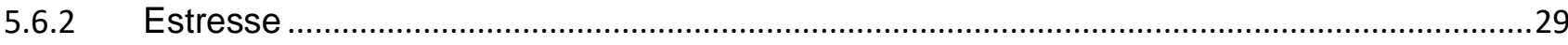

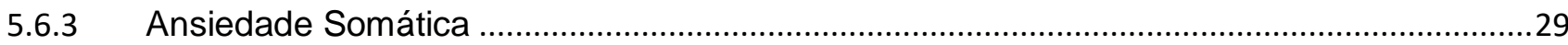

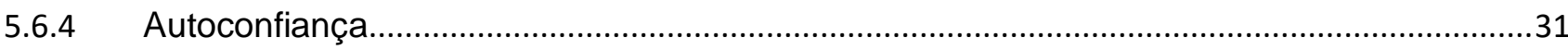

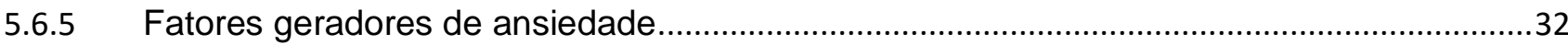

5.7 O uso do "CSAI -2R" em estudos nos esportes de competição................................................32

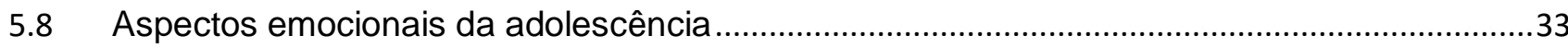

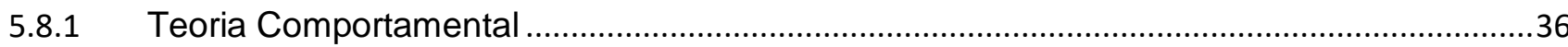

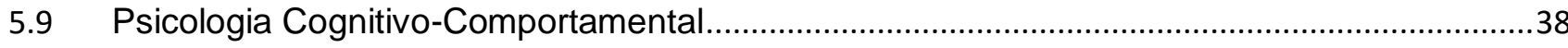

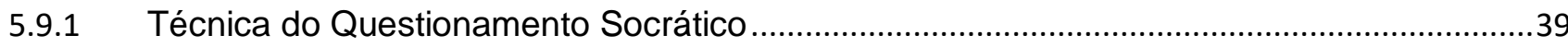

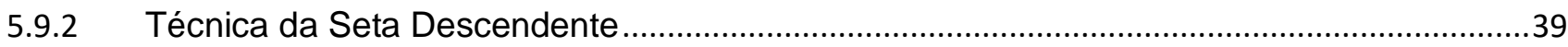

5.9.3 Técnica do registro de pensamentos disfuncionais - RPD ….............................................40

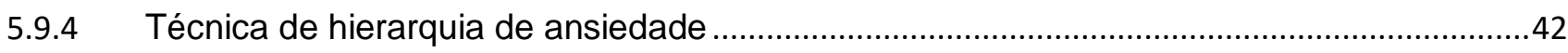

5.9.5 Técnica de dessensibilização sistemática por imagem .........................................................42

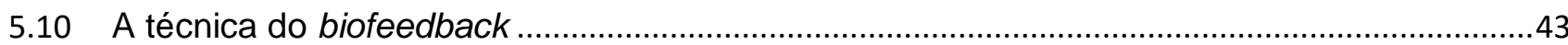


5.11 A técnica biofeedback de condutância galvânica.....................................................................44

5.12 A técnica biofeedback de variabilidade cardíaca ...................................................................45

5.13 O uso da técnica de biofeedback no esporte..........................................................................47

5.14 O biofeedback e psicologia-cognitivo comportamental .........................................................48

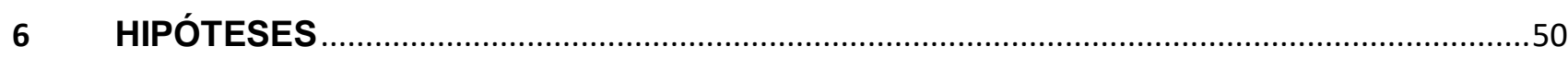

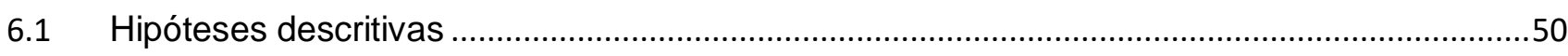

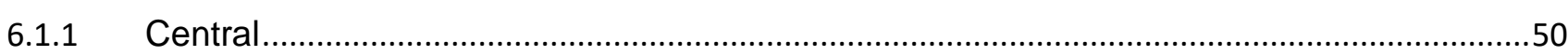

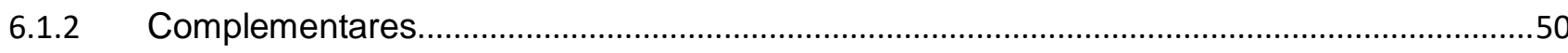

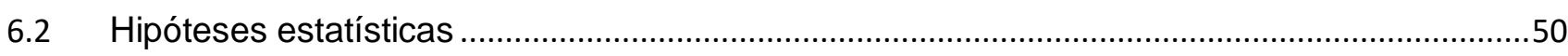

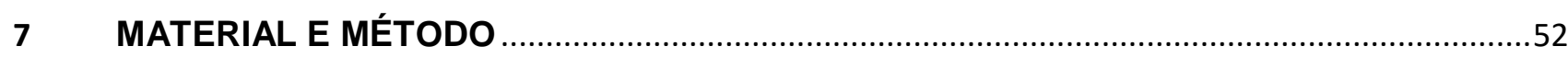

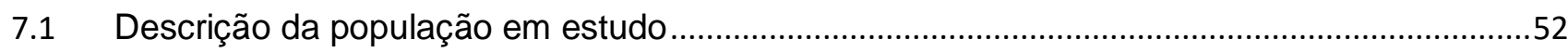

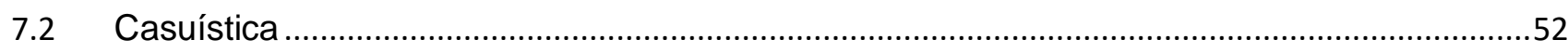

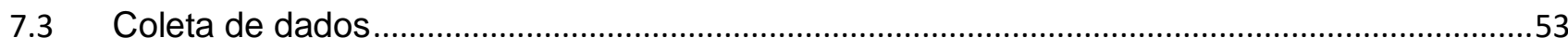

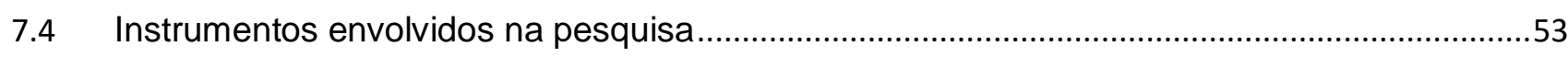

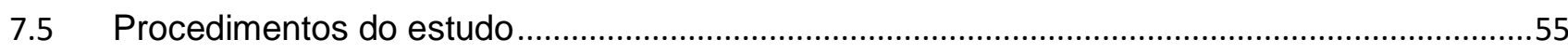

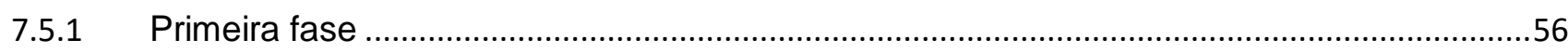

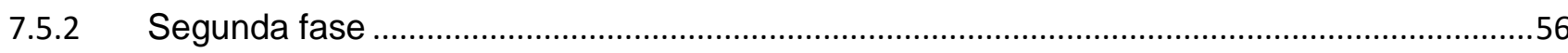

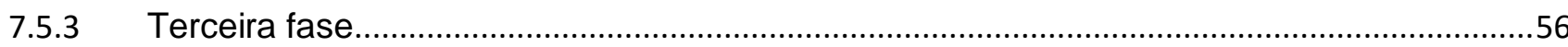

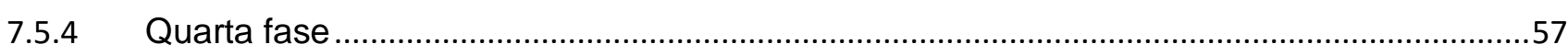

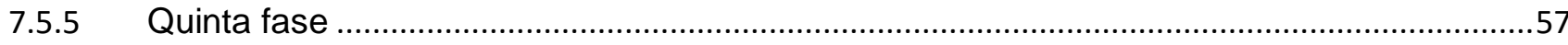

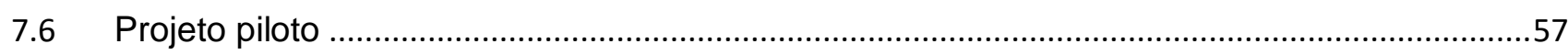

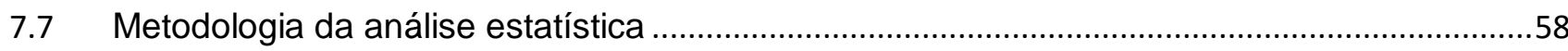

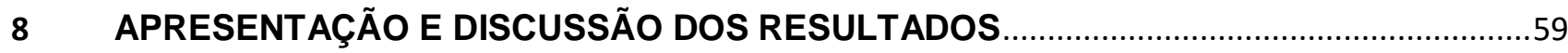

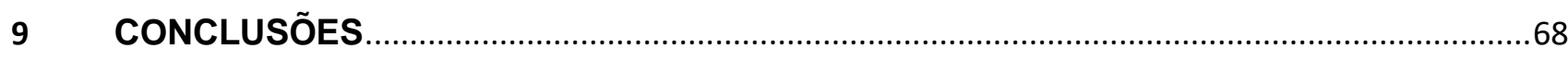

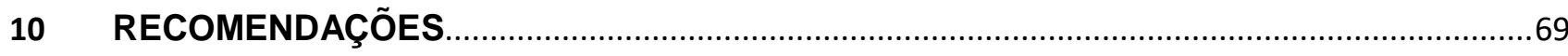

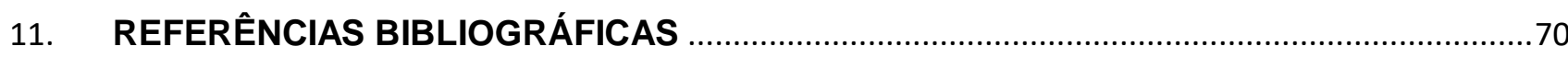




\section{INTRODUÇÃO}

A literatura mostra que o futebol de campo tem sido objeto de estudo acerca de vários fatores que envolvem o desempenho dos futebolistas. Alguns desses estudos, têm se concentrado nas áreas fisiológicas, enquanto aspectos relacionados a psicologia, cognições e emoções dos atletas tem sido pouco explorados (REILLY; GILBOURNE, 2003). Consta da literatura que o futebol de campo é um fenômeno social e psicológico de marcante universalidade - moldado por um conjunto de fatores envolvidos com as competências físicas, atléticas e emocionais - que atuam como força no comportamento dos atletas.

Na realidade, o estado de ansiedade gerado pelas cobranças de pênaltis no futebol tem sido um dos grandes problemas para os atletas de futebol responsáveis por essas cobranças. Muitos atletas são levados a cobrar pênaltis sob a influência desse estresse emocional, que pode impactar negativamente o resultado dessa cobrança. Trata-se de um problema relacionado com a necessidade e o desejo de concretizar uma ação competitiva por excelência. Em 1982 as cobranças de pênalti começaram a ser usadas para decidir partidas entre seleções na Copa do Mundo na Espanha. Antes dessa edição, as partidas corriam livremente na prorrogação até haver um desempate, ou até eram decididas no "cara ou coroa" (MURRAY, 2000). Desde então, a responsabilidade dos cobradores aumentou ainda mais, já que um pênalti perdido pode significar a desclassificação dos representantes de um país na maior competição do mundo.

Wisiak (2001) pontuou que desde 1986 ao menos três partidas em cada edição da Copa do Mundo de futebol são decididas em disputas de pênalti. Wisiak e Cunha (2004) mostram que na prática os jogadores perdem muitos pênaltis. Somente na Copa do Mundo de 1990, 28\% dos 38 pênaltis cobrados não foram convertidos em gol. Na edição de 1998, os erros foram de $35 \%$ do total de 28 cobranças de penalidades (WISIAK, 2001). Simulando situações de pênalti, Silveira (1998) afirmou que se este fosse cobrado com força suficiente no canto inferior do gol, não haveria possibilidade de o goleiro chegar, a não ser que se antecipasse, movendo-se em direção ao canto antes do batedor chegar à bola, o que possibilitaria o batedor a trocar o lado que chutaria a bola. Porém, em geral a decisão sobre a estratégia de aguardar o goleiro saltar ou chutar de maneira independente do goleiro é tomada antes da própria cobrança, salvo em momentos de grande estresse e ansiedade. 
Jordet (et al 2007b) apontou que o percentual de pênaltis perdidos é maior em partidas de futebol de campo de maior importância do que em jogos de menor importância, e sugere que o estresse e a ansiedade são, em boa parte, fatores responsáveis pelo desperdício nessas cobranças. Até mesmo um leigo pode perceber que um número considerável de cobradores de pênalti fica ansioso, e esse estado de ansiedade pode prejudicar um atleta nessa tarefa. Se essa ansiedade pode ser observada em atletas profissionais, em jovens atletas amadores, é notado que durante os pênaltis, ou outros momentos em que as habilidades técnicas e táticas são publicamente avaliadas, o atleta adolescente parece demonstrar uma ansiedade mais elevada do que atletas adultos, devido à autoestima mais baixa, avaliação dos colegas, pais e treinadores (CRATTY, 1984; SANTOS; PEREIRA, 1997).

No caso de atletas mais experientes, Landers (et. al., 1994) e Salazar (et. al., 1990), observaram que existe uma tendência de diminuição do ritmo cardíaco no momento da execução de tarefas que exigem foco de atenção mais elevado, quando comparado com atletas menos experientes. Nesses estudos, esse decréscimo do ritmo cardíaco foi relacionado a um melhor desempenho nessas tarefas, e seu aumento associado a uma incidência maior de estresse.

McGrady (et al., 1981) asseverou que o estresse desencadeia inúmeras reações psicofisiológicas, e alguns desses sintomas podem ser: rigidez muscular, aceleração e palpitação cardíaca, respiração rápida, tontura e muitos outros. Essas são reações do sistema nervoso simpático de atletas que deveriam estar com a taxa cardíaca mais reduzida, respiração lenta, sinais de sistema parassimpático, características de atletas condicionados fisicamente, mas não estão, podendo atrapalhar diretamente o rendimento dos atletas durante uma partida, e principalmente em um momento que necessitam de diversas habilidades físicas e psicológicas para tomar decisões, bom controle motor, capacidade de percepção do ambiente para alteração de resposta, como é o momento da cobrança do pênalti.

Não há consenso na literatura sobre o que seria um pênalti bem cobrado. Já o senso comum diz que "um pênalti bem cobrado é aquele que a bola entra no gol, e o jogador deve estar concentrado e focado no chute que dará para superar o goleiro adversário". Muitos dizem que o atacante deve ter calma para aguardar a decisão do goleiro que geralmente escolhe um canto onde supõe que a bola será endereçada. 
Com relação a ansiedade no momento do pênalti, são vários os autores que apontam a incoerência entre cobrar um bom pênalti com estresse e ansiedade alta, porém não consideram a ansiedade apenas como um mecanismo destrutivo, mas como um equipamento biológico normal e necessário à sobrevivência da espécie humana (PEREIRA et. al. 2003).

Ante o exposto acima, poderíamos considerar que os comportamentos perceptíveis e imperceptíveis gerados pela ansiedade deste momento decisivo na partida de futebol, surgem a partir de cognições e estados de humor que podem ser investigados e trabalhados com técnicas da psicologia cognitivo-comportamental, associadas a uma técnica denominada biofeedback, que pode ser considerada um instrumento que permite a mensuração e retroalimentação de parâmetros fisiológicos do estresse em tempo real, permitindo ao atleta identificar e treinar a redução do estado de ansiedade.

Neste sentido, estabeleceu-se os seguintes objetivos: 


\section{OBJETIVOS}

\subsection{Geral:}

Investigar se o protocolo de técnica de biofeedback associada à psicologia cognitivocomportamental envolvendo atletas de categoria de base de equipes de futebol poderia ser considerada como um protocolo determinante para reduzir o estado de ansiedade desses agentes nas cobranças de pênalti.

\subsubsection{Específicos}

- Elaborar um protocolo de treinamento de redução de ansiedade associando técnicas de psicologia cognitivo-comportamental com o instrumento biofeedback.

- Verificar se existe diferença estatisticamente significativa no aumento da autoconfiança pós-treinamento, na comparação com o grupo controle, no momento da cobrança de pênalti.

- Verificar se existe diferença estatisticamente significativa na redução do estado de ansiedade somática e cognitiva do grupo ativo, pós-treinamento, na comparação com o grupo controle, no momento da cobrança de pênalti. 


\section{JUSTIFICATIVA}

As cobranças de pênalti muitas vezes definem o resultado final de uma partida de futebol de campo. Por conta disso, diversos estudos analisam essas cobranças para tentar identificar decisões e estratégias que jogadores e goleiros tomam no momento para maximizarem suas chances. Estudos demonstram que independentemente da estratégia que o cobrador utiliza no momento do pênalti, o estresse pode afetar diretamente seu desempenho e resultado.

É importante ressaltar que os estudos atuais exploram como as cobranças de pênaltis se alteram quando o jogador está ansioso e estressado. Decorre daí a necessidade de se investigar com mais profundidade a maneira pela qual os atletas podem ser preparados para ter seus estados de tensão e de estresse reduzidos.

Em estudos sobre ansiedade no esporte, um dos instrumentos de maior eficácia na redução dessa ansiedade é o biofeedback, que vem sendo estudado no esporte de alto rendimento para melhorar o desempenho de atletas em diversas modalidades através da autorregulação.

Nesta perspectiva, para se analisar essa questão pelo aspecto técnico, táticos e cientifico, um protocolo foi elaborado, incluindo técnicas de biofeedback e de psicologia cognitivo-comportamental, de natureza quantitativa e qualitativa, com o objetivo de ampliar o campo de conhecimento dos fatores cognitivo-comportamentais relacionados com a competência dos atletas nas cobranças de pênaltis. 


\section{DELIMITAÇÃO DO ESTUDO}

O presente estudo se restringiu as seguintes delimitações:

- A obter dados sobre os estados de ansiedade de atletas de 15 a 16 anos de categorias de base pertencentes a clubes sociais esportivos, do estado de São Paulo, que mantém equipes de futebol de alto rendimento mediante o uso do inventário denominado CSAI-2R, visando analisar os estados de ansiedade dos cobradores de pênalti antes e depois da intervenção com um protocolo experimental de biofeedback e terapia cognitivocomportamental. Os dados foram obtidos durante o período de treinamento das equipes para aumentar a validade ecológica.

- O pesquisador não delimitou a coleta de dados em função do tempo de permanência dos atletas nas equipes, religiosidade, situação social, ou composição corporal. Não foram investigados crenças e simbolismos sobre o vencer e outros aspectos simbólicos relativos ao desempenho. Tampouco se observou a fase de treinabilidade dos jogadores em estudo.

- Não foram consideradas diferenças de estrutura funcional dos clubes, do qual as equipes faziam parte, cujos atletas seriam os sujeitos desse estudo.

- Não foram coletados sinais fisiológicos dos atletas durante as cobranças de pênaltis.

- Não foram comparados os resultados diretos de atletas com diferentes estratégias de cobrança de pênalti, ou diferentes goleiros.

- Não foi mensurada a ansiedade-traço dos atletas.

É possível que esses fatores exerçam influência nos estados de ansiedade dos atletas. Comentários e generalizações acerca dos resultados devem ser feitos com a devida cautela dessa delimitação. 


\section{REVISÃO DE LITERATURA}

Em vista à temática e conceitos levantados acima, a presente revisão literária organizou-se em tópicos, a saber:

\subsection{Esporte de Alto Rendimento}

A prática esportiva pode ser considerada como uma atividade de enorme impacto na vida de diversos indivíduos. Com um valor humano e humanizador, o esporte tende a ser uma atividade social aberta a todos, e nela podem viver sem grande complexidade uma oportunidade de expressar o seu desejo, de se superar, e se aperfeiçoar.

Nesse aspecto, a competição penetrou em todo o patrimônio cultural. No caso do esporte como escolha profissional, quanto mais se avança na carreira esportiva, mais o atleta se compromete com a competitividade. Serassuelo Junior (et al., 2005) cita que a participação competitiva exige que o atleta se submeta a regras do alto rendimento, da modalidade esportiva, da instituição, do grupo, de empresários, treinadores, entre outros sujeitos que estão envolvidos com o Esporte Espetáculo.

A expressão "rendimento" nos leva a pensar em mensurar resultados, e a eficiência que este atleta na modalidade esportiva que ele está inserido. Cria-se a necessidade de o atleta ganhar todos os seus desafios para ser considerado vencedor, mesmo antes de atingir uma maturidade na carreira, tornar-se profissional. Em nome do Esporte de Alto Rendimento, pressões institucionais e de seus empresários, em que acabam muitas vezes por "coisificar" os atletas, criando situações em que sejam objetos de transações e de negócios visando o simples lucro, e nem sempre de acordo com a vontade do atleta. Desta maneira, cada atleta motiva-se de uma forma diferente para agir e competir de acordo com a adversidade encontrada no Esporte Competitivo.

\subsection{Futebol}

A história mostra que o futebol é uma das modalidades esportivas mais populares no mundo. Huerta (2004) realça que ele é um dos esportes coletivos que mais produz sentimentos e emoções, que leva as pessoas a um "continuum" de manifestações e comoções dentro e fora dos estádios. A origem desta modalidade não é precisa. É provável 
que o futebol tenha evoluído junto com a humanidade, se iniciando na pré-história, quando era jogado apenas com crânios, pedras e pinhas (MORELLI, 1986).

Witzig (2006), afirma que um jogo mais regrado, próximo do futebol moderno emergiu em escolas da Inglaterra no início do século XIX, se opondo as regras que não permitiam a prática de esportes dentro das instituições. Porém, neste momento o jogo ainda era jogado tanto com as mãos quanto com os pés, causando discórdias entre escolas e estudantes sobre sua forma de jogar. Em 1823 Cambridge definiu em suas regras que o Football proibia o uso das mãos pelos jogadores de linha, e poucos anos depois, em 1828, Thomaz Arnold definiu que no Rúgbi School se jogaria o Football Rúgbi, que permitia aos atletas que carregassem a bola nas mãos (VOSER; GUIMARÃES; RIBEIRO, 2006), separando definitivamente o esporte hoje conhecido como rúgbi do futebol que conhecemos.

O clube de futebol mais antigo que se tem notícia é o Sheffield FC, fundado em 1857, pouco depois da divisão de Cambridge, mas usava regras modificadas, o que ficou conhecido como Sheffield Rules. Em 1853 foi formada a Associação Britânica de Futebol (BFA), e 3 meses depois seus fundadores escreveram um "livro" que organizava o futebol, com 13 regras em uma só página. Hoje, o livro de Regras da FIFA contém 17 regras, escritas em 83 páginas. Foi somente em 1890 que a FIFA instituiu que no futebol se jogam 11 em cada time, definiram o tamanho máximo e mínimo do campo e que as faltas dentro da área seria todas cobradas em uma marca centralizada em frente ao gol, 11 metros a sua frente, sem nenhum jogador a frente da bola a não ser o goleiro (DUARTE, 2005).

Duarte (2005) conta que o futebol chegou ao Brasil pelos marinheiros ingleses, que jogavam futebol nas praias brasileiras, mas levavam as bolas consigo de volta para a Inglaterra. Charles Miller, paulista que estudou na Banister Court School da Inglaterra e jogava futebol regularmente, trouxe de lá em 1894 duas bolas, calções, bomba de encher bola e chuteiras, dando início ao futebol no Brasil (DUARTE, 2005).

\subsection{Psicologia do Esporte no futebol}

Segundo Cruz (1991), o início da Psicologia do Esporte no Brasil se deu no início da década de 1950, com os estudos e atuações no boxe, na arbitragem e no futebol do psicólogo João Carvalhaes ainda antes do Congresso de Roma, que ocorreu em 1965, e formalizou a existência da Psicologia do Esporte no mundo (VALDÉS CASAL, 2007). No ano de 1954, João Carvalhaes foi contratado pela Federação Paulista de Futebol para realizar 
trabalhos como seleção, avaliação e treinamento dos árbitros de futebol, por conta de sua experiência e estudos sobre o uso da Psicologia e personalidade para a contratação de funcionários para funções adequadas (CARVALHAES, 1960), e interesse pela pesquisa científica associada à criação de instrumentos de medida para o desenvolvimento de suas atividades de avaliação psicológica (HERNANDEZ, 2011).

Carvalhaes observou o trabalho dos árbitros mais experientes e identificou diversas habilidades que eles utilizavam para exercer suas funções, como personalidade, nível mental, visão estereoscópica, estimativa da velocidade relativa, noção de espaço, tempo de reação, reação psicomotora (estímulo auditivo), tempo médio de reação (estímulos visuais e auditivos) e atenção (HERNANDEZ, 2011). Contratado pelo São Paulo Futebol Clube por cerca de 20 anos, também participou da comissão técnica da seleção brasileira que foi à Copa do Mundo de Futebol em 1958, a qual conquistou o primeiro título mundial para o país, na Suécia. Machado (1997), cita que, como a psicologia ainda não considerava aspectos psicomotores, focando em fatores intelectuais, os trabalhos de Carvalhaes deixaram a desejar nesta época.

De Lima Argimon e colaboradores (2006) cita que mesmo sendo uma ciência nova, a Psicologia do Esporte vem enfatizando a intersecção entre psicologia e esporte, com uma abordagem não mais somente individual, mas também grupal de aspecto preventivo e não mais curativo. Essa abordagem exalta a autorregularão de seus processos psicológicos, melhorando seu bem-estar e visando utilizar de teorias e métodos específicos de psicologia e psicofisiologia referentes à modalidade esportiva em que vai atuar (SAMULSKI, 2002).

A Psicologia Esportiva também poderia trabalhar comportamentos pertinentes ao contexto esportivo, auxiliando os atletas no trabalho de suas emoções, como tolerância a frustração, ansiedade pré-competitiva, e instrumentalizando a comissão técnica. Franco (2000) afirma que os técnicos muitas vezes acumulam funções próprias de outros profissionais, como o de professor, fisioterapeuta e psicólogo, o que poderia sobrecarregálo.

Hernandez (2011) diz que, por conta do foco principal dos estudos e trabalhos psicológicos ser a humanização, e este se contrapor ao objetivo central do treinador que é a busca pela vitória, há uma dificuldade por parte dos psicólogos em trabalhar com essa ambivalência. Os psicólogos acabam por abdicar de um olhar humanizado para acatar os pedidos da comissão técnica, ou enfrenta grande resistência dela. Porém, o psicólogo pode manter seu foco humano, buscando dar assistências ao trabalho da comissão técnica, 
demonstrando que sua prática de intervenções individuais ou coletivas visa a prevenção de futuros problemas pré-competitivos, competitivos e interpessoais não só dos atletas, mas da instituição de modo geral (HERNANDEZ, 2011).

A preocupação em render mais, ser mais resistente, forte e deixar sua marca de sucesso, questões vividas com muita intensidade na vida esportiva, poderia mobilizar diversos aspectos pertinentes ao trabalho psicológico, como os níveis de estresse e ansiedade do atleta, prejudicando não somente seu desempenho, mas também sua própria saúde, e qualidade de vida (VALLE, 2003).

\subsection{Cobranças de Pênaltis e Fatores Gerais Envolvidos}

Toda cobrança de pênalti envolve necessariamente dois jogadores: goleiro e o cobrador. Cobrar um pênalti é uma habilidade motora discreta, isto é, há um início e um final claro. Requer movimentos complexos e exigem um alto nível de coordenação motora. Há duas principais estratégias dos cobradores de pênalti: estratégia goleiro dependente, e a estratégia independente do goleiro.

$\mathrm{Na}$ estratégia goleiro dependente, o jogador que irá cobrar o pênalti reagiria ao movimento do goleiro, chutando a bola do lado oposto ao que o goleiro saltaria. Para ter sucesso, o atleta dependeria de sua habilidade de se adaptar as mudanças do ambiente (posicionamento do goleiro), pois o tempo mínimo que o jogador necessitaria para modificar com sucesso a trajetória da bola para o lado oposto ao goleiro é de 0,3 segundos (BOWTELL; KING; PAIN, 2009).

Em outro estudo, Van der Kamp (2006), apontou que, de maneira geral, em seu estudo os cobradores de pênalti levaram ao menos 0,4 segundos, porém um dos participantes conseguiu alterar a direção do chute com somente 1,73 segundos de antecedência, diversos participantes não conseguiram mudar a direção da bola com 0.6 segundos disponíveis para isso, e um dos participantes não conseguiu nem com 0.773 segundos. Dessa maneira, o atleta cobrador de pênalti que tiver sucesso em antecipar o lado que o goleiro irá saltar pode direcionar a bola para o lado oposto, que estará vazio (VAN DER KAMP, 2006).

Na estratégia de cobrança independente do goleiro, o atleta escolheria um canto para direcionar a bola, independente do posicionamento ou movimento do goleiro. Para que essa estratégia seja eficiente, o atleta cobrador do pênalti deverá direcionar a bola, de maneira 
razoavelmente precisa nos cantos superiores ou inferiores da extrema direita ou extrema esquerda do gol (VAN DER KAMP, 2006; NONNEMACHER; VOSER, 2012). Em um estudo analisando 193 cobranças de pênaltis de 21 decisões de campeonatos internacionais de seleções de futebol de campo, Nonnemacher e Voser (2012) dividiram o gol em diferentes quadrantes, e notaram que $95,45 \%$ dos chutes que acertaram o quadrante inferior direito ou esquerdo (Q3 e Q15) entraram, e 100\% dos chutes que acertaram o quadrante superior direito ou esquerdo (Q1 e Q13) também entraram, como mostrado na figura abaixo.

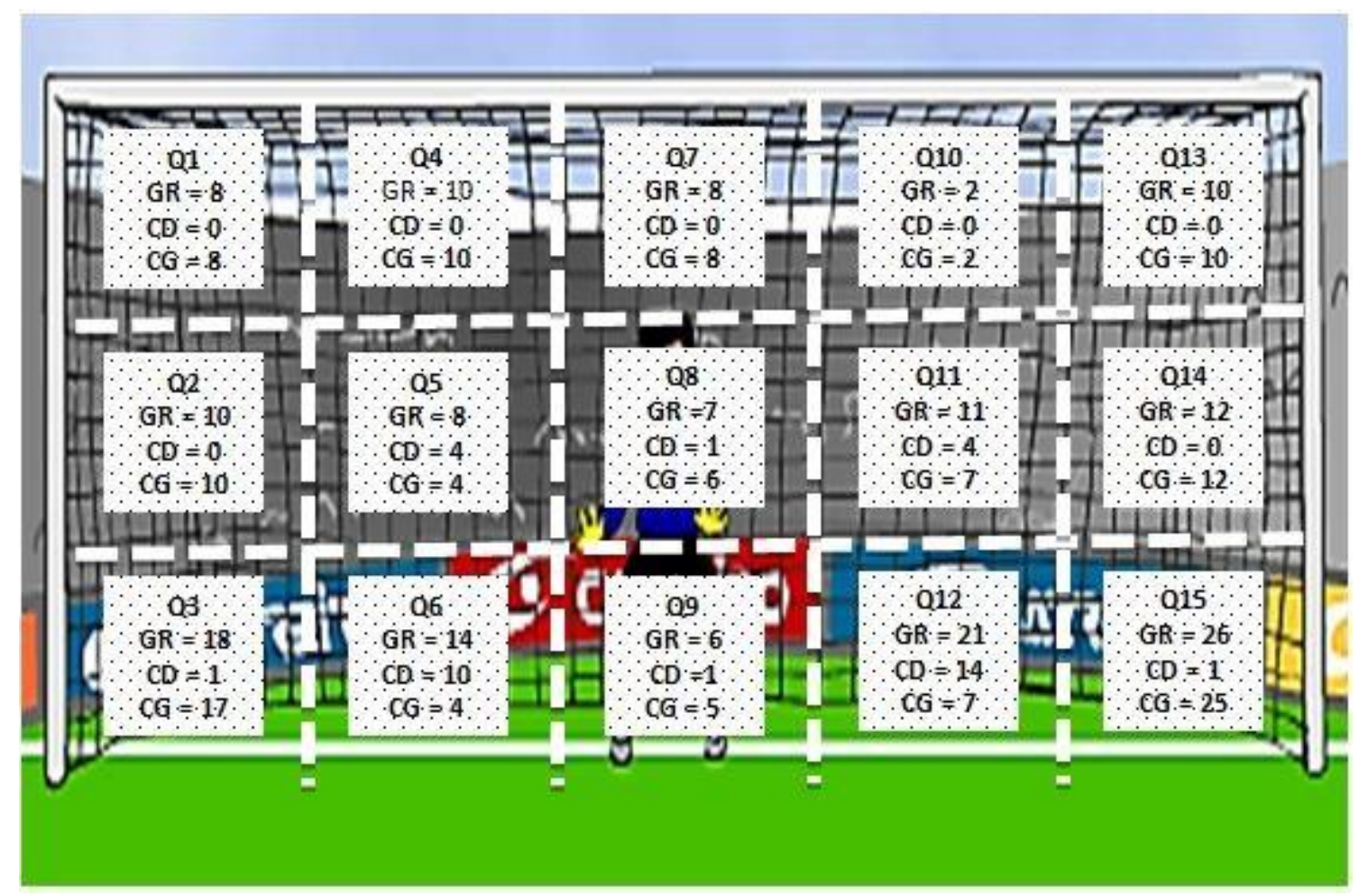

FIGURA 1 - RELAÇÃO DAS COBRANÇAS REALIZADAS (CR), COBRANÇAS CONVERTIDAS EM GOL (CG) E COBRANÇAS DEFENDIDAS (CD).

Fonte: Nonnemacher e Voser (2012)

Em um estudo que analisou o momento do salto dos goleiros em pênaltis cobrados no futebol profissional foi visto que, em média, a bola leva $344 \mathrm{~ms}$ (0,34 segundos) para alcançar a linha de gol então grande parte dos goleiros salta antes do jogador tocar a bola para tentar aumentar a distância a ser alcançada (MORYA et al., 2005). Para os goleiros, também há diferentes estratégias no momento do pênalti. Analisando 66 cobranças de pênalti de competições europeias entre os anos de 1981 e 1983, Kuhn (1988) notou que em 
$77 \%$ das cobranças realizadas os goleiros saltaram antes do chute, e defenderam um total de $60 \%$ dessas cobranças, e em $23 \%$ das cobranças os goleiros saltaram após o chute e defenderam apenas $7,8 \%$ delas.

Goleiros também observariam movimentos corporais do cobrador para tentar prever a direção e força do chute (WOOD, 2010), se posicionariam imperceptivelmente fora do centro do gol para influenciar a direção do chute (MASTERS; VAN DER KAMP; JACKSON, 2007), e modificariam suas posturas para alterar a percepção de sua altura (VAN DER KAMP; MASTERS, 2008). De maneira geral, podemos destacar que diversos fatores que podem contribuir para que um jogador de futebol não converta o pênalti em gol. Fadiga física, nível de habilidade, estratégia má executada, tomada de decisão ruim, e nível de ansiedade alta podem colaborar para que o atleta tenha um desempenho ruim, além de a capacidade, habilidade física, técnica e mental.

\subsection{Cobranças de Pênaltis e Ansiedade}

O atleta profissional que cobra o pênalti muitas vezes está na frente de milhares de pessoas que 0 vaiam ou 0 exaltam além daquelas que 0 assistem pela televisão. Diferentemente de outros esportes coletivos populares como o basquetebol e o voleibol, o futebol é um esporte em que se marcam poucos pontos (gols) por partida. Desta maneira, qualquer gol de pênalti pode fazer a diferença no resultado final do jogo.

De forma geral, a expectativa da mídia, torcida, treinador e dos próprios jogadores, é que o pênalti é um "gol certo". Fato esse que acaba por aumentar a responsabilidade do jogador que irá cobrar o pênalti, o que poderia aumentar ainda mais a ansiedade.

Jordet, Hartman, Visscher e Lemmink (2007) verificaram que quanto mais decisivas são as cobranças de pênaltis durante as partidas, menor o índice de acerto dos cobradores. Os autores concluíram que o fator psicológico influencia o fator físico e a habilidade no momento de converter um pênalti em um momento importante da partida, e sugerem que os times devam receber preparo apropriado para lidarem com essas situações.

Wilson, Vine e Wood (2009), por exemplo, compararam o foco visual em jogadores de futebol em cobranças de pênaltis com e sem estímulos ansiogênicos. Quando estavam ansiosos, os jogadores fixavam o olhar no goleiro, e por um tempo mais longo do que nos momentos que não haviam estímulos ansiogênicos, o que significou uma queda significativa nos acertos, tornando os chutes mais centrais, mais facilmente alcançáveis pelo goleiro. Diversos autores (WILSON; VINE; WOOD, 2009, JORDET et al., 2007a; JORDET et al., 
2007b), reforçam que a ansiedade tem sido reportada como a maior causa de perdas de pênaltis em diferentes pesquisas realizadas no assunto.

Wilson, Vine e Wood (2009) compararam a percepção do estado de ansiedade de sujeitos de pesquisa cobrando pênalti com e sem estímulos aversivos, e encontraram uma diferença significativa, mostrando que os indivíduos se sentiram realmente mais estressados quando colocados em situações que provariam sua habilidade.

Em um estudo exploratório sobre as emoções que jogadores profissionais de futebol experienciariam nos minutos que antecederam uma decisão por pênaltis na edição de 2004 da Eurocopa, "ansiedade" foi o item mais mencionado por todos os atletas participantes da entrevista, e o momento que estão reunidos no meio do campo foi citado como o período em que a ansiedade era mais alta (JORDET et al., 2008)

Greenlees e colaboradores (2008) verificaram que a percepção do goleiro sobre a probabilidade de os cobradores de pênalti conseguirem marcar o gol teve relação com o tempo em que o jogador fixava o olho no goleiro em um primeiro momento. Cobradores que olharam para o goleiro por apenas $10 \%$ do tempo, desde a aproximação para arrumar a bola até o chute, foram percebidos como menos prováveis de acertar o pênalti, em comparação com cobradores que olham diretamente para o goleiro por $90 \%$ do tempo. Neste tema, Wood (2010) verificou que quando ansiosos cobradores de pênalti mudavam o tempo de fixação do olhar nos goleiros, comparando com momentos em que não estavam tensos.

Jordet, Hartman e Sigmundstad (2009) analisaram vídeos de cobranças reais de pênalti em situações de grande pressão, e compararam o tempo que os jogadores levavam para realizar as tarefas (andar, posicionar a bola, tomar distância, aguardar o apito, resposta ao apito e corrida até a bola), e perceberam que havia relação entre o tempo de resposta do atleta depois do apito do juiz, e o número de erros, tendo o maior número de erros atletas que respondiam rapidamente ao apito do juiz.

Os pesquisadores atribuem esse fato a jogadores que para escapar da desconfortável situação de pressão e ansiedade cobravam rapidamente o pênalti, tentando "livrar-se" deste sentimento, mas assim precipitando a cobrança. Em outro estudo, Jordet, Hartman e Vuijk (2012) mostraram que jogadores de times com histórico recente de derrotas em disputas de pênaltis tiveram um pior desempenho e menor tempo de resposta após o apito do árbitro quando comparado a times com sucesso recentes nessas disputas, ou que nunca estiveram em uma situação semelhante. 
A distância entre os desempenhos aumentou ainda mais na comparação entre times que ganharam as últimas duas disputas e os que perderam as duas últimas, mesmo que tenham acontecido muitos anos antes e os jogadores não fossem os mesmos. Esses dados sugerem que exista um efeito de dependência histórico de desempenho em situações importantes, dramáticas e de alta pressão (JORDET; HARTMAN; VUIJK, 2012). Miyamoto (2010) simulou cobranças de pênaltis com voluntários em situação normal, e frente a uma torcida contrária, e verificou que os níveis fisiológicos de estresse do sujeito subiram consideravelmente quando a tarefa tinha que ser realizada frente à torcida, e seus acertos passaram, em média, de $50 \%$ para $25 \%$, o que coincidiu com a literatura sobre pênaltis perdidos em competições oficiais nacionais e internacionais (MIYAMOTO apud MILLER, 1998; BONIZZONI, 1988). Apesar de não ser o único fator que causaria um cobrador de pênalti a não ter um desempenho ótimo ou a não marcar o gol, pode-se compreender que a ansiedade dificulta que o atleta exerça suas estratégias de maneira ótima do modo como realiza em treinos, ou em momentos sem grande importância competitiva e sem pressão emocional.

\subsection{Ansiedade}

A ansiedade é um estado psíquico relacionado a energia que existe para agir em determinada situação (FRISCHNECHT, 1990). Acompanha excitação ou inibição para responder de maneira eficaz à tarefa que lhe é exigida (VIANA, 1989). Ela é uma reação fisiológica do corpo que o prepara para a ação de lutar ou de fugir. Essa energia é altamente necessária para um atleta, porém diferentes esportes e pessoas necessitam de níveis diferentes de ansiedade para atingir um nível ótimo de performance.

Araújo, Mello e Leite (2007) citam que pessoas ansiosas tendem a interpretar estímulos que são razoavelmente neutros como ameaçadores e perigosos, e é essa distorção cognitiva que dispara pensamentos automáticos catastróficos que geram a ansiedade. Para a medicina, a ansiedade é vista como o um estresse emocional. Lipp (1984) define o estresse como um processo, uma reação de um organismo frente à uma situação que o irrite, amedronte, excite ou confunda. Uma ocorrência fisiológica do corpo todo, tanto físico quanto emocional. 
Spielberger (1971) separou a ansiedade em 2 categorias: ansiedade-traço e estado de ansiedade (ou ansiedade-estado). O estado de ansiedade é categorizado pelo nível de ativação físico-psicológico que muda de um momento para outro, de uma jogada para outra muitas vezes até dentro do mesmo jogo (WEINBERG; GOLD, 2008).

Weinberg e Gold (2008, pg.97) definem o estado de ansiedade como: "um estado emocional temporário, em constante variação, com sentimentos de apreensão e tensão conscientemente percebidos, associados com a ativação do sistema nervoso autônomo".

O traço de ansiedade se refere a uma disposição pessoal, relativamente estável, a responder frente a diferentes estímulos aversivos e situações. Weinberg e Gold (2008, pg.97) definem traço de ansiedade como:

"Uma tendência comportamental de perceber como ameaçadoras circunstancias que objetivamente não são perigosas e de responder a elas com ansiedade estado desproporcional. As pessoas com ansiedade-traço elevada geralmente têm mais ansiedadeestado em situações de avaliação e naquelas altamente competitivas do que as pessoas com ansiedade-traço mais baixa."

O modelo multidimensional de ansiedade tem como hipótese que a ansiedade pode ser determinada por dois fatores: ansiedade somática, que diz respeito as reações do sistema nervoso autonômico à situações estressantes, e ansiedade cognitiva, que se refere a emoções, pensamentos e preocupações acerca do estímulo (DAVIDSON; GOLEMAN; SCHWARTZ,1976). Essa teoria diz que a ansiedade deve ser observada a partir destes dois componentes independentes, pois tem diferentes antecedentes e suas consequências influenciam o desempenho de maneira diversa.

Martens, Vealey e Burton (et al., 1990), separaram os componentes cognitivos duas dimensões distintas. A primeira levando em conta os pensamentos negativos disfuncionais, pontuado como ansiedade cognitiva, e a segunda área, positiva, denominada autoconfiança.

Os autores apresentam como hipótese uma relação linear negativa entre o estado de ansiedade cognitiva e o desempenho, enquanto o estado de ansiedade somática e o desempenho teria um relacionamento em forma de $U$ invertido (figura 2). Assim, os atletas deveriam buscar um estado de ansiedade cognitiva reduzida (medo do fracasso, medo do sucesso e pensamentos disfuncionais de forma geral), nível moderado de ansiedade somática (frequência cardíaca, transpiração temperatura, respiração, etc), enquanto mantém um alto nível de confiança no seu próprio desempenho. 


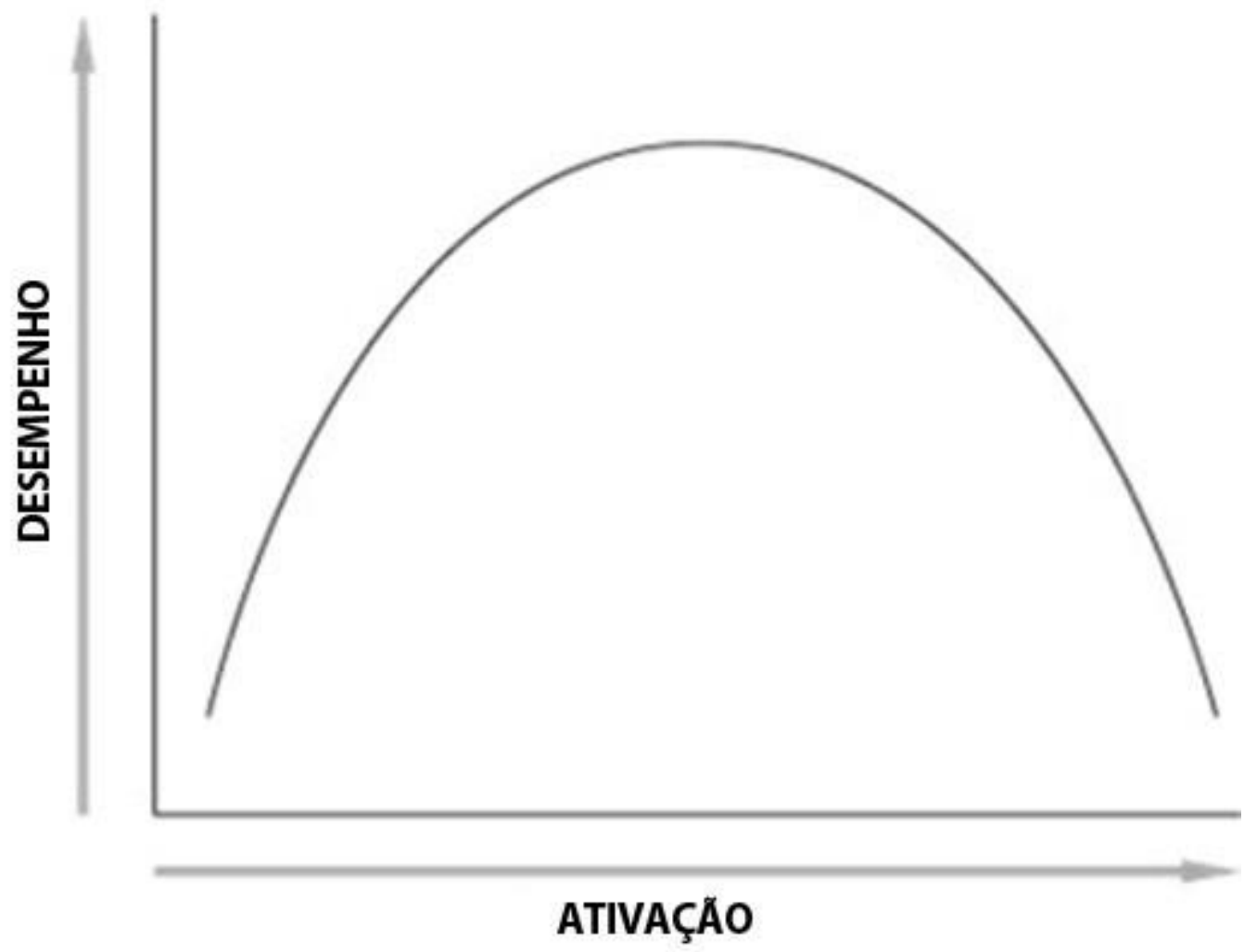

FIGURA 2 - TEORIA DO U INVERTIDO

Fonte: Weinberg; Gold, 2008

Levando em conta a teoria multidimensional, os estados de ansiedade devem ser avaliados considerando essas diferentes dimensões, mensurando assim características psicológicas e psicofisiológicas. Diversas ferramentas são utilizadas para avaliar o estado de ansiedade no esporte. Uma das mais utilizadas é o CSAI-2R (Revised Competitive State Anxiety Inventory), que investiga os fatores somáticos, cognitivos e de autoconfiança, além de manter uma pontuação geral do estado de ansiedade, sendo um dos instrumentos psicológicos amplamente utilizados com este propósito (FERNANDES; VASCONCELOSRAPOSO; FERNANDES, 2012). 


\subsubsection{Ansiedade Cognitiva}

A ansiedade cognitiva representa os pensamentos negativos, as preocupações, pensamentos disfuncionais, perda da capacidade de concentração e expectativas negativas a respeito do desempenho do próprio atleta, devido ao medo de avaliações negativas (MARTENS; VEALEY; BURTON, 1990). Morris (et al., 1981) definiu ansiedade cognitiva como expectativas negativas e preocupações sobre si mesmo, a situação apresentada e consequenciais em potencial. Esses pensamentos podem causar apreensão, apatia, desinteresse, e outras emoções vistas como negativas para momentos de alto rendimento.

Em esportes coletivos que exigem maior concentração, como o xadrez, tiro ao alvo, golfe, etc., a ansiedade cognitiva pode prejudicar de maneira ainda mais negativa (MARTENS; VEALEY; BURTON, 1990). De maneira geral, a ansiedade cognitiva manifestase negativamente, prejudicando as expectativas do atleta, a avaliação de seu próprio desempenho (FERREIRA, 2006). Um atleta com alta ansiedade cognitiva teria preocupações sobre não conseguir desempenhar seu papel frente aos desafios a serem apresentados.

Com um maior grau de ansiedade cognitiva, os ambientes competitivos podem transformar em negativas as expectativas sobre seu desempenho (BURTON, 1988). Desta maneira, a percepção sobre seu próprio desempenho dependerá da ansiedade cognitiva, da confiança em sua própria competência competitiva, baseada em experiência anteriores, assim como na capacidade de seu adversário. Quando as expectativas são incertas, e o controle sobre seu próprio desempenho diminui, é mais provável que os atletas experimentem uma diminuição da autoconfiança e um aumento da ansiedade cognitiva. A percepção subjetiva sobre seu próprio rendimento pode ser alterada não somente sobre os resultados nas últimas competições, mas também por conta de lesões, elogios, críticas, desempenho nos treinamentos, entre outros (FERREIRA, 2006).

Martens, Vealey e Burton (1990), afirma que somente um índice alto de ansiedade cognitiva seria prejudicial ao rendimento esportivo, porém Hardy, Parfitt e Pates (1994), citam que um nível alto de ansiedade cognitiva somente seria maléfico quando combinado com um alto índice de ansiedade somática.

Vickers e Williams (2007), em um estudo sobre os efeitos da pressão psicológica/emocional, ansiedade e fixação ocular em atletas de biatlon, descreveram que o 
índice de ansiedade cognitiva foi significativamente maior durante situações de alta pressão, quando comparadas com situações de baixa pressão emocional.

Em meta-análise realizada por Woodman e Hardy (2003), tanto a queda da autoconfiança quanto o aumento da ansiedade cognitiva mostraram relações significativas com uma diminuição no desempenho esportivo. A ansiedade cognitiva foi mais alta para atletas do sexo masculino do que atletas do sexo feminino, e também mais alta para competições de grande importância, quando comparada com a ansiedade cognitiva de competições de importância menor.

\subsubsection{Estresse}

$\mathrm{Na}$ literatura uma grande sobreposição do conceito de estresse e de ansiedade, assim como um debate em que um seria a origem do outro. Selye $(1986, p .10)$ define o estresse como o "resultado inespecífico de alguma exigência sobre o corpo". O estresse geraria uma reação fisiológica de "luta ou fuga", preparando o corpo para essas situações da mesma maneira se elas forem ameaças físicas reais, ou apenas situações compreendidas pelo indivíduo como uma ameaçadoras (SAPOLSKY, 2004). Esse estresse pode ser avaliado como positivo (eustress), ou negativo (distress), sendo a própria avaliação do indivíduo sobre a situação o essencial para determinar essa diferença (SELYE, 1975).

\subsubsection{Ansiedade Somática}

A ansiedade somática diz respeito aos sintomas fisiológicos da ansiedade sentidos no corpo do atleta através da ativação do Sistema Nervoso Simpático, e a queda parassimpática, seguindo o princípio da inibição recíproca. Essa ativação pode ser caracterizada por sintomas físicos como hiperventilação, aceleração do ritmo cardíaco, aumento de sudorese, hipertensão, hipertonia, taquipsiquia, agitação entre outros sintomas que preparam o indivíduo para momentos de luta ou fuga. O corpo entra em estado de alerta, sendo mobilizado como um todo, aumentando níveis de adrenalina e cortisol.

Essa preparação do corpo pode ser positiva para atividades que necessitam de explosão, velocidade, resistência e força, já que a ativação Sistema Nervoso Simpático pode proporcionar condições propícias para tais atividades. Porém, esse nível de ativação elevado é prejudicial para habilidades complexas que exigem capacidades motoras mais refinadas, 
concentração, rapidez de raciocínio, melhor tomada de decisão e tempo de reação (MARTENS; VEALEY; BURTON, 1990).

A ansiedade somática pode ser caracterizada como a percepção da excitação fisiológica de si mesmo, e dessa maneira ela poderia ser útil como uma medida indireta dos níveis fisiológicos de ansiedade (WOODMAN; HARDY, 2003).

O momento que se pode perceber a ansiedade somática de uma maneira mais intensa é no momento pré-competição (ansiedade pré-competitiva), como uma resposta condicionada a um estímulo avaliativo (competição), porém ocorre com maior presença durante um período não avaliativo (aquecimento e rotina pré-jogo, momentos anteriores a competição) (FERREIRA, 2006). Desta maneira, entende-se que a ansiedade somática poderia influenciar mais no desempenho inicial, permitindo que os sintomas de ativação do Sistema Nervoso Simpático atrapalhem nos primeiros minutos da partida/competição (MARTENS; VEALEY; BURTON, 1990). Porém, estudos questionam ainda se existem evidências suficientes para comprovar esta tese, sendo possível encontrar pesquisas que apontam que a ansiedade somática continua de maneira intermitente durante todo 0 desempenho (HARDY; MAIDEN; SHERRY, 1986).

Em um estudo com atletas de natação amadores e de elite, Jones, Hanton e Swain (1994), investigaram as diferenças entre indivíduos que diziam que a ansiedade alta facilitava seu desempenho, e indivíduos que citavam que a ansiedade somática os atrapalhava, diminuindo seus rendimentos. No grupo dos atletas amadores, os autores encontraram um nível maior de ansiedade naqueles que acreditavam que a ansiedade os atrapalhava, quando comparados com os atletas amadores que viam a ansiedade como força impulsionadora de seu desempenho.

No grupo de elite, quanto mais positivo o atleta julgava seus sintomas pré-competitivos, maior sua autoconfiança. Os autores afirmam que seria importante modificar o conceito e o nome da ansiedade considerada benéfica, já que neste caso, ela não seria sequer considerada ansiedade pelo atleta, e sim como "agitação", "excitação", "motivação", etc.

A modalidade esportiva em que o atleta participa poderia também influenciar na percepção do próprio atleta de que a ansiedade somática seria vista como benéfica ou maléfica para o seu desempenho. De maneira geral, ela pode ser vista como facilitadora em modalidades curtas, de pequena duração, e prejudicial em modalidades de longa duração ou que necessitem de um maior controle motor fino (JONES; HANTON; SWAIN, 1994). 


\subsubsection{Autoconfiança}

A autoconfiança se dá na ausência da ansiedade cognitiva. Dessa forma, a ansiedade cognitiva é vista como falta de autoconfiança (MARTENS; VEALEY; BURTON, 1990). Segundo Weinberg e Gold (2008), ela é a crença que o atleta tem de que irá conseguir realizar uma tarefa com sucesso. Essa confiança pode ser em suas habilidades físicas, psicológicas, físicos e de tomada de decisão.

A autoconfiança está em um "continuum" que abrange desde a completa falta de confiança, até a confiança excessiva, passando pelo nível ótimo de confiança, que se encontra entre essas duas extremidades. Desta maneira, a elevação da autoconfiança pode diminuir o efeito da ansiedade no desempenho (CRUZ; VIANA, 1996).

O trabalho para a redução do estado de ansiedade passaria pelo aumento da autoconfiança, e também do trabalho motivacional, características aparentes de atletas bemsucedidos (CRUZ; VIANA, 1996). Como a autoconfiança possui uma relação linear positiva com o rendimento, ela pode ser considerada como um fator diferenciador, demonstrando a confiança do atleta em suas habilidades, aprendizagem, aperfeiçoamento de todas as competências (CRAFT et al., 2003).

É de amplo conhecimento a grande importância que a autoconfiança tem no desempenho de atletas. Tanto para o público, jornalistas, treinadores ou atletas, todo tem a consciência de que um atleta tem um melhor rendimento quando confia nas suas capacidades pessoais e competitivas. Os profissionais envolvidos na atividade esportiva competitiva têm fundamental importância na elevação dos níveis de autoconfiança de seus atletas. Devem buscar equilibrar suas capacidades técnicas, táticas, físicas e psicológicas com o desafio a ser enfrentado, criando um sistema de reforço dos comportamentos esperados, como um facilitador desta elevação da autoconfiança de maneira objetiva e realista.

O atleta com índices baixos de autoconfiança pode ter um viés confirmatório ao falhar, ser criticado, e ver seu desempenho piorar ainda mais, enquanto um atleta confiante em suas competências poderá vê-las sendo reforçada de uma maneira positiva (FERREIRA, 2006).

A autoconfiança é elevada quando os atletas atingem suas metas e objetivos, o que ressalta a importância de terem metas reais, concretas e mensuráveis, que possam contribuir em um ciclo positivo de reforço, tendo um ambiente desafiador, em que ele possa 
se concentrar em aspectos controláveis do desempenho, e não apenas na vitória (VALEY, 1986). Outros fatores como forças socioculturais e cultura organizacional poderiam também influenciar na autoconfiança dos atletas, além do reforço e feedback positivo ou negativo de treinadores, técnicos, coaches, e outros sujeitos envolvidos na sua preparação esportiva.

\subsubsection{Fatores geradores de ansiedade}

Em sujeitos saudáveis, de maneira geral, a intensidade da ansiedade percebida por um sujeito está diretamente relacionada a situação aversiva/ameaçadora que ele esteja enfrentando de maneira externa ou interna. Por vezes, essas causas são imperceptíveis, e se mantém desconhecidas pelos atletas.

Questões globais como a pressão social podem ser fatores que elevam o nível de ansiedade que determina o que é um atleta vencedor, ativando pensamentos automáticos disfuncionais associados ao medo do fracasso, decepção pessoal e coletiva e incapacidade (FERREIRA, 2006), aumentando o estado de ansiedade cognitivo.

Esses pensamentos podem ser devastadores para o desempenho do atleta, levandoo a errar por excesso de cautela ou comportamentos compensatórios contrários, e correndo o risco de ser repreendido por seu treinador, pais e torcida, criando assim um ciclo de reforçamento da crença de incapacidade que pode levar a um decréscimo no índice de autoconfiança. Alguns autores colocam o apoio ou rejeição da torcida como um fator determinante no aumento ou diminuição dos estados de ansiedade, porém sugerem que a expectativa em torno do atleta de maneira geral por patrocinadores, pais, treinador, amigos, criam um fator gerador de ansiedade (FERREIRA, 2006; JÚNIOR 2004).

Entende-se como primordial o atleta controlar sua própria expectativa não somente sobre seu próprio desempenho, mas também sobre atender as demandas colocadas sobre ele, e tenha de maneira clara quais são suas metas e objetivos individuais e coletivos, para assim motivar-se frente a estas cobranças, ao invés de sucumbir-se a elas.

\subsection{O uso do “CSAl -2R” em estudos nos esportes de competição}

O instrumento acima citado é um dos mais utilizado para medir níveis de ansiedade pré-competitiva é o CSAI-2 (COX; MARTHENS; RUSSEL, 2003). O "CSAl" (Competitive State Anxiety Inventory) em sua origem, foi uma modificação do State-Trait Anxiety Inventory, como um inventário específico para mensurar o estado de ansiedade no esporte. 
Uma grande limitação do instrumento foi sua uma concepção unidirecional de ansiedade, não levando em conta aspectos cognitivos e somáticos.

O CSAI-2 é um instrumento que apresenta diversas análises de reprodutibilidade e validade, e foi desenvolvido para abranger a mensuração tanto da ansiedade cognitiva, quanto a ansiedade somática. Sua versão final continha 27 itens com uma escala Likert de 1 a 4, relativos às duas dimensões de ansiedade. A autoconfiança foi inserida na fase de validação (MARTENS; VEALEY; BURTON, 1990). Um estudo realizado por Tsorbatzoudis, Varkoukis, Kaissidis Rodafinos e Grouios (1998) com atletas gregos, demonstrou limitações sobre aspectos psicométricos do inventário, demonstrando que três dos itens assinalados como ansiedade cognitiva se apresentavam como indicadores de autoconfiança.

Seguiram-se outros estudos neste sentido (LANE et al, 1999) e então Cox, Martens e Russel (2003) fizeram uma revisão do CSAI-2, decidindo eliminar 10 itens, e criaram o "Revised Competitive State Anxiety Inventory - CSAI-2R". Este instrumento divide-se em 3 subescalas: Ansiedade Cognitiva ( 5 perguntas), Ansiedade Somática ( 7 perguntas) e Autoconfiança (5 perguntas), respectivamente analisando sensações negativas sobre o rendimento do atleta, a percepção de indicadores fisiológicos de ansiedade, e o grau de

confiança que este tem no seu desempenho (invertido no momento da análise). É solicitado aos pesquisados que respondam as afirmações apresentadas classificando-as numa escala Likert de 1 (Nada) a 4 (Muito) de acordo com o que sentem no momento. Desde então, este instrumento é utilizado para avaliação de ansiedade pré-competitiva em diversos países (LUNDQVIST; HASSMÉN, 2005, RAUDSEPP; KAIS, 2008, MARTINENT, et al., 2010).

No Brasil, Fernandes et al. (2012), encontraram evidências que o CSAI-2R (de 17 itens) tem boas propriedades psicométricas quando relacionado ao contexto e cultura brasileira, e é o que se constitui como a melhor representação estrutural dos dados, verificando-se valores mais adequados para os diferentes índices de ajustamento, evidências de validade fatorial e invariância da versão brasileira, e sugerem o uso para avaliar ansiedade pré-competitiva e autoconfiança em atletas no território brasileiro.

\subsection{Aspectos emocionais da adolescência}

Diferente de quando praticado na infância e na idade adulta, o esporte na adolescência não só exerce um papel relevante na vida do indivíduo, mas também é utilizado pelos jovens atletas de acordo com suas demandas emocionais. 
Piaget (1972) pontuou que durante a infância, a criança passa pelas fases sensóriomotora, período pré-conceitual até alcançar o período do pensamento lógico-concreto, em que as operações mentais necessitam de situações concretas, presentes, a fim de se processarem. Já na fase da adolescência, o jovem passa pelo desenvolvimento da lógica formal, baseada na ação internalizada e símbolos. Neste momento o adolescente consegue trabalhar no plano das ideias, não necessitante de referências concretas, e tirando suas próprias conclusões (PIAGET, 1972).

Motivos de natureza intrínseca como a diversão, o fazer amigos, fazer algo novo, etc., estão entre as principais razões que fazem com que crianças iniciem suas atividades esportivas (WEINBERG; GOLD, 2008). Na adolescência, jovens continuam fazendo atividades físicas por diversos motivos, e mesmo quando desistam ou abandonem alguma modalidade, em geral para abrir tempo para outros interesses, muitas vezes já estão exercendo outra atividade física (WEINBERG; GOLD, 2008). Durante a prática de atividades esportivas, jovens podem sofrer diversas pressões, sociais, institucionais, do treinador, e a principal delas por parte dos pais, na busca do adolescente pela vitória (WEINBERG; GOLD, 2008);

O esporte exige dos atletas um processo de preparação técnica, tática, física e mental. Desta forma, é necessária a compreensão das influências biopsicossociais que regem os comportamentos desses jovens atletas diante dessas exigências. Para Aberastury e Knobel (1989), a adolescência caracteriza-se por um período entre a infância e a vida adulta que predomina uma crise necessária para o desenvolvimento, um momento de contradições, confuso, ambivalente e doloroso, caracterizado por conflitos com o meio familiar e social, além da falta de plena aquisição de capacidades e habilidades do adulto.

Erickson (1976) institucionalizou a adolescência como uma fase especial de vida entre a infância e a idade adulta, em que o jovem busca sua própria identidade. Aberastury e Knobel (1989) introduziram o termo de "síndrome normal da adolescência", que se constitui por: "1) busca de si mesmo e da identidade; 2) tendência grupal; 3) necessidade de intelectualizar e fantasiar; 4) crises religiosas, que podem ir desde o ateísmo mais intransigente até o misticismo mais fervoroso; 5) deslocalização temporal, em que o pensamento adquire as características de pensamento primário; 6) evolução sexual manifesta, desde o autoerotismo até a heterossexualidade genital adulta; 7) atitude social reivindicatória com tendências anti ou associais de diversa intensidade; 8) contradições sucessivas em todas as manifestações da conduta, dominada pela ação, que constitui a 
forma de expressão conceitual mais típica deste período da vida; 9) uma separação progressiva dos pais; e 10) constantes flutuações de humor e do estado de ânimo" (KNOBEL, 1981, p.29).

$\mathrm{Na}$ segunda fase da adolescência (a partir dos 14 anos), o adolescente deseja libertar-se do adulto, mas ainda depende dele. Deseja ser aceito pelos colegas. O grupo de amigos é um importante referencial para o jovem, determinando as palavras, as vestimentas e outros aspectos de seu comportamento. Neste momento ele começa a estabelecer sua moral individual, que é referencial a moral do grupo. Segundo Cavalcante, Alves e Barroso (2008), caracterizar a adolescência não é simples, pois se somam características socioculturais do ambiente do jovem com os fatores biológicos do indivíduo. Desta forma, poder-se-ia entender que o momento da adolescência é diretamente influenciado pelo ambiente familiar, cultural e social.

Em um estudo sobre atletas de remo conduzido por Côté (1999), foi apresentado três estágios de participação do jovem no esporte. Um primeiro estágio de experimentação, de 6 a 13 anos, em que os pais apresentam os filhos a atividade esportiva com o objetivo de divertimento e entretenimento. No segundo estágio, caracterizado como anos de especialização, dos 13 aos 15 anos, cresceria o interesse e comprometimento pelo esporte. A partir dos 15 anos, definiu como os anos de investimento, com o aumento do compromisso e na superação de dificuldades.

No futebol, um estudo transcultural sobre a introdução dos atletas nessa modalidade realizado em 7 países, incluindo o Brasil, demonstra que a média de idade em que os atletas têm sua iniciação esportiva no futebol é com 5 anos, e que participam de um treinamento formal em clubes com 11 ou 12 anos, principalmente por conta da busca de novos talentos precoces por parte dessas instituições (FORD et al., 2012).

Bohme (2007) sugere que a busca para detectar jogadores talentosos seja cada vez mais concentrada na idade entre 12 e 13 anos, permitindo tempo para aperfeiçoamento das habilidades motoras, técnicas, físicas, intelectuais e emocionais. Desta forma, o processo de desenvolvimento se consolidaria no longo prazo, com tempo para a sua adaptação ao meio social, institucional e cultural que o futebol está inserido.

No processo de se tornar atleta de alto rendimento, na adolescência o jovem atleta se depara com um conjunto de forças e pressões biopsicossociais que influenciam seu comportamento. Desde familiares, amigos, treinador, patrocinador, colegas e seu próprio eu 
mental e físico, cobram por um ótimo resultado em competições. Nessa busca desenfreada por vitórias, muitas vezes a atenção com seu próprio desenvolvimento psicológico é abandonada em troca da dura exigência por resultados, e muitas vezes não por bom processo e desempenho (SINGER, 1977).

Se a adolescência é caracterizada pelo desejo de enfrentar o desconhecido e experimentar o novo a partir de novas realidades, há o receio de deixar a segurança do conhecido, trocando o certo pelo incerto. $O$ desejo de crescer só prevaleceria se a nova realidade fosse experimentada como suficientemente atrativa e gratificante para compensar a perda da segurança (MACHADO; BRANCO; SOUZA, 2008). Porém, a sedutora carreira do esporte e a busca por talentos precoces encontram esses jovens atletas no início da adolescência.

\subsubsection{Teoria Comportamental}

Skinner (1953), afirma que o comportamento é uma característica primordial dos seres vivo, quase identificado com a vida propriamente dita. $O$ autor afirma que ao observar esses comportamentos de maneira objetiva é possível compreendê-los e tomar um curso mais sensato de ação. Skinner (1972), descreve a aprendizagem como mudanças de comportamentos ensinadas através de reforços imediatos, contínuos ou intermitentes, como resposta à um estímulo (comportamento) emitido pelo sujeito, que seja próximo do comportamento (resposta) desejado. Dessa maneira, as respostas emitidas serão cada vez mais próximas à desejada, até atingir o condicionamento desejado. Por meio do condicionamento respondente (clássico, ou pavloviano), respostas orgânicas poderiam ficar sob o controle de novos estímulos. Pavlov associaria estímulos neutros (presença de um pesquisador) com uma resposta orgânica - ou reflexa não condicionada - (salivação de um cachorro), e então iniciou uma série de experimentos em que condicionou um cão a salivar associando à entrega do alimento com um som ou luz, criando assim a teoria do condicionamento clássico (SKINNER, 1953).

O processo de aprendizagem em que a resposta, e ação posterior, dependem das consequências obtidas após sua conclusão é chamado de condicionamento operante. É este tipo de aprendizagem que atribui ao indivíduo algum grau de controle sobre o seu ambiente, dando a possibilidade de produzir mudanças em sua situação, realizando ações apropriadas. O condicionamento operante é um tipo de seleção por consequências, em que o comportamento sofre reforçamento após ele ocorrer, como uma estrela após a criança ter 
acertado o exercício, água após o animal ter pressionado a barra corretamente, etc. O termo reforçamento menciona algo que aumenta a força de uma resposta adquirida, e que aumenta a probabilidade de que ela ocorrera novamente.

Este reforçamento pode ser positivo ou negativo. Se positivo a ação é diretamente recompensada, introduzindo um reforçador positivo no ambiente (água, bala, estrela, troféu, etc.). Se o reforço é negativo é, a ação é indiretamente recompensada pela retirada de um estimulo aversivo, desagradável. Para extinguir um comportamento não desejável, há um processo de desaparecimento de resposta como resultado da ausência do reforçamento, chamado de extinção. No caso de condicionamentos operantes, isso ocorre quando o estímulo condicionado é apresentado repetidas vezes, e não tem em sequência a presença de um estímulo reforçador, causando a quebra na contingência (MOREIRA e MEDEIROS, 2007). Segundo Skinner (1953, p. 76) "em geral, quando nos empenhamos em comportamentos que 'não compensam' encontramo-nos menos inclinados a comportamentos semelhantes no futuro".

Skinner (2007) cita que, enquanto na extinção há a quebra dessa contingência, na punição negativa acontece a retirada do estímulo reforçador como aplicação de algum tipo de penalidade ou evento desagradável com a finalidade de eliminar o comportamento indesejável. O autor define como "punição positiva" o estímulo aversivo apresentado que tem como propósito reduzir a probabilidade da resposta se repetir, e reconhece que punição é a mais comum das formas de controle do comportamento humano na vida moderna (SKINNER, 1953).

A punição é definida por Azrin e Holz (1966) como "uma consequência do comportamento que reduz a probabilidade futura daquele comportamento". Os autores ressaltam que após a apresentação de um estímulo específico, a punição reduz a probabilidade futura de uma resposta indesejada. Além disso, mencionam que, para a punição ter o efeito esperado, diversas circunstâncias são necessárias. Todorov (2001, pg. 38), lista essas circunstâncias:

“1). Não pode haver fuga possível do estímulo punitivo. 2) O estímulo deve ser tão intenso quanto possível, e (3) tão frequente quanto possível. 4) A punição tem que ser imediata. 5) A intensidade não pode ser aumentada gradualmente - desde a primeira aplicação, o estímulo tem que ser tão intenso quanto possível.6) Se a intensidade for baixa, os períodos de punição 
devem ser curtos. 7) A punição não deve ser associada à apresentação de um estímulo reforçador positivo, para não adquirir propriedades de estímulo discriminativo. 8) A punição deve sinalizar um período de extinção para a resposta.9) O grau de motivação para a resposta deve ser diminuído.10) A frequência de reforço positivo para a resposta deve ser diminuída.11) Uma resposta alternativa à que é punida deve estar disponível.12) Se não há resposta alternativa na situação, o sujeito deve ser levado a outra situação com acesso ao estimulo reforçador.13) Se um estímulo aversivo primário não pode ser aplicado após a resposta, pode-se usar um estímulo aversivo condicionado.14) Em último caso, punição pode ocorrer pela apresentação de timeout ou pelo aumento no custo da resposta."

\subsection{Psicologia Cognitivo-Comportamental}

A Terapia Cognitivo-Comportamental (TCC) fundamenta-se na coligação entre pensamento, emoção e comportamento, considerando que a cognição funciona como mediadora da relação do sujeito com o mundo externo, determinando assim seu comportamento (BECK, 1997). Beck (et al., 1979), seguidor de filósofos do Estoicismo Grego como Epíteto, desenvolveu um modelo que se baseia na visão de que "os homens não se perturbam pelas coisas que acontecem, mas sim pelas opiniões sobre essas coisas" (Epitectus; Higginson, 1955, p.14). O modelo cognitivo baseia-se em uma tríade: a visão de si mesmo, visão do mundo e visão do futuro. Esse modelo propõe que a maneira disfuncional e/ou distorcida que um indivíduo possa ter sobre si, sobre o mundo ou sobre seu futuro está diretamente ligada a emoções, comportamentos e até psicopatologias que esse indivíduo tenha ou pode vir a ter.

Os modelos cognitivos colocam em primeiro plano, os pensamentos automáticos, que aparecem fora do controle do indivíduo, e que estão logo abaixo da superfície da mente consciente (exemplo: "Ele sabe onde vou chutar o pênalti"). Em geral ocorrem de forma rápida, e são imperceptíveis, pré-conscientes, até que a atenção seja voltada a eles, e em geral após certo tempo de treinamento (WRIGHT, 2006). Em um segundo plano, mais profundo, o modelo cognitivo cita as crenças intermediárias. Geralmente ocorrem como regra ou suposição (exemplo: "se eu perder o pênalti, então não será mais titular"), em sua maior parte disfuncional, sem muita conexão com a realidade, que quando observadas e questionadas atentamente, são descartadas como não verdadeiras. 
Essas regras não estão diretamente relacionadas à uma situação específica, mas a uma tendência cognitiva geral do indivíduo. São mais resistentes a mudanças do que os pensamentos automáticos, pois "protegem" a crença central e criam um sistema que alivia a dor que esta causa (FALCONE em RANGÉ, 2001). Em um nível mais profundo, o modelo cognitivo define as crenças centrais como verdades absolutas que um indivíduo tem dele mesmo, do mundo e do futuro. As crenças centrais podem ser categorizadas entre Crenças de Desamparo, Crenças de Desamor, e Crenças de Desvalor, e se desenvolvem de conflitos pessoais com seu ambiente desde a infância (WRIGHT, 2006; BECK, 1997).

O objetivo da Terapia Cognitiva é o de promover a reestruturação cognitiva, isto é, modificar pensamentos, emoções e crenças disfuncionais, utilizando-se de sessões estruturadas com diversas técnicas, priorizando a aliança terapêutica, para assim alterar os estados de humor e o comportamento do indivíduo (BECK, 1997).

\subsubsection{Técnica do Questionamento Socrático}

Uma das maneiras que a terapia cognitiva utiliza para atingir a Reestruturação Cognitiva é o Questionamento Socrático. Esse método se constitui por questionar sistematicamente de forma elaborada o tema em pauta, para levar o indivíduo a conclusões lógicas, desenvolver expectativas realistas de uma forma cooperativa (WRIGHT, 2006). Esse método também pode trazer definições universais dos termos utilizados pelos sujeitos, assim como informações do "mundo real", podendo inclusive despersonalizar o problema, colocando-o em uma pessoa imaginária ou um amigo para chegar de maneira mais simples a soluções logicas possíveis.

\subsubsection{Técnica da Seta Descendente}

Outra técnica utilizada pela Psicologia Cognitiva para chegar às crenças mais centrais é a Seta Descendente (ou Flecha Descendente). Para se aproximar da crença central, o psicólogo faz perguntas sobre o significado que aquele pensamento específico, aquela crença tem sobre si mesmo, e aprofundando a cada pergunta, até chegar na crença central (WRIGHT, 2006). 
FIGURA 3 - FLECHA DESCENDENTE

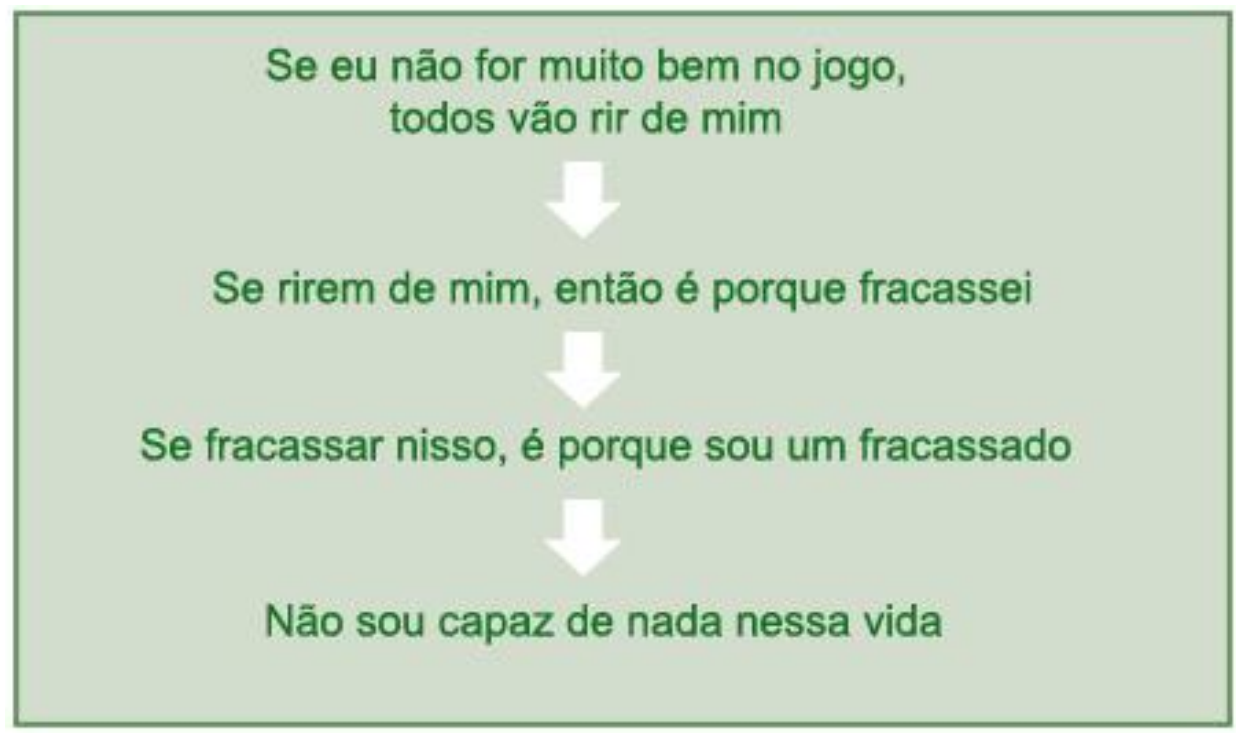

Fonte: Mello (2017)

Segundo Wright (2006), para gerar essa sequência de pensamentos, como o da figura 3, o psicólogo questiona qual seria o significado pessoal do paciente para cada pensamento. "Se todos rirem, o que isso diz sobre você? ", por exemplo, levando o indivíduo a relatar sua crença de incapacidade. Wright (2006) também cita sobre a importância de desenvolver um vínculo positivo com o indivíduo antes de utilizar a técnica da seta descendente, já que o paciente teria que relatar cognições negativas íntimas e dolorosas que formam uma representação de si mesmo. Esta técnica pode ser utilizada de forma verbal ou de forma escrita.

\subsubsection{Técnica do registro de pensamentos disfuncionais - RPD}

A função do RPD é a de facilitar a identificação e análise de um pensamento automático disfuncional de maneira direta e sistemática, e assim aumentar sentimentos positivos, ou minimizar sentimentos ou emoções disfuncionais (WRIGHT, 2006). Após o indivíduo relatar uma situação em que se sentiu incomodado, o psicólogo toma nota na primeira coluna da figura 4, de maneira precisa e pontual, situações reais não hipotéticas. Respondendo a perguntas como "o que você sentiu nessa situação? ", a segunda coluna será preenchida com um sentimento/emoção, assim como uma escala de percepção sobre a intensidade daquela emoção. 
Na terceira coluna o psicólogo relata os pensamentos disfuncionais automáticos que veio à mente do indivíduo quando exposto a esta situação, independentemente do quanto absurdo ou incoerente esse pensamento possa parecer.

TABELA 1 - REGISTRO DE PENSAMENTOS DISFUNCIONAIS - RPD

\begin{tabular}{|c|c|c|c|c|c|}
\hline Situação & Emoção & $\begin{array}{l}\text { Pensamento } \\
\text { Automático }\end{array}$ & $\begin{array}{l}\text { Evidencias à } \\
\text { favor }\end{array}$ & $\begin{array}{l}\text { Evidencias } \\
\text { Contrária }\end{array}$ & Resultado \\
\hline $\begin{array}{l}\text { Ouviu } \\
\text { críticas do } \\
\text { treinador } \\
\text { sobre seu } \\
\text { desempe } \\
\text { nho em } \\
\text { cruzamen } \\
\text { tos }\end{array}$ & $\begin{array}{l}\text { Ansiedade } \\
(90 \%) \\
\text { Raiva } \\
(50 \%) \\
\text { Medo } \\
(70 \%)\end{array}$ & $\begin{array}{l}\text { Ele vai me } \\
\text { tirar do time } \\
\text { Vou ficar sem } \\
\text { emprego } \\
\text { Meus } \\
\text { últimos dois } \\
\text { jogos foram } \\
\text { ruins, vou } \\
\text { ser afastado. }\end{array}$ & $\begin{array}{l}\text { Criticou meu } \\
\text { desempenho } \\
\text { mais de uma } \\
\text { vez. } \\
\text { Cochicha } \\
\text { coisas } \\
\text { quando eu } \\
\text { passo perto } \\
\text { dele. }\end{array}$ & $\begin{array}{l}\text { Sou eficiente } \\
\text { na maioria } \\
\text { das partidas. } \\
\text { Foi a } 2^{\text {a }} \\
\text { critica nesse } \\
\text { ano todo só, } \\
\text { e sobre nos } \\
\text { últimos jogos. }\end{array}$ & $\begin{array}{l}\text { Preciso } \\
\text { melhorar meus } \\
\text { desempenho } \\
\text { em } \\
\text { cruzamentos. }\end{array}$ \\
\hline
\end{tabular}

Fonte: Mello (2017).

Após ter as três primeiras colunas preenchidas, o psicólogo questiona sobre qual dos pensamentos assinalados incomoda mais, e o seleciona como o "pensamento quente", e exercita com o indivíduo evidencias que apoiem ou refutem esse pensamento disfuncional, finalizando com um resultado, ou resposta adaptada a situação. 


\subsubsection{Técnica de hierarquia de ansiedade}

A psicologia cognitivo-comportamental utiliza-se de técnicas de enfrentamento às situações aversivas, porém, toma o devido cuidado para não expor, por exemplo, um jogador que fica apavorado quando vai bater um pênalti a cobrá-lo em uma partida decisiva, pois se há uma crença de incapacidade, mesmo que ele consiga fazer o gol, é possível que este funcione como um reforço intermitente apenas, podendo se sentir inseguro e percebendo que por vezes ele é incapaz, e em outros momentos ele tem sorte.

Para a exposição, a psicologia cognitivo-comportamental utiliza-se da hierarquia de ansiedade, em que é criada uma estratégia de aproximação da situação mais temida, posicionando situações mais e menos aversivas (CABALLO; CLAUDINO, 1996). Desenvolve-se, junto com o atleta, uma hierarquia em ordem crescente de grandeza de ansiedade, inserindo medos particulares daquele atleta, ou comuns entre os indivíduos (BARRETO, 2003). Essa escala poderia ser usada, então, para uma exposição gradual realizada de maneira concreta, ou de forma imaginativa.

\subsubsection{Técnica de dessensibilização sistemática por imagem}

A técnica de Dessensibilização Sistemática foi primeira utilizada por Wolpe no final da década de 50, porém primeiro como exposição ao vivo, para somente depois ser utilizada na imaginação. Esse método resume-se a um enfrentamento gradual, controlado pelo paciente e terapeuta, que expõe na imaginação o paciente a estímulos que the causem ansiedade, durante um estado fisiológico oposto, isto é, de relaxamento, e assim incompatível com o estado de ansiedade.

Esse artifício é considerado um contra condicionamento, em que o paciente é apresentado com estímulos reforçadores e agradáveis, mas também estímulos aversivos ansiogênicos. O objetivo desta técnica é retirar as respostas fisiológicas de ansiedade do paciente, frente aquelas situações específicas e modificar seu comportamento de esquiva (FERRAZ em ABREU e GUILHARDI, 2004).

No esporte, Weinberg e Gold (2008), citam o método de visualização, também conhecida como treino mental, trata-se de um processo de criação de uma experiência na mente do atleta. Uma simulação interna de uma realidade, uma experiência sensorial externa. Pode simular um evento anterior, ou uma situação imaginária, nova. Ainda segundos os autores, o processo deve incluir o máximo de sentidos possível, utilizando-se da visão para visualizar em primeira pessoa, o cinestésico para sentir-se movimentando o 
corpo e acessórios esportivos, o auditivo para ouvir os sons próprios do momento, e o olfato para sentir o cheiro do ambiente de competição.

\subsection{A técnica do biofeedback}

O termo biofeedback foi criado em 1969, na primeira reunião do Biofeedback Research Society, que mais tarde mudou para Biofeedback Society of America e hoje é conhecido como Association for Applied Psychophysiology and Biofeedback. Essa terminologia relata a união de dois processos: a) um sistema tecnológico (uma tecnologia), o qual interage com o sistema fisiológico para obter informações deste e apresentar informações a este mesmo sistema; b) um princípio sistêmico, o qual relata que todo sistema interdependente é capaz de provocar modificações em seus processos interligados, desde que seja capaz de se relacionar com o mesmo (LEHRER et. al. 2007, SCHWARTZ, 1995; BIRBAUMER; FLOR, 1999; FOZA, 2005).

É um processo através do qual o indivíduo aprende a alterar a ativação fisiológica com o propósito de melhorar a saúde e desempenho (ASSOCIATION FOR APPLIED PSYCHOPHYSIOLOGY AND BIOFEEDBACK, 2008). Utilizando o conhecimento de Luigi Galvani sobre a ação fisiológica da eletricidade, diversas modalidades de biofeedback foram desenvolvidas para auxiliar no controle voluntário de funções corporais e processos psicofisiológicos que estão normalmente fora da consciência do indivíduo (POPJORDANOVA; DEMERDZIEVA, 2010).

Os diversos usos do biofeedback foram desenvolvidos ao redor do mundo com o passar dos anos. Pesquisas de diversos países comprovam a eficácia do biofeedback em ansiedade (MOORE, 2000), concentração (HSIEH; HUANG e HUNG, 2010), estresse póstraumático (PYNE E GEVIRTZ, 2009). Além das áreas que dizem respeito a tratamentos, o biofeedback tem se mostrado eficiente para a alta-desempenho em esportes, música e para executivos. (POP-JORDANOVA; CAKALAROSKA, 2008; EGNER; GRUZELIER, 2003; RAYMOND; SAJID; PARKINSON E GRUZELIER, 2003; HATFIELD E HILLMAN, 2001). Mesmo dentro da categoria de biofeedback existem diferentes modalidades, diversas medidas que os aparelhos captam do corpo humano e retroalimentam em forma de som ou imagem em monitores de computador.

Schwartz (1995) descreve a captação de vários sinais fisiológicos anteriores a essa retroalimentação, entre eles o impulso neural (EEG), impulso nervoso motor (EMG), 
condutividade e resistência da pele e impulso cardíaco (EKG). Todos esses sinais estão envolvidos em complexas atividades cognitivas, simpáticas e parassimpáticas (SCHWARTZ, 1995), respondendo rapidamente à pensamentos, emoções e agentes estressores. Este processo é uma forma de condicionamento operante, em que a informação retroalimentada reforça positiva ou negativamente determinado comportamento, favorecendo a aprendizagem deste comportamento (CATANIA, 1999).

O treinamento ou tratamento com biofeedback envolve aparelhos eletrônicos, que mensuram sinais fisiológicos que indicam níveis de ativação do Sistema Nervoso Autonômico. Este aparelho é conectado ao corpo por sensores que captam tensão muscular, temperatura, condutância galvânica ou variabilidade cardíaca, e convertem em informações significativas para o indivíduo, como sinais auditivos agradáveis, e/ou estímulos visuais como imagens, vídeos, animações. O indivíduo utiliza estas informações como parâmetro enquanto pratica diversas técnicas para a manutenção dos objetivos específicos do treinamento (APPOLINARIO, 2001).

\subsection{A técnica biofeedback de condutância galvânica}

Uma das modalidades mais utilizadas de biofeedback é a de resposta galvânica da pele, medindo a transpiração de uma das mãos através da condução de eletricidade. Schwartz (1995), por exemplo, cita que a pele é um complexo elétrico, e que cada centímetro quadrado de pele na mão contém até 2000 glândulas sudoríparas. Cada glândula pode ser considerada um caminho elétrico individual da superfície da pele até as camadas mais profundas. Normalmente esses caminhos tem uma alta resistência, porém quanto mais glândulas estão "ligadas", menor é a resistência da pele, como mostra a figura abaixo.

FIGURA 4 - GLÂNDULAS SUDORÍPARAS. AS O “LIGADAS" E AS “DESLIGADAS"

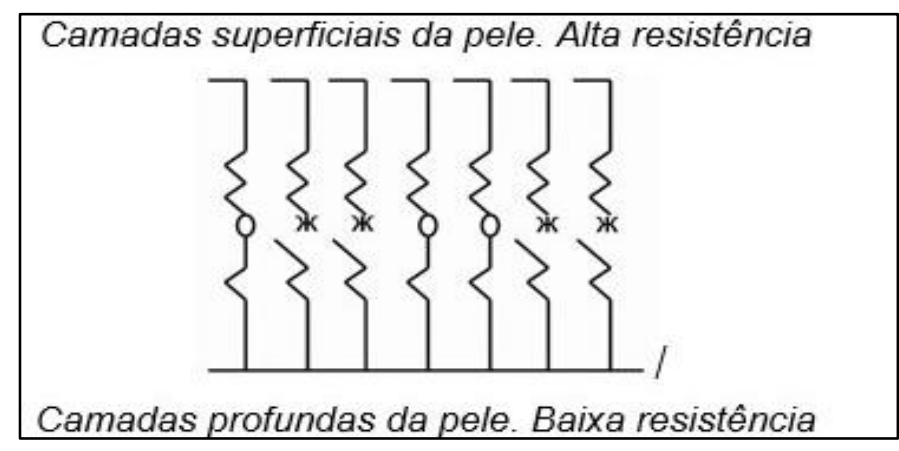

Fonte:Schwartz (1995), citado por Venables e Christie (1980) 
As camadas mais profundas da pele são altamente condutivas, enquanto as camadas superficiais são altamente resistentes. Essas conexões são isoladas na superfície da pele, porém conectadas nas camadas mais profundas (SCHWARTZ, 1995). A modalidade GSR (galvanic skin response), EDR (electro-dermal response) ou até SRL (Skin Resistance Level) monitora a atividade elétrica das glândulas sudoríparas aplicando uma pequena voltagem na pele, criando uma corrente elétrica e medindo sua resistência de acordo com a lei de Ohm (voltagem é igual resistência vezes a intensidade da corrente, ou seja, $V=I^{\star} R$ ).

A figura 5 demonstra o funcionamento de um aparelho de biofeedback da modalidade SRL.

FIGURA 5 - LOOP ELÉTRICO DE CONDUTIVIDADE DA PELE

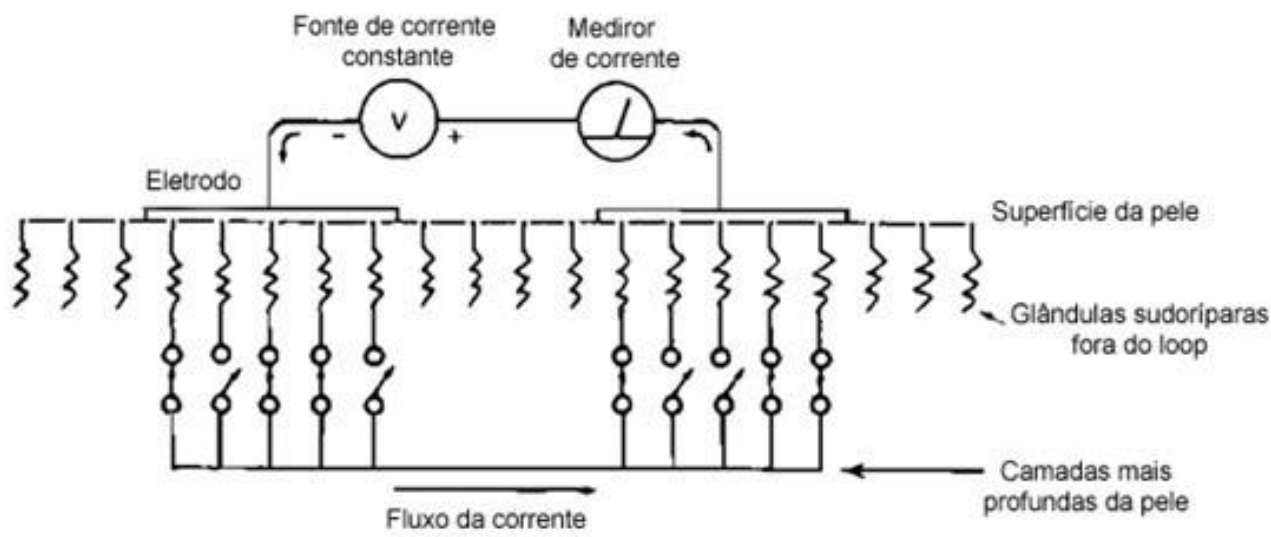

Fonte: Schwartz, 1995 adaptado por Mello, 2017

\subsection{A técnica biofeedback de variabilidade cardíaca}

Outra modalidade de biofeedback é a variabilidade cardíaca. Nesta categoria a medida utilizada é a do intervalo entre batimentos cardíacos e sua variação. Pode-se pensar em variabilidade cardíaca (Hearth Rate Variability ou HRV) como medida geral de adaptabilidade. Pouca coerência cardíaca pode indicar estresse elevado. As flutuações do ritmo cardíaco entre as batidas nos proporcionam uma medida indireta da saúde cardíaca, estresse e equilíbrio entre a atividade do sistema nervoso simpático e parassimpático. A variação de velocidade do batimento cardíaco que acompanha a respiração é chamada de Arritmia Sinusal Respiratória (RSA).

A Arritmia Sinusal Respiratória promove eficiência respiratória, deixando o sangue mais disponível quando a concentração de oxigênio nos alvéolos está no seu máximo, ou 
seja, durante a inspiração. Essa eficiência aumenta quando se respira a aproximadamente seis vezes por minuto, e quando se respira nesta frequência a RSA está completamente em compasso com a respiração, aumentando a taxa cardíaca simultaneamente com a inspiração e diminuindo simultaneamente com a expiração.

O ritmo cardíaco é primariamente controlado pelo nervo vago, que inibe a frequência cardíaca. Na inspiração a atividade do nervo vago é inibida e a frequência cardíaca aumenta. Na expiração, o nervo vago é ativado e ocorre a inibição da taxa cardíaca. O grau de flutuação da frequência cardíaca também é controlado significativamente por impulsos regulares dos barorreceptores (sensores de pressão) nas artérias aorta e carótidas. Quando a RSA é aumentada por meio de biofeedback, a meta é geralmente reforçar a atividade natural de feedback dos barorreceptores através do padrão respiratório. Outro componente importante para a variabilidade cardíaca são os dos barorreceptores, que funcionam como sensores de pressão nas artérias e controlam a pressão sanguínea. Quando a pressão arterial sobe, os barorreflexos diminuem os batimentos cardíacos e a pressão, aumentando a respiração e aumentando os batimentos cardíacos.

O biofeedback, quando utilizado para maximizar a amplitude da variabilidade cardíaca, automaticamente o indivíduo respira na frequência ressonante e estimula os barorreflexos. Se essa estimulação é frequente com práticas diárias, o biofeedback HRV funciona como um exercício, tendendo a aumentar o ganho em barorreflexos (LEHRER et al., 2007) e assim indiretamente reduzir a pressão arterial e estresse a longo prazo, garantindo que as oscilações persistam após estimulação inicial.

A relação entre frequência cardíaca e oscilações na pressão arterial nesta frequência é exatamente $180^{\circ}$, e a relação entre oscilações na frequência cardíaca e oscilações e respirações é $0^{\circ}$ (LEHLER; WOOLFOLK; SIME,2007).

Lehler (et. al., 2007) afirma que respirar na frequência ressonante aumenta a oscilação em HR e estimula a frequência rítmica e com a inspiração coincidindo com a aceleração cardíaca, as maiores amplitudes são alcançadas. DeBoer, Karemaker e Strackee (1987) consideram que o sistema cardiovascular é conhecido por funcionar com características ressonantes a uma frequência aproximada de $0.1 \mathrm{~Hz}$.

O biofeedback de variabilidade cardíaca pode reforçar a respiração na frequência de 5 a 7 respirações por minuto, bem como a produção de um pico dominante de HRV em $0.1 \mathrm{~Hz}$. Um décimo de um hertz é igual a um décimo de um ciclo por segundo, portanto, $0.1 \mathrm{~Hz}$ 
é igual a seis ciclos por minuto. Ciclos de 5 a 7 respirações por minuto produzem um pico dominante de HRV em $0.1 \mathrm{~Hz}$.

\subsection{O uso da técnica de biofeedback no esporte}

Diversos estudos foram realizados com biofeedback em atletas amadores e de alto rendimento. Em um estudo de caso, Lagos (et al. 2008) mostra como aplicaram biofeedback HRV em um golfista e isso o auxiliou a lidar com o estresse.

Chartier, Collins e Koons (1997) aplicaram biofeedback EEG em atletas profissionais de golfe e 14 de 15 sujeitos de pesquisa notaram diferenças significativas em seu jogo e $83 \%$ dos sujeitos apresentaram com perfil iceberg. Já visando a observação de outro aspecto cognitivo, Foza (2005), após realizar um estudo com jogadores juvenis de futebol de campo, afirma que a técnica de biofeedback é capaz de modificar e/ou desenvolver os processos de atenção visual seletiva.

Wilson e Peper (2011) afirmam que o treinamento com biofeedback difere na clínica e no esporte, já que pacientes buscariam uma redução de sintomas, enquanto atletas recorreriam por conta de uma melhora no desempenho esportivo. As diferenças ocorreriam em propósitos diferentes, organização da sessão, entre outros fatores. Diferente de pacientes, atletas transfeririam de maneira mais intensa a aprendizagem. Porém, os autores também citam que, apesar do biofeedback ser um importante técnica para melhorar o rendimento, há outros fatores que impactam diretamente no desempenho.

Em um estudo com atletas universitários de voleibol, Tanis (2008) aplicou biofeedback em 14 atletas, e afirma que 13 melhoraram expressivamente a capacidade de controlar seus próprios batimentos cardíacos. Em um estudo com treino de biofeedback e técnicas de redução de estresse da terapia cognitiva em atletas amadores de futebol e basquete, DeWitt (1980) demonstrou diferenças significativas de desempenho entre os sujeitos de pesquisa e o grupo controle.

Strack (2003), investigou os efeitos do biofeedback e o rendimento de atletas praticantes de baseball, criando competições de rebatidas antes e depois de um treinamento com biofeedback. Após seis semanas, os participantes que receberam treinamento melhoraram o desempenho em $60 \%$, e os sujeitos controle apenas $21 \%$. Porém, os pesquisadores apontaram que o inventário de ansiedade utilizado (CSAI-2) não apontou melhoras significativas na redução de ansiedade. 
Em um estudo sobre o treinamento de biofeedback em atletas de basquetebol de 18 a 28 anos de idade, Paul e Garg (2012), examinaram a relação entre ansiedade e desempenho, além da eficácia de um protocolo de redução de estresse. Os resultados indicaram que o grupo de biofeedback reduziu consideravelmente a ansiedade quando comparado com grupos controle e placebo, além de melhorar o desempenho em acertos de passes, dribles e arremessos.

Bar-Eli e Blumenstein (2004), pesquisaram a relação entre treinamento mental com biofeedback com atletas de natação de 16 a 18 anos de idade, comparando-os com um grupo controle. Os resultados mostraram que os atletas do grupo experimental, que receberam o treinamento mental com biofeedback melhoraram o desempenho (velocidade), quando comparados com o grupo controle. Os autores concluíram que o treinamento tradicional somado ao treinamento mental com o uso de biofeedback poderia levar a um desempenho melhor do que somente o treinamento tradicional.

Embora na literatura seja possível encontrar um razoável número de estudos com biofeedback para redução de ansiedade no esporte, ainda são escassos os estudos que utilizam as técnicas de biofeedback associadas com psicologia cognitivo-comportamental para comprovar a redução do estado de ansiedade em atletas. Também através da literatura fica clara a necessidade de estudos que investiguem métodos de redução de estresse e estado de ansiedade do atleta cobrador de pênalti.

\subsection{O biofeedback e psicologia-cognitivo comportamental}

A terapia cognitivo-comportamental almeja diminuir os sintomas de ansiedade desafiando o pensamento disfuncional dos indivíduos, utilizando a reestruturação cognitiva e expondo-o a situação aversiva de maneira gradual, sendo essa exposição real ou imaginária (PELLETIER, 2003).

A reestruturação cognitiva envolve a redução da frequência e da força da crença nos pensamentos negativos. Isso é atingido, por exemplo, pelo desenvolvimento de interpretações mais realísticas das situações. A dessensibilização sistemática a situações temidas é utilizada para romper a conexão entre o estímulo ansiogênico e a resposta de ansiedade (WRIGHT, 2006). Para combater o ciclo de reforço causado pela evitação, o indivíduo é levado a confrontar as situações causadoras de ansiedade de maneira imaginária e gradualmente. A combinação de reestruturação cognitiva e dessensibilização sistemática 
tem recebido suporte empírico em diversos campos de estudo (OLATUNJI; CISLER; DEACON, 2010).

Ante esta sumária revisão de literatura, alguns questionamentos foram ser levantados, como:

1) Será que a técnica de biofeedback é um instrumento eficiente enquanto método e eficaz enquanto resultado?

2) Será que a técnica de dessensibilização sistemática associada ao biofeedback é eficaz para reduzir o estado de ansiedade de atletas de base de futebol de campo?

3) Será que um protocolo de biofeedback e psicologia cognitiva comportamental reduz de maneira maior a ansiedade somática do que a cognitiva?

4) Será que o resultado direto das cobranças de pênalti de antes e depois do treinamento com o protocolo sofrerá mudanças positivas?

Esses questionamentos poderiam ser mais bem aprofundados se levantássemos algumas hipóteses descritivas para estabelecer relações entre o protocolo de técnica de biofeedback associada à psicologia cognitivo-comportamental e a redução do estado de ansiedade dos atletas de futebol de categoria de base. 


\section{HIPÓTESES}

\subsection{Hipóteses descritivas}

\subsubsection{Central}

O estado de ansiedade em atletas de categoria de base de futebol de campo no momento da cobrança de pênaltis pode ser reduzido através do protocolo de técnica de biofeedback associada à psicologia cognitivo-comportamental.

\subsubsection{Complementares}

- O protocolo de técnica de biofeedback associada à psicologia cognitivocomportamental reduz a ansiedade somática de atletas amadores de futebol de campo no momento da cobrança de pênalti.

- O protocolo de técnica de biofeedback associada à psicologia cognitivocomportamental reduz a ansiedade cognitiva de atletas amadores de futebol de campo no momento da cobrança de pênalti.

- O protocolo de técnica de biofeedback associada à psicologia cognitivocomportamental aumenta a autoconfiança de atletas amadores de futebol de campo no momento da cobrança de pênalti.

\subsection{Hipóteses estatísticas}

Em função dessas hipóteses descritivas, foi considerada a possibilidade de depararse com a hipótese nula $(\mathrm{H} 0)$, como presumidamente verdadeira, ou hipótese alternativa (H1), no caso de confirmada a hipótese descritiva.

- H0 - Não existe redução estatisticamente significativa do nível geral de ansiedade depois do treinamento com técnicas de psicologia cognitivo-comportamental associadas ao biofeedback em atletas amadores de futebol de campo no momento da cobrança de pênalti. 
- H1 - Existe redução estatisticamente significativa do nível geral de ansiedade depois do treinamento com técnicas de psicologia cognitivo-comportamental associadas ao biofeedback em atletas amadores de futebol de campo no momento da cobrança de pênalti.

- H0 - Não existe redução estatisticamente significativa do nível de ansiedade somática depois do treinamento com técnicas de psicologia cognitivo-comportamental associadas ao biofeedback em atletas amadores de futebol de campo no momento da cobrança de pênalti.

- H1 - Existe redução estatisticamente significativa do nível de ansiedade somática depois do treinamento com técnicas de psicologia cognitivo-comportamental associadas ao biofeedback em atletas amadores de futebol de campo no momento da cobrança de pênalti.

- H0 - Não existe redução estatisticamente significativa do nível de ansiedade cognitiva depois do treinamento com técnicas de psicologia cognitivo-comportamental associadas ao biofeedback em atletas amadores de futebol de campo no momento da cobrança de pênalti.

- H1 - Existe redução estatisticamente significativa do nível de ansiedade cognitiva depois do treinamento com técnicas de psicologia cognitivo-comportamental associadas ao biofeedback em atletas amadores de futebol de campo no momento da cobrança de pênalti.

- H0 - Não existe aumento estatisticamente significativa do nível de autoconfiança depois do treinamento com técnicas de psicologia cognitivo-comportamental associadas ao biofeedback em atletas amadores de futebol de campo no momento da cobrança de pênalti.

- H1 - aumento estatisticamente significativa do nível de autoconfiança depois do treinamento com técnicas de psicologia cognitivo-comportamental associadas ao biofeedback em atletas amadores de futebol de campo no momento da cobrança de pênalti. 


\section{MATERIAL E MÉTODO}

O método utilizado no presente estudo se caracteriza por um delineamento experimental paralelo, de aspecto quantitativo-qualitativo, visando analisar se o estado de ansiedade de atletas de futebol de campo de categoria de base poderia ser reduzido mediante o uso de um protocolo de treinamento com biofeedback associado a técnicas de psicologia cognitivo-comportamental. Este é pertinente à área de interesse, no caso o Esporte e a Educação Física, entre grupos de atletas amadores de futebol de campo brasileiros. A contrapartida apresentada foi o acesso aos dados da pesquisa, e o treinamento do psicólogo da equipe na técnica, que poderia ser aplicada a qualquer momento após o final da pesquisa. O presente estudo foi apresentado e aprovado pelo Comitê de Ética em Pesquisa da Escola de Educação Física e Esporte da Universidade de São Paulo, sob o número 40688214.5.0000.5391.

\subsection{Descrição da população em estudo}

O presente estudo foi desenvolvido no estado de São Paulo, com atletas com idade cronológica entre 15 e 16 anos, idade, pertencentes às categorias de base de duas equipes de futebol de campo. Além disso, só participaram do processo de investigação, os jovens atletas que assinaram o Termo de Consentimento Livre e Esclarecido e/ou foram assinados pelos seus responsáveis, conforme APÊNDICE C.

\subsection{Casuística}

Fizeram parte do estudo 34 atletas como parte de amostra de conveniência, pertencentes a duas equipes de futebol de campo, pertencentes a dois clubes que mantinham equipes em competições promovidas pela Federação Paulista de Futebol Estado de São Paulo, do sexo masculino, oriundos de diversas classes sociais, com idade cronológica entre 15 e 16 anos. 


\subsection{Coleta de dados}

Os dados foram coletados pelo próprio pesquisador no transcorrer de seis dias corridos de treinamentos das equipes, mediante o uso do instrumento de pesquisa denominado CSAI-2R, visando obter informações a respeito dos estados de ansiedade em relação as cobranças de pênaltis por parte dos atletas cobradores de pênalti dos grupos experimentais e controle, antes e depois de quatro encontros individuais de intervenção do pesquisador com os atletas do grupo experimental. Nesses encontros foi aplicado o protocolo de técnicas da psicologia cognitivo-comportamental associado ao biofeedback.

A coleta dos dados ocorreu de maneira coletiva, momentos antes às cobranças de pênaltis, e após uma breve explicação sobre a atividade para ambos os grupos. A não coleta dos dados deu-se somente por motivos alheios ao pesquisador, ou seja, por desistência pela vontade própria do atleta, falta em uma das fases do processo, e/ou a não autorização dos pais ou responsáveis.

\subsection{Instrumentos envolvidos na pesquisa}

O instrumento de pesquisa denominado CSAI-2R - Revised Competitive State Anxiety Inventory - 2 - foi utilizado com o objetivo de mensurar o nível do estado de ansiedade frente às cobranças de pênaltis antes e após o protocolo de redução de ansiedade com técnicas de biofeedback e psicologia cognitivo-comportamental.

O CSAI-2R foi utilizado com sua pontuação geral, e nos seus subitens (ansiedade somática, ansiedade cognitiva e autoconfiança). Foram usadas técnicas cognitivocomportamentais-comportamentais de debate socrático, registro de pensamentos disfuncionais e dessensibilização sistemática como parte do protocolo de intervenções adotadas pelo pesquisador com o uso de um aparelho de biofeedback de variabilidade cardíaca e condutância galvânica. Este aparelho é denominado IOM (figura 6), e o fabricante é a empresa norte-americana WildDivine. Os softwares utilizados durante a intervenção com biofeedback são denominados Alive (figura 7) e DualDrive Pro 3 (figura 8), da empresa SomaticVision. 


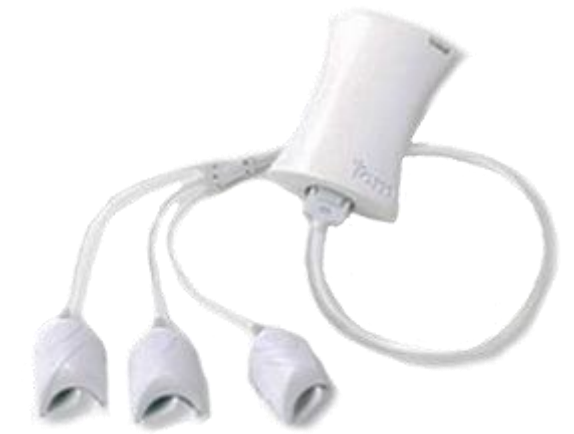

FIGURA 6 - IOM - Wild Divine

O software Alive (figura 7) fornece um gráfico para observar a variabilidade cardíaca e condutância galvânica, além de oferecer alguns jogos simples para possibilitar o treino da respiração.

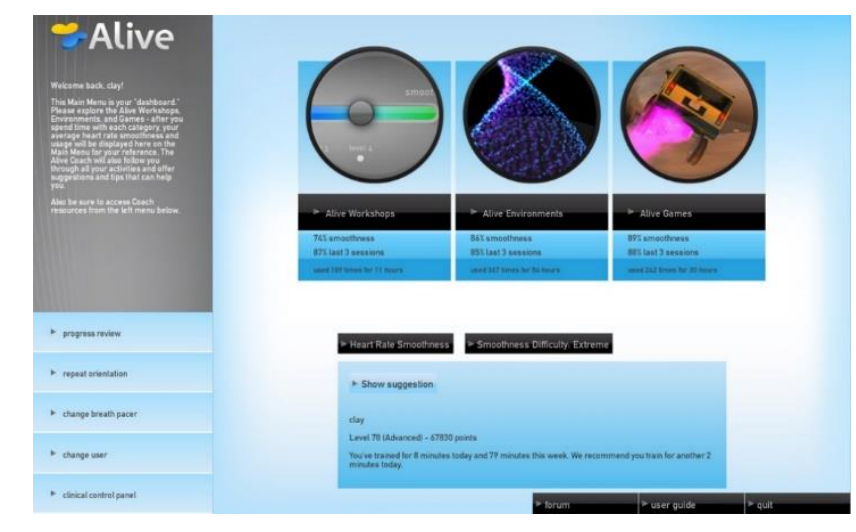

FIGURA 7 - Alive, software da Somatic Vision

O software Dual Drive Pro 3 (figura 8) é um jogo de carro, em que o feedback da variabilidade cardíaca ou condutância galvânica é fornecido através da velocidade do carro (com o sujeito mais relaxado, mais veloz o carro é).

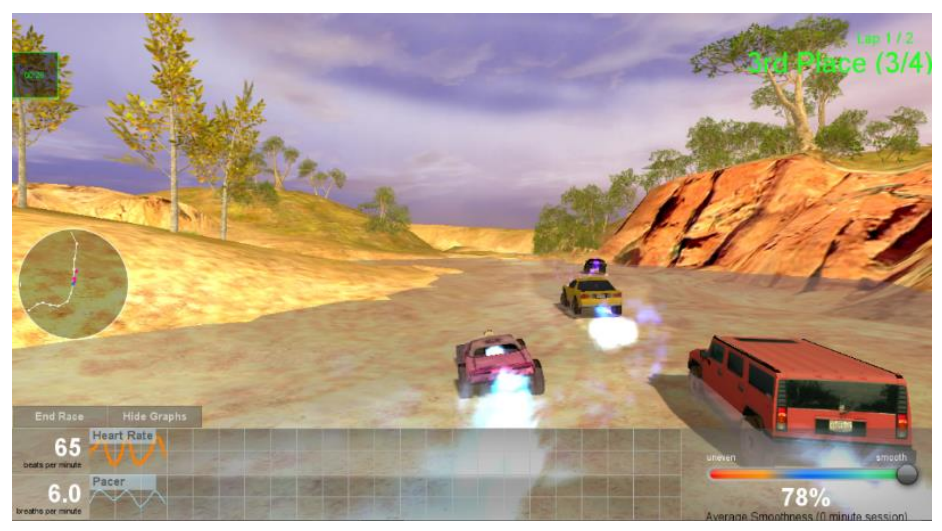

FIGURA 8 - Dual Drive Pro 3, software da Somatic Vision 


\subsection{Procedimentos do estudo}

O estudo foi desenvolvido mediante as seguintes fases, apresentadas no Quadro 1:

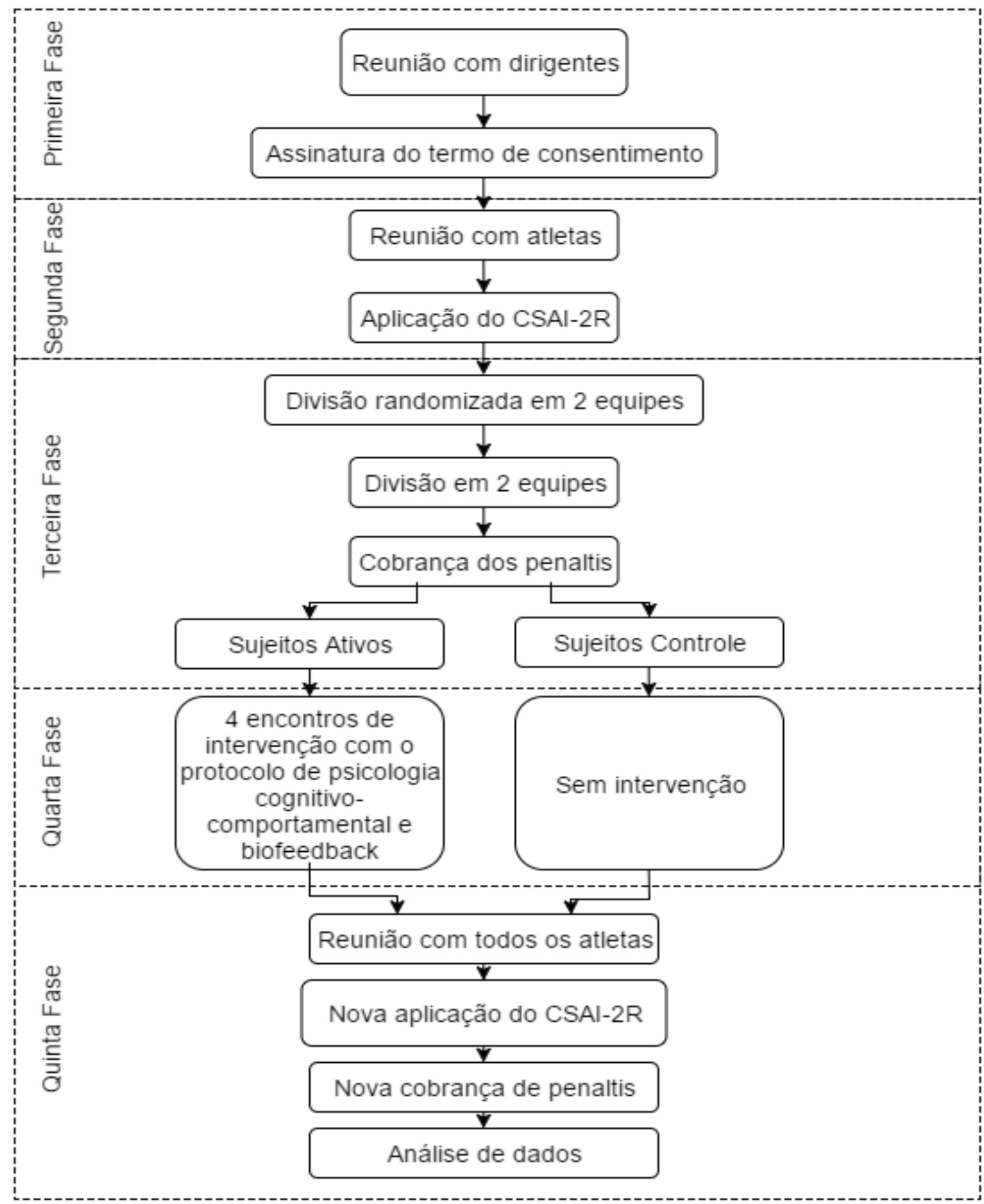

QUADRO 1 - DESENHO DO ESTUDO 


\subsubsection{Primeira fase}

Essa fase foi marcada pela elaboração de projeto de pesquisa que foi entregue aos dirigentes dos clubes responsáveis pelas equipes que seriam investigadas, com o objetivo de explicar as propostas de pesquisa por parte do pesquisador junto aos dirigentes e responsáveis pelos atletas que gostariam de participar do projeto de investigação. Essa fase foi marcada, também, pela entrega e assinatura do Termo de Consentimento e Livre Esclarecido - termo que solicitava o consentimento por parte dos responsáveis pelos atletas suas participações no projeto (APÊNDICE C).

\subsubsection{Segunda fase}

Esta fase foi norteada por uma reunião com os grupos de atletas, que receberam informações e explicações acerca dos objetivos, justificativas, benefícios que o estudo proporcionaria a eles e às suas equipes. Com o objetivo de simular a ansiedade durante uma competição real de pênaltis inserindo estímulos aversivos que imitariam a realidade de um atleta de alto rendimento cobrando pênalti, os atletas foram orientados a torcer contra a equipe adversária, e também foi mencionado que a excelência ou fracasso do seu desempenho poderia ser exibido na USP, através da filmagem que seria realizada. Que os cinco melhores poderiam ser mostrados como exemplos de cobradores de pênalti, e os cinco piores como exemplo de como não se executa uma cobrança. Essa fase também foi delineada pela aplicação do instrumento "CSAI-2R" dentro do campo de futebol e minutos antes das cobranças de pênaltis por parte dos sujeitos pesquisados.

\subsubsection{Terceira fase}

Foi marcada pela divisão randomizada de duas equipes para a competição de pênaltis e decisão dos atletas pela ordem de cobrança - e, pelo aviso aos atletas de que uma das equipes receberia um treinamento especifico e a outra seria mantida como grupo controle. As cobranças de penalidades foram filmadas com uma filmadora Sony Camcorder, enquanto os atletas da equipe adversária foram orientados a vaiar o cobrador para simular a pressão de uma torcida adversária, aproximando ao máximo à situação de um jogo real, e de seus agentes causadores de ansiedade. 


\subsubsection{Quarta fase}

Essa fase foi delineada por quatro (4) encontros em dias consecutivos em uma sala reservada no próprio clube, executados da seguinte maneira:

1. Relato por parte dos atletas dos pensamentos envolvidos após a explicação da atividade (e antes do preenchimento do inventário e da competição por pênaltis). Trabalho de reestruturação cognitiva para reduzir os pensamentos disfuncionais e ansiedade cognitiva dos atletas utilizando o RPD. Ensino da técnica de respiração diafragmática.

2. Trabalho de reestruturação cognitiva para reduzir os pensamentos disfuncionais com RPD, associado a um trabalho de redução do estado de ansiedade com jogos de biofeedback

3. Trabalho com jogos de biofeedback

4. Trabalho com jogos de biofeedback, e dessensibilização sistemática feita do momento da cobrança do pênalti para redução do estado de ansiedade.

\subsubsection{Quinta fase}

Delineada pela nova explicação da atividade de cobrança de pênaltis, reaplicação do instrumento "CSAI-2R" - seguido de novas cobranças entre as mesmas equipes, dentro da mesma situação proposta na terceira fase. Essa fase foi delineada, também, pela análise dos dados e pela perspectiva de conclusão dos resultados.

\subsection{Projeto piloto}

Com o objetivo de testar a eficiência dos instrumentos bem como o método, realizouse um estudo piloto com cinco atletas entre quatorze e dezesseis anos pertencentes a uma equipe de futebol de um clube de relevância na cidade de São Paulo. Neste piloto, aplicouse o protocolo de treinamento com biofeedback e técnicas de psicologia cognitivocomportamental com a finalidade de comparar a ansiedade antes de competições com pênaltis de maneira anterior e posterior ao treinamento. Diante dos dados foi possível notar uma considerável redução nas médias de ansiedade cognitiva $(28,30 \%$ em relação a pontuação pré-treino), ansiedade somática (18,64\%) e aumento da autoconfiança (16,28\%).

Coube ressaltar o fato de a ansiedade cognitiva ter diminuído de maneira mais expressiva do que a ansiedade somática. Essa diminuição da ansiedade cognitiva nos levou a duas hipóteses: a primeira supondo que se o treinamento cognitivo com redução dos 
pensamentos automáticos disfuncionais foi um marcador responsável pela redução da ansiedade cognitiva, e; a segunda sugerindo que com a redução dos níveis de ansiedade somática alcançado pelo treinamento respiratório e biofeedback os pensamentos automáticos intrusos, geradores de ansiedade, diminuíram por consequência, abaixando os níveis de ansiedade cognitiva mensurados no CSAI-2R.

Neste estudo piloto não foi possível verificar se houve efeito de aprendizagem do CSAI2R, então foi estabelecido que no estudo principal haveria um grupo controle para anular este efeito na análise estatística. A partir dos dados obtidos foi possível assumir que os procedimentos utilizados eram tecnicamente possíveis de serem executados e acrescentando um grupo controle a pesquisa, os dados seriam suficientes para responder às questões levantadas no projeto.

Os dados obtidos no projeto piloto podem ser vistos no apêndice deste trabalho (APÊNDICE D).

\subsection{Metodologia da análise estatística}

Os dados foram analisados no programa estatístico $R$ versão 3.1.1 para Windows ( $R$ CORE TEAM, 2016). A análise descritiva das variáveis quantitativas foi realizada por meio do cálculo das medidas de tendência central e de dispersão (média aritmética, desvio padrão e erro padrão da média). Os dados quantitativos foram organizados em tabelas e gráficos para facilitar a visualização dos resultados. A significância dos níveis de ansiedade antes e após o tratamento psicológico dos grupos Experimental e Controle foram avaliados com o uso de Modelos Lineares de Efeitos Mistos ajustados pela Máxima Verossimilhança Restrita (PINHEIRO et al., 2016). Contrastes Ortogonais ajustados pelo método single-step method foram utilizados quando necessários (HOTHORN et al., 2008). O pressuposto de normalidade dos resíduos e multicolinearidade do modelo foi avaliado por meio do teste de Shapiro-Wilk e inspeção gráfica. O nível de significância adotado foi o de $5 \%(p<0,05)$. 


\section{APRESENTAÇÃO E DISCUSSÃO DOS RESULTADOS}

Os valores médios dos subitens entre grupos, pré e pós avaliação e totais, com seus respectivos desvios padrão estão descritos na tabela abaixo:

TABELA 2 - MÉDIA ENTRE GRUPOS PRÉ E PÓS INTERVENÇÃO

\begin{tabular}{llllllll}
\hline \multirow{2}{*}{ Variável } & \multirow{2}{c}{ Grupo } & Pré & Pós & Total & Avaliação & Grupo & Interação \\
\cline { 3 - 6 } Ansiedade & Controle & $10,25(3,09)$ & $10,06(3,04)$ & $10,15(3,01)$ & $P=0,726$ & $P=0,552$ & $P=0,051$ \\
Somática & Experimental & $10,88(3,26)$ & $9,22(2,96)$ & $10,05(3,18)$ & & & \\
\hline \multirow{2}{*}{ Ansiedade } & Controle & $9,06(3,08)$ & $8,87(3,67)$ & $8,96(3,33)$ & $P=0,788$ & $P=0,921$ & $P=0,094$ \\
Cognitiva & Experimental & $9,17(3,05)$ & $7,33(2,27)$ & $8,25(2,81)$ & & & \\
\hline \multirow{2}{*}{ Autoconfiançan } & Controle & $10,37(1,93)$ & $9,50(2,58)$ & $9,93(2,28)$ & $P=0,187$ & $P=0,398$ & $P=0,381$ \\
& Experimental & $9,66(3,18)$ & $8,00(1,60)$ & $8,83(2,62)$ & & & \\
\hline \multirow{2}{*}{ Escore Geral } & Controle & $29,68(6,28)$ & $28,69(7,73)$ & $29,19(5,83)$ & $P=0,444$ & $P=0,987$ & $P=0,023$ \\
& Experimental & $29,72(6,11)$ & $24,50(4,28)$ & $27,11(5,83)$ & & &
\end{tabular}

Os valores obtidos no efeito principal da "Avaliação" são referentes a comparação das pontuações pré e pós intervenção, desconsiderando a divisão dos grupos controle e experimental. Os $p$-valores obtidos desta análise não foram significativos $(p>0,05)$, indicando que, ao desconsiderar a análise por grupos segmentados de tratamento (controle e experimental), as pontuações dos subitens de ansiedade não reduziram significativamente da terceira para a quinta fase, demonstrando que o efeito de aprendizagem do CSAI-2R, da primeira para a segunda aplicação, não teve efeito estatisticamente significativo.

No efeito principal do "Grupo", foi ignorado o efeito da avaliação pré e pós, para verificar se os grupos controle e experimental apresentam resultados com relevância estatisticamente diferentes, utilizando a média geral de cada grupo. O efeito principal não foi significativo, indicando que as diferenças das médias nos subitens entre os grupos não são significativamente diferentes, como pode ser visto na tabela acima. 
A tabela 3, a seguir, apresenta os resultados da interação da intervenção com o protocolo de biofeedback e psicologia cognitivo comportamental sobre o escore geral por meio das comparações múltiplas. Como pode ser observado, houve redução no escore geral apenas no grupo 1, o grupo experimental $(P<0,001)$.

Tabela 3. Tabela de comparações múltiplas das médias: Contrastes de Tukey com as médias das diferenças e seus respectivos intervalos de confiança de $95 \%$.

\begin{tabular}{clccc}
\hline Contrastes para & Média das & \multicolumn{2}{c}{$\begin{array}{c}\text { IC95\% das médias das } \\
\text { diferenças }\end{array}$} & \\
\cline { 3 - 4 } & Diferenças & $\begin{array}{c}\text { Lim. } \\
\text { Inferior }\end{array}$ & $\begin{array}{c}\text { Lim. } \\
\text { Superior }\end{array}$ & P-valor \\
\hline \hline 1 Pré vs 0 Pré & 0,035 & $-4,121$ & 4,190 & 1,000 \\
0 Pós vs 0 Pré & $-1,000$ & $-3,533$ & 1,533 & 0,856 \\
1 Pós vs 0 Pré & $-5,188$ & $-9,343$ & $-1,032$ & 0,062 \\
0 Pós vs 1 Pré & $-1,035$ & $-5,190$ & 3,121 & 0,958 \\
1 Pós vs 1 Pré & $-5,222$ & $-7,610$ & $-2,834$ & $<0,001$ \\
1 Pós vs 0 Pós & $-4,188$ & $-8,343$ & $-0,032$ & 0,182 \\
\hline P-valor ajustado pelo método "single-step method" & &
\end{tabular}

A figura 9 apresenta o comportamento médio e individual dos atletas do grupo Controle e Experimental do escore total do CSAI-2R. Quando comparado o escore geral do CSAI-2R do grupo Experimental com o Controle da primeira aplicação para a segunda, observa-se um efeito significativo de interação $(p=0,023)$, sugerindo uma redução significativa de ansiedade do grupo Experimental comparado com o Controle, após a intervenção.

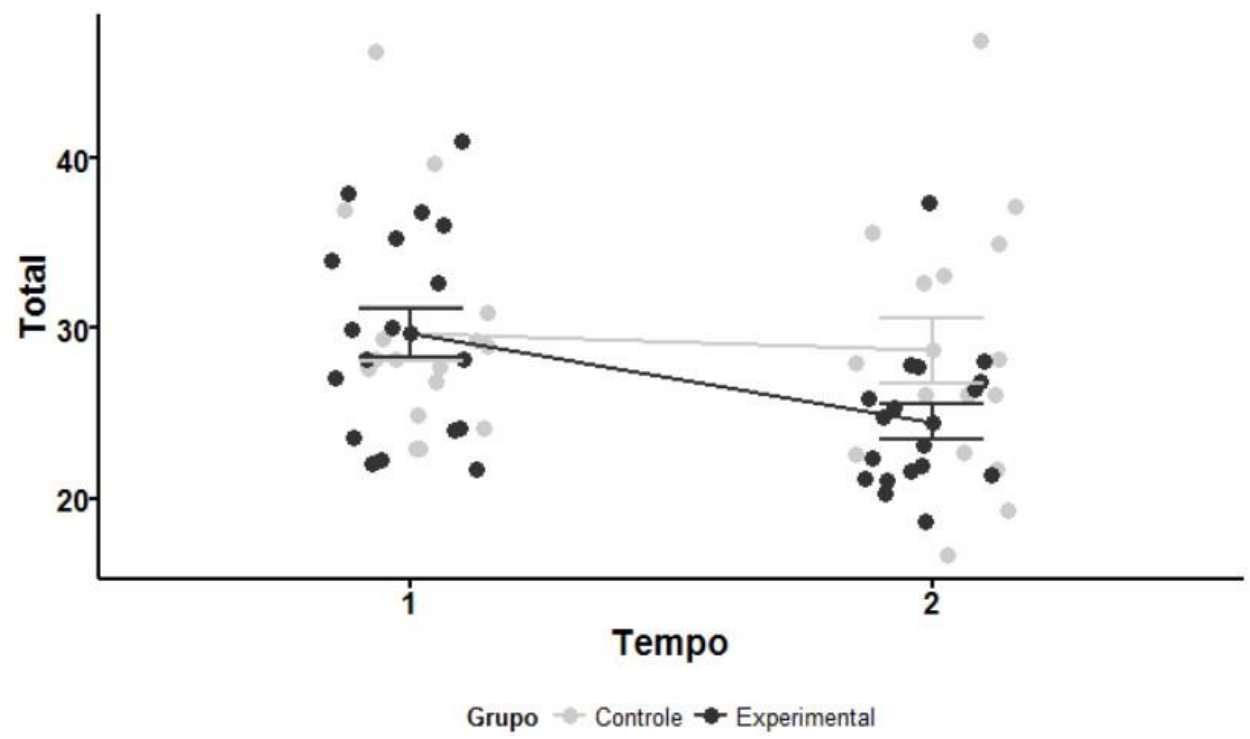

FIGURA 9 - MÉDIAS DA PONTUAÇÃO GERAL DO CSAI-2R 
Em média, o grupo experimental apresentou redução de - 5,2 pontos (intervalo de confiança 95\%: - $7,61 /-2,83, p<0,001$ ), indicando que a intervenção com o protocolo de psicologia cognitivo-comportamental e biofeedback foi eficiente para reduzir o estado de ansiedade geral dos jogadores do Grupo Experimental na cobrança dos pênaltis.

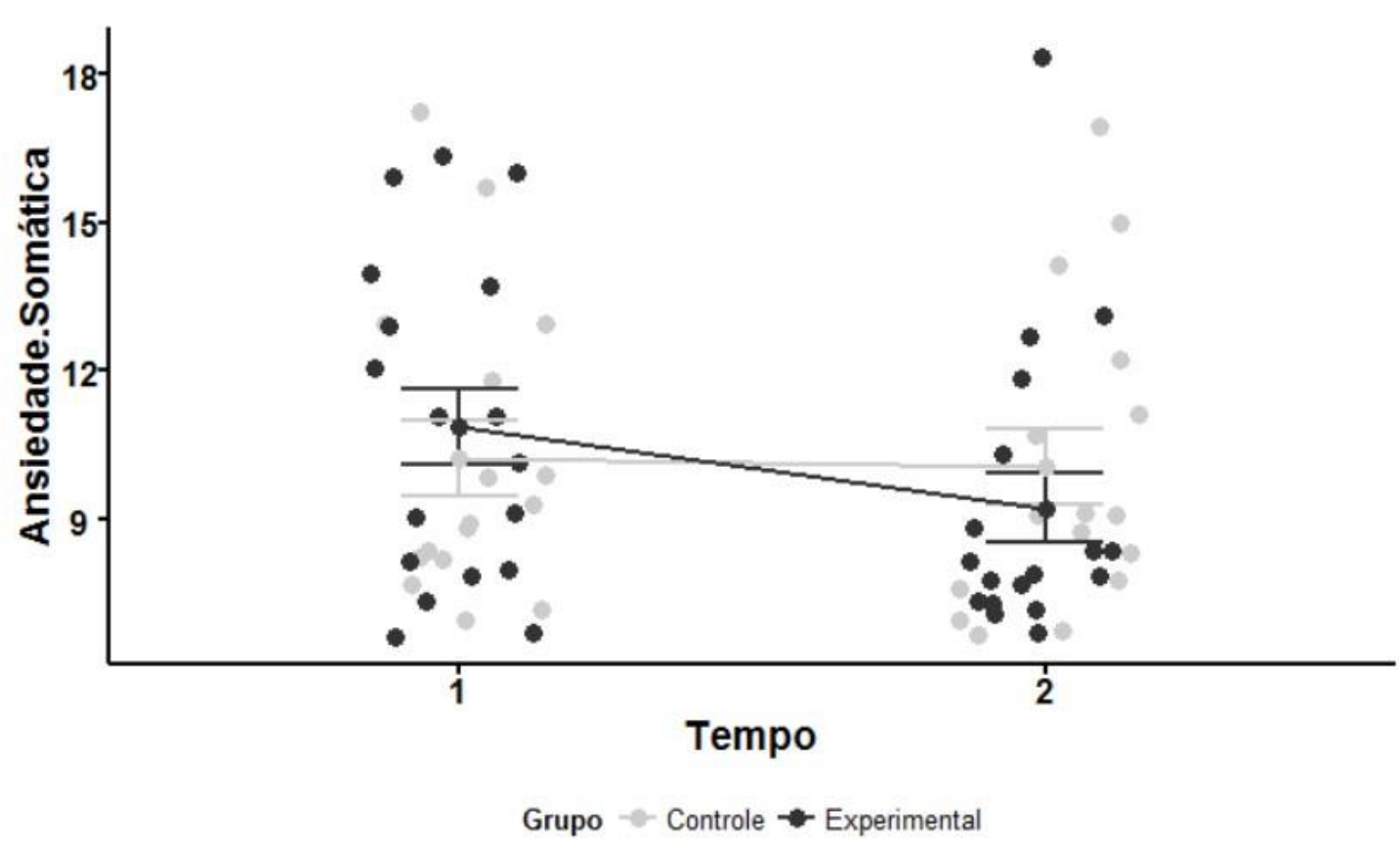

FIGURA 10 - MÉDIAS DO SUB ITEM ANSIEDADE SOMÁTICA DO CSAI-2R

A figura 10 apresenta o comportamento médio e individual dos atletas dos grupos Controle e Experimental no subitem Ansiedade Somática, que observa os sintomas e efeitos fisiológicos da ansiedade no corpo do indivíduo.

É possível verificar que houve efeito marginal de interação no subitem Ansiedade Somática, indicando que o protocolo, em uma amostra maior, poder-se-ia ter-se mostrado eficaz para reduzir a ansiedade somática.

Este resultado é compatível com o estudo de Lagos (et al., 2008), em que o treinamento com técnicas de biofeedback foi eficiente na redução de ansiedade somática de um atleta. Também está de acordo com a pesquisa realizada com um atleta de tiro conduzida 
por Prapavessis (et al., 1992), em que a ansiedade somática e cognitiva foi reduzida com um protocolo de técnicas cognitivas e biofeedback. É importante ressaltar que ambos os estudos citados tiveram como objetivo reduzir o estado de ansiedade competitiva dos atletas de maneira geral, não se utilizando de nenhuma técnica de dessensibilização sistemática, e não focando em algum momento específico do desempenho, como foi o caso do presente estudo.

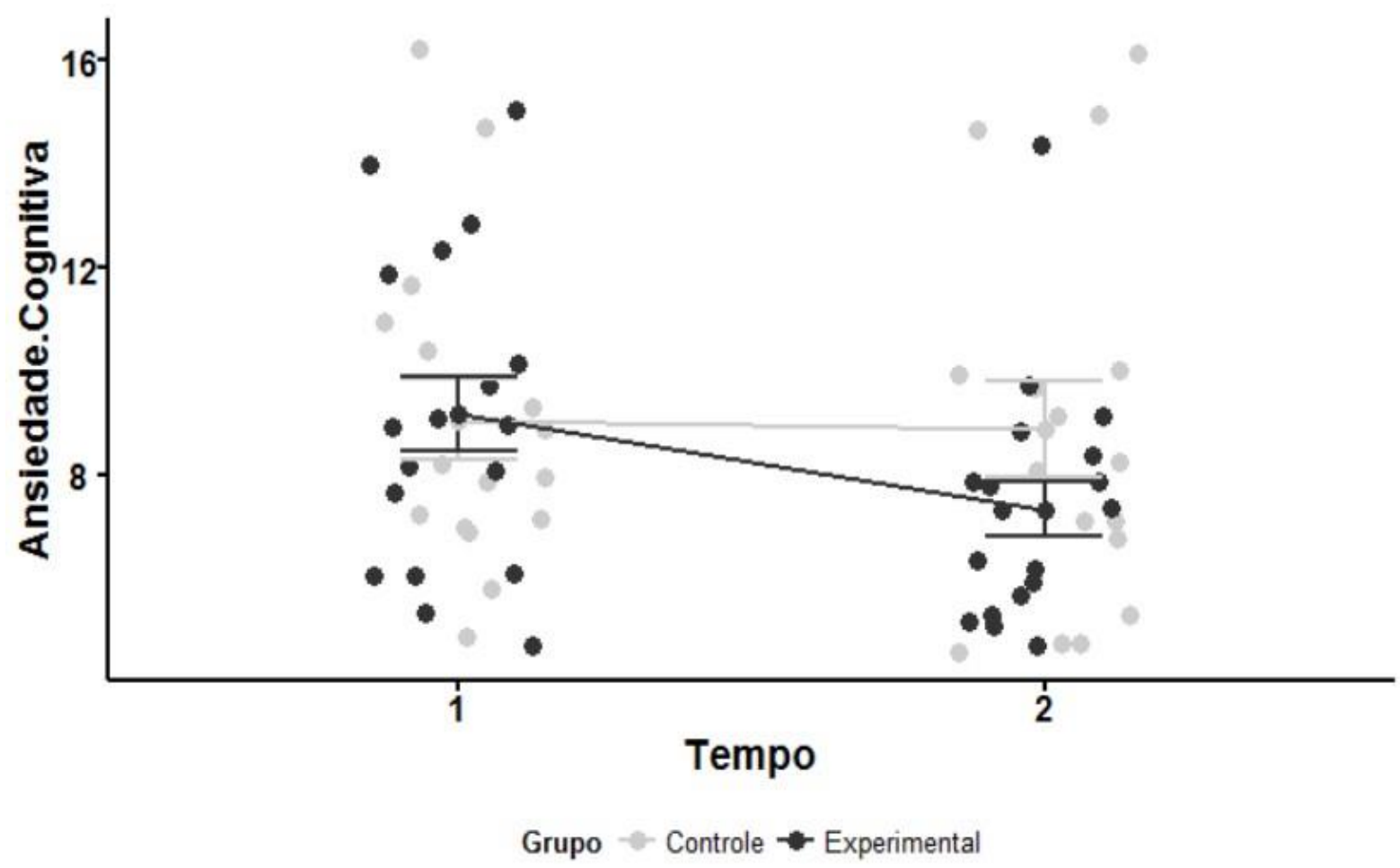

FIGURA 11 - MÉDIAS DO SUBITEM ANSIEDADE COGNITIVAS DO CSAI-2R

A figura 11 apresenta o comportamento médio e individual dos atletas dos grupos Controle e Experimental do subitem Ansiedade Cognitiva, que examina as expectativas negativas, preocupações e consequências negativas de um eventual fracasso do atleta.

A análise do subitem ansiedade cognitiva na comparação entre grupos apresentou efeito marginal, sinalizando que em uma amostra maior, provavelmente seria possível observar um efeito estatisticamente significativo na redução da ansiedade cognitiva através do protocolo de intervenção utilizado. Resultado também compatível com o de outros 
estudos (LAGOS et al., 2008; PERRY, SHAW, ZAICHKOWSKY, 2011; PRAPAVESSIS et al., 1992; DE WITT, 1980).

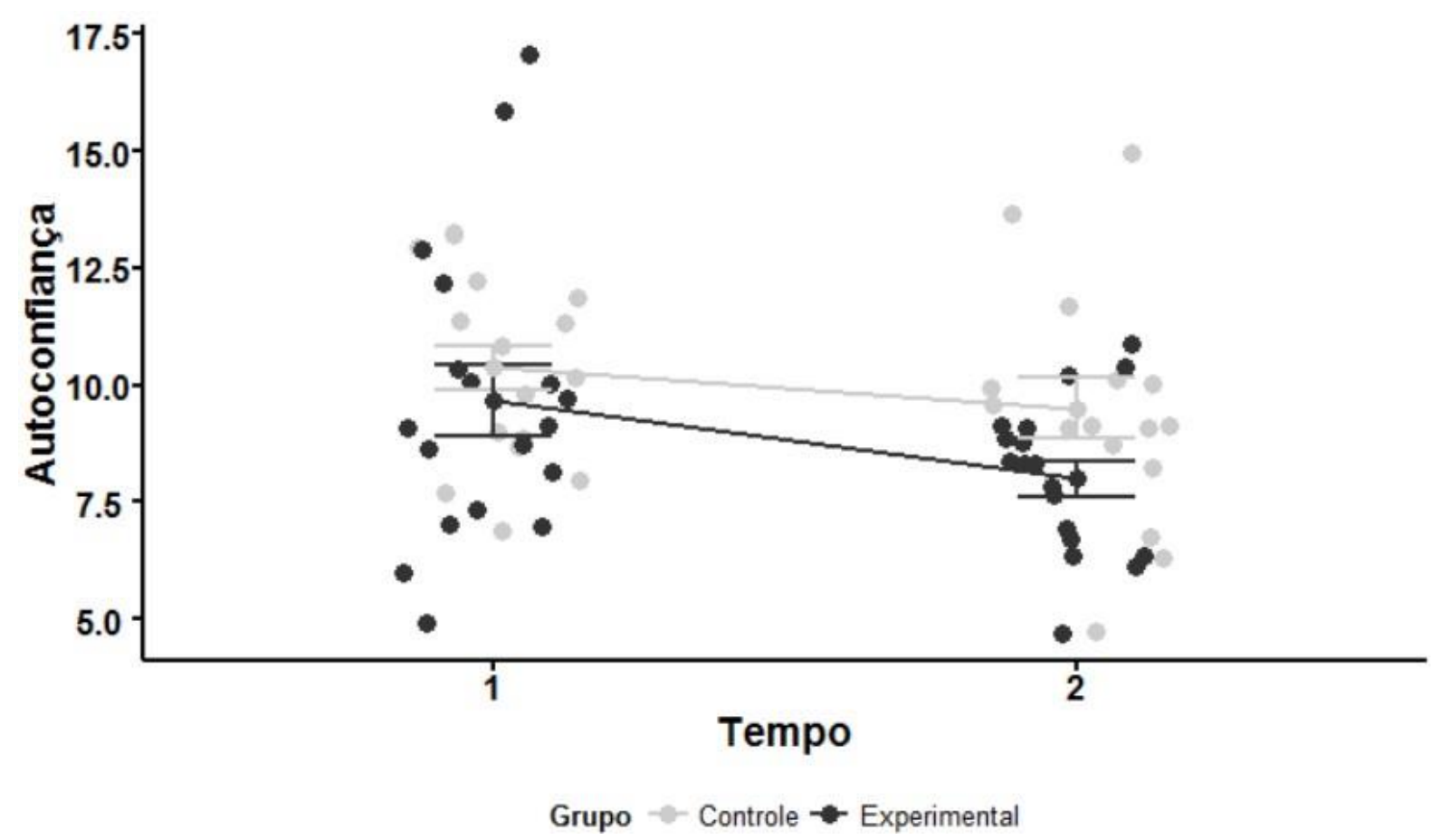

FIGURA 12 - MÉDIAS DO SUB ITEM AUTOCONFIANÇA DO CSAI-2R

A figura 12 apresenta o comportamento médio e individual dos atletas do grupo Controle e Experimental do subitem Autoconfiança, relacionado a crenças e expectativas da execução positiva sobre o enfrentamento dos desafios que a tarefa propõe. Não houve melhora estatisticamente significativa neste fator. Segundo Martens, Vealey e Burton (1990), a autoconfiança se elevaria na diminuição ou ausência da ansiedade cognitiva.

Durante o decorrer do experimento foram percebidos diversos outros fatores, relatados abaixo.

Na primeira testagem, durante a fase três, ambos os goleiros reclamaram de não fazer parte do experimento, argumentando que poderiam fazer parte tanto como goleiros, quanto como cobradores de pênalti, já que em um jogo oficial podem ser chamados a cobrá- 
los. Como não era do escopo desta pesquisa, estes não foram avaliados nem na sua ansiedade, nem nos desempenhos individuais na primeira, ou na segunda testagem.

Durante toda a fase 4, enquanto alguns atletas do grupo Experimental estavam realizando suas intervenções, outros atletas do grupo Controle e também do grupo Experimental treinavam pênaltis fora do horário usual. Quando questionados sobre isso, um dos atletas disse que "não queria fazer feio", e outro disse que "como errei na primeira vez vou treinar um pouco mais para ter certeza que acerto na segunda". Ambos os relatos demonstram a preocupação com a exposição e pressão, a preocupação com o seu desempenho e o alto estado de ansiedade dos atletas não somente durante a competição, mas também de maneira pré-competitiva.

A ansiedade pré-competitiva consiste em reações antecipatórias e duradouras a estímulos aversivos. Este "medo do futuro", do desempenho incerto, pode prejudicar suas habilidades competitivas, pois um dos fatores que mais influenciam no desempenho é o alto grau do estado de ansiedade no momento em que precede a competição (JORDET et al., 2007b).

Quanto mais se aproxima o momento da competição, mais os níveis de ansiedade podem se elevar, deixado que um possível entusiasmo seja transformado em receio e dúvidas sobre seu desempenho (STEFANELLO, 1990). Segundo o relato de alguns atletas, a torcida contrária trabalhou como um grande gerador de ansiedade, e a possibilidade de a imagem deles ser associada a um fracasso na cobrança de pênalti sendo exibida na USP, ainda mais. Desta maneira, pode-se perceber que tanto a pressão social de seus pares presentes no ambiente, como também a pressão de uma plateia invisível e avaliadora foram fatores que contribuíram para a elevação de ansiedade desses atletas, resultado compatível com outros estudos (FERREIRA, 2006; MARTENS; VEALEY; BURTON, 1990 JORDET et al., 2007a; JORDET et al., 2007b; JORDET; HARTMAN; VUJIK, 2012; WILSON; VINE; WOOD, 2009; MIYAMOTO, 2010). Desta maneira, poder-se-ia sugerir a treinadores que utilizassem da mesma técnica de inserir torcida contrária no momento em que se treinará pênaltis.

Alguns atletas que fizeram gol na primeira oportunidade, se comportaram de maneira visivelmente mais displicente na segunda, inclusive um dos atletas que perdeu pênalti na segunda competição mencionou a seguinte frase no primeiro encontro da intervenção: "não vou aparecer lá na USP como um dos piores com certeza, porque cobrei bem o primeiro 
pênalti, e já teve muita gente que cobrou mal". A autoconfiança se comportaria como um "continuum", desde a baixa autoconfiança, destruidora de desempenhos pelos pensamentos disfuncionais e interpretações enviesadas de situações corriqueiras, até autoconfiança excessiva, em que o atleta acaba por economizar seus recursos e aumenta o risco de errar pela falta de empenho. No caso mencionado acima, podemos observar que a autoconfiança estava demasiadamente alta desde o momento em que o atleta acertou o pênalti, e provavelmente até antes disso.

Como os estímulos do ambiente reforçam esquemas e crenças já estabelecidas do indivíduo, a confirmação do gol para o atleta que já tinha uma autoestima demasiadamente elevada apenas confirmou a qualidade de seu desempenho, enquanto para um atleta com autoestima baixa, um gol feito na primeira competição não necessariamente o tranquiliza para a próxima, como no discurso de uma das mães, que encontrou o pesquisador indo embora do clube, um dia antes da segunda competição: "Meu filho é o X. Ele marcou o gol, mas ele está nervoso com o outro pênalti. Está com medo de ir mal e passar vergonha”.

Vale também ressaltar que apesar de vários atletas mencionarem o fato de não quererem aparecer no vídeo errando um pênalti, nenhum deles citou o desejo de aparecer como um dos melhores cobradores de pênalti do grupo, mesmo que os cinco melhores, assim como os cinco piores, também apareceriam nos vídeos.

O fator de ter sua falha exposta para outras pessoas funcionou como uma punição positiva, em que seria inserido um fator aversivo (exposição desagradável) após o comportamento indesejado (errar o pênalti), mas também foi inserido um reforço positivo (exposição de suas qualidades) como recompensa de um comportamento desejado (acertar o pênalti). A punição positiva gerou diversos níveis do estado de ansiedade nos atletas, e de tal maneira que o reforço positivo não foi sequer reconhecido.

Com todos os grupos de atleta, após o pesquisador mencionar que as cobranças seriam filmadas e os cinco melhores cobradores poderiam ser mostrados na USP, poucos atletas se manifestaram de maneira verbal ou não verbal, a não ser com mudanças na sua expressão facial. Porém, quando em seguida foi mencionado que os cinco piores também poderiam ser mostrados, houve risos de maneira generalizada. O público que eles poderiam ter seus vídeos apresentados seria o mesmo, porém a reação de ter algo ruim sendo mostrado sobre ele superou a expectativa de ter algo bom sendo mostrado. 
Apesar da redução do estado de ansiedade da primeira para a segunda avaliação, a figura 10 mostra que não houve aumento dos acertos (conversão em gol) dos pênaltis no grupo Experimental, o que poderia ser esperado, uma vez que a literatura afirma que a ansiedade é um dos causadores da perda de pênaltis (MILLER, 1998; JORDET et al., 2007a; JORDET et al., 2007b; JORDET; HARTMAN; VUJIK, 2012; BONIZZONI, 1988).

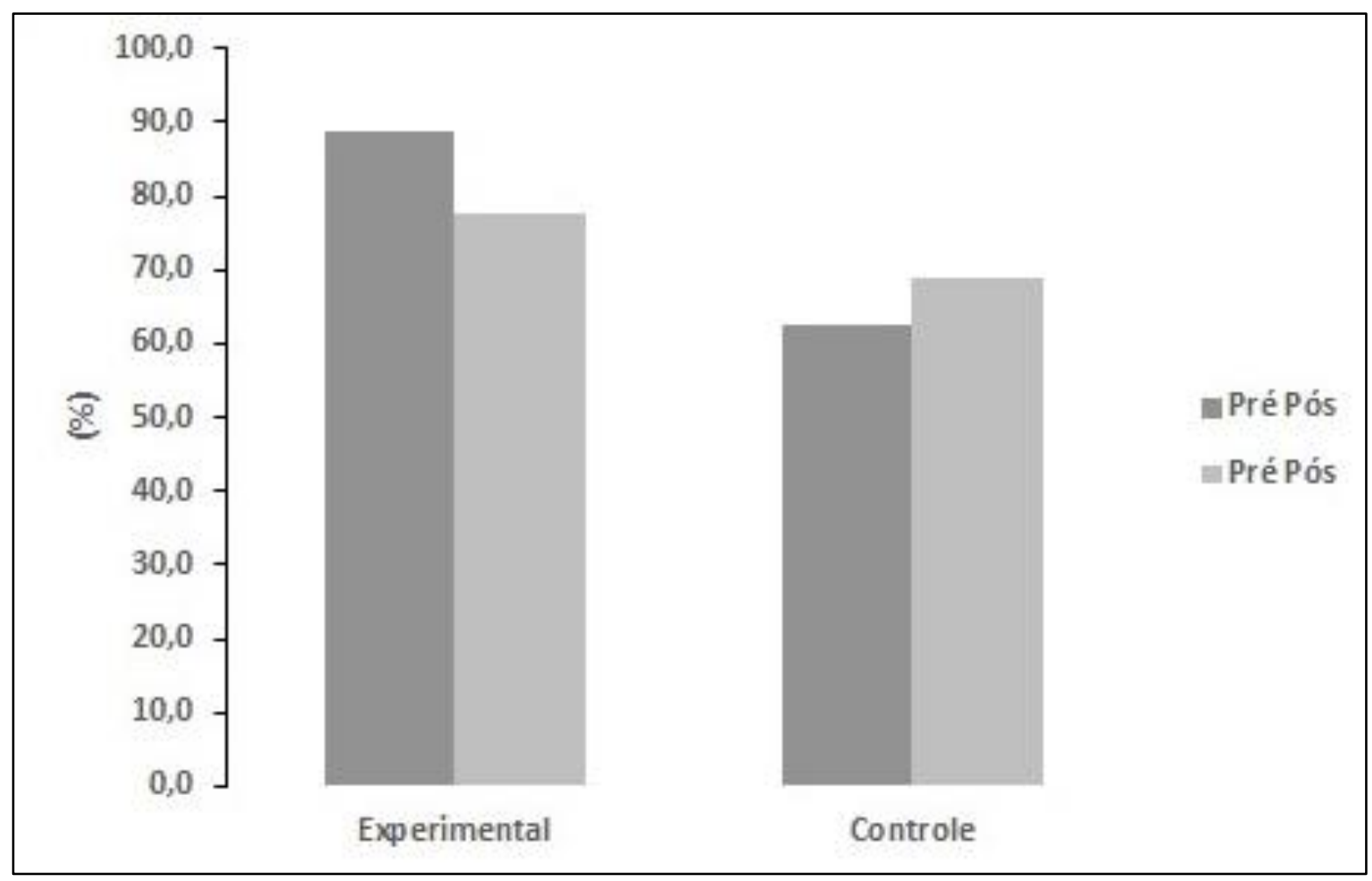

FIGURA 13 - PÊNALTIS CONVERTIDOS EM GOL

Em ambas as pesquisas de De Witt (1980) com futebol americano e basquete, e também de Perry, Shaw e Zaichkowsky (2011), com atletas de ginástica e hóquei no gelo, o treinamento de redução de ansiedade com biofeedback surtiu efeito nos resultados esportivos, porém em todas as pesquisas, os resultados dependiam diretamente de seu rendimento, diferentemente da conversão de pênaltis em gol, no presente estudo, em que o resultado pode depender de diversos outros fatores, como por exemplo, o goleiro.

Além da ansiedade, diversos fatores que poderiam influenciar nos acertos na cobrança de pênaltis não foram controlados, como a estratégia do cobrador (aguardar o salto do goleiro / definir um canto com antecedência), qualidade dos goleiros que iriam defender o pênalti, volume de treinamento da habilidade entre uma competição e outra, entre outros fatores. . 
Em um estudo que verificou a eficiência de um treinamento com biofeedback para a melhora do desempenho, Bar-Eli e Blumenstein (2004), citam que escolheram realizar o estudo com atletas de natação, por conta de que a melhora do atleta independe de variáveis externas, podendo ser mensurado medidas independentes, como o tempo em que o atleta leva para terminar a prova, descartando o desempenho de outros competidores adversários. Já nas cobranças de pênaltis em futebol de campo, o goleiro está envolvido no resultado direto dessas cobranças, então não é possível isolar a variável em uma situação real de cobrança de pênalti.

No estudo de Paul e Garg (2012) realizado com atletas de basquetebol, foram usados parâmetros mais específicos para análise de rendimento. Apesar de serem utilizados porcentagens de acertos de passes, dribles e arremessos, essas medidas foram retiradas de tarefas durante o treinamento, realizados sem oponentes, controlando assim esta variável. Ressalta-se, ainda, o fato da ansiedade cognitiva ter diminuído de maneira mais expressiva do que a ansiedade somática.

Essa diminuição da ansiedade cognitiva nos leva a duas hipóteses: a primeira supondo que se o treinamento cognitivo com redução dos pensamentos automáticos disfuncionais foi um marcador responsável pela redução da ansiedade cognitiva, e; a segunda sugerindo que com a redução dos níveis de ansiedade somática alcançado pelo treinamento respiratório e biofeedback os pensamentos automáticos intrusos, geradores de ansiedade, diminuíram por consequência, abaixando os níveis de ansiedade cognitiva mensurados no CSAI-2R.

De forma geral, os resultados encontrados sugerem ser esta uma linha de investigação promissora, na qual diversas questões futuras podem ser levantadas, como por exemplo: que efeito teria esse mesmo protocolo se aplicado durante mais encontros? Será que seria possível ver uma diferença estatística ainda maior? Além disso, pesquisas com um $N$ maior e principalmente com mais sessões de intervenção podem contribuir ainda mais a área. 


\section{CONCLUSÕES}

Em consonância com os objetivos, hipóteses e resultados obtidos nessa pesquisa, poder-se-ia concluir como defesa de tese:

- Que o protocolo de técnica de biofeedback associada a psicologia cognitivocomportamental aplicado em atletas de futebol de categorias de base revelou-se como um protocolo eficiente enquanto método, e eficaz como resultado na redução do estado de ansiedade para o momento da cobrança de pênalti, confirmando a hipótese descritiva central desta tese.

Concluiu-se ainda que:

- Existe diferença significativa entre o estado de ansiedade de jogadores de futebol amadores de 15 a 16 anos no momento da cobrança de pênalti antes e depois de aplicado o protocolo de psicologia cognitivo-comportamental e biofeedback. A hipótese central está confirmada, demonstrando o protocolo de biofeedback e psicologia cognitivocomportamental é eficiente na redução do estado de ansiedade. H0 é rejeitada, e a hipótese $\mathrm{H} 1$ é aceita como verdadeira, em sintonia com os desenvolvimentos da literatura já discutida anteriormente, e que apontam para os bons resultados do biofeedback na redução de ansiedade.

- A análise individual dos subitens ansiedade somática e ansiedade cognitiva de interação entre grupos apresentou efeito marginal.

- No fator autoconfiança não houve uma melhora significativa entre grupos $A$ hipótese HO não foi rejeitada para este fator.

- Não se apresentou melhoras na conclusão dos pênaltis após a intervenção com o protocolo de psicologia cognitivo-comportamental e biofeedback. A hipótese H0 é aceita como verdadeira. 


\section{RECOMENDAÇÕES}

Estudos longitudinais sobre os efeitos do protocolo de treinamento de biofeedback com técnicas da psicologia cognitivo-comportamental devem ser realizados, pois podem contribuir com informações úteis a comunidade científica e preparação mental dos atletas. Novos estudos também devem ser feitos com um maior número de encontros de intervenção, para verificar se com um treinamento mais longo o efeito de redução de ansiedade poderia ser ainda mais significativo. 


\section{REFERÊNCIAS BIBLIOGRÁFICAS}

ABERASTURY, A.; KNOBEL, M. Adolescência normal. Porto Alegre: Artmed, 1989. APPOLINÁRIO, F. Avaliação dos Efeitos do Treinamento em Neurofeedback sobre o Desempenho Cognitivo de Adultos Universitários. Universidade de São Paulo: Instituto de Psicologia. Curso de Pós-Graduação em Psicologia. São Paulo, 2001.

ARAÚJO, S. R. C. D.; MELLO, M. T. D.; LEITE, J. R. Transtorno de ansiedade e exercício físico. Revista Brasileira de Psiquiatria, São Paulo, v. 29, n. 2, p. 164-171, 2007.

ASSOCIATION FOR APPLIED PSYCHOPHYSIOLOGY AND BIOFEEDBACK disponível em: <https://www.aapb.org/i4a/pages/index.cfm?pageid=3463> Acesso em 21 mar. 2015.

AZRIN, N. H., HOLZ, W. C. Punishment, in W. K. Honig, \& W. Staddon (Eds.), Handbook of operant behavior. Areas of research and application, pp.380-447. New York: Academic Press, 1966.

BAR-ELI, M.; BLUMENSTEIN, B. Performance enhancement in swimming: The effect of mental training with biofeedback. Journal of Science and Medicine in Sport, v. 7, n. 4, p. 454464, 2004.

BARRETO, J. A. Psicologia do esporte para o atleta de alto rendimento. Rio de Janeiro: Shape, 2003.

BECK, A. T. Cognitive therapy of depression. Guilford press, 1979.

BECK, J. S. Terapia Cognitiva-Teoria e Prática. Porto Alegre: Artmed, 1997.

BOHME, M. T. S. O tema talento esportivo na ciência do esporte. Revista Brasileira de Ciência e Movimento, v. 15, p. 119-126, 2007.

BONIZZONI, L. Penalty. Calcio di punizione. Calcio d'anglolo. Rimessa laterale. Roma: Società Stampa Sportiva, 1988.

BOWTELL M.; KING M.; PAIN M. Analysis of the keeper-dependent strategy in the soccer penalty kick. Int J Sport Sci and Eng 2009;

BIRBAUMER, N.; FLOR, H. Applied psychophysiological regulation. Applied Psychophysiological and Feedback, 24 (1): 1-3, 1999.

BURTON, D. Do Anxious Swimmers Swim Slower? Re-examining the Elusive AnxietyPerformance Relationship. Journal of Sport and Exercise Psychology. (10), 45-61, 1988.

CABALLO, V. E.; CLAUDINO, M. D. Manual de técnicas de terapia e modificação do comportamento. Santos, 1996.

CARVALHAES, J. Alguns fatores psicológicos da produtividade. Arquivos Brasileiros de Psicotécnica, ano 12, n. 1, p. 77-82, jan. /mar.1960. 
CATANIA, C. A. Aprendizagem: Comportamento, linguagem e cognição. Porto Alegre: Artmed, 1999.

CAVAlCANTE, M. B. P. T.; ALVES, M. D. S.; BARROSO, M. G. T. Adolescência, álcool e drogas: uma revisão na perspectiva da promoção da saúde. Esc Anna Nery Rev Enferm, 12(3), 555-9, 2008.

CÔTÉ, J. The influence of the family in the development of talent in sport. The Sport Psychologist, 13, 395-417, 1999.

COX, R.H.; MARTHENS, M.P.; RUSSELL, W.D. Measuring Anxiety in Athletics: The Revised Competitive State Anxiety Inventory-2. Journal of Sport \& Exercise Psychology 25: 519-533, 2003

CHARTIER, D.; COLLINS, L.; KOONS, D. Peak Performance EEG Training and The Game of Golf, apresentado na 5th Annual Conference on Brain Function/EEG, Palm Springs, CA, 1997.

CRAFT, L. L.; MAGYAR, T. M.; BECKER, B. J.; FELTZ, D. L. The relationship between the Competitive State Anxiety Inventory-2 and sport performance: A meta-analysis. Journal of sport and exercise psychology, 25(1), 44-65, 2003.

CRATTY, B. J. Psicologia no esporte. 2 ed. Rio de Janeiro: Prentice-Hall do Brasil, 1984.

CRUZ, J. Historia de la Psicología del Deporte. In: RIERA, J.; CRUZ, J. (Eds.). Psicología del Deporte: aplicaciones y perspectivas. Barcelona: Ediciones Martínez Roca, S. A., 1991. p. 13-42.

CRUZ, J.; VIANA, M. Auto-confiança e Rendimento na Competição Desportiva. In: Manual de Psicologia do Desporto. Instituto de Educação e Psicologia, Universidade do Minho e Instituto Superior de Psicologia Aplicada, Lisboa. 265-286, 1996.

DAVIDSON, R. J.; GOLEMAN, D. J.; SCHWARTZ, G. E. Attentional and affective concomitants of meditation: A cross-sectional study. Journal of Abnormal Psychology, 85(2), 235-238, 1976.

DEBOER, R. W.; KAREMAKER, J. M.; STRACKEE, J. Hemodynamic fluctuations and baroreflex sensitivity in humans: a beat-to-beat model. Am J Physiol, 253(3 Pt 2), H680H689, 1987.

DE LIMA ARGIMON, I.; PALMA, C. C.; BOAZ, C., DE LA ROSA, H. R.; DALDON, K. A.; DO NASCIMENTO, R. F. L.; DE LIMA ARGIMON, I. I. Técnicos de futebol e a prática da psicologia no esporte. CEP, 91010, 003, 2006.

DE WITT, D. J. Cognitive and biofeedback training for stress reduction with university athletes. Journal of Sport Psychology 2: 288-294, 1980.

DUARTE, O. Futebol: regras e comentários. São Paulo: Editora Senac, 2005. 
EGNER T.; GRUZELIER J.H. Ecological validity of neurofeedback: modulation of slow wave EEG enhances musical performance. Neuroreport;14(9):1221-1224, 2003.

EPICTETUS, HIGGINSON, T. W. The Enchiridion. New York, Liberal Arts Press, 1955.

ERICKSON, E. Identidade, juventude e crise. Rio de Janeiro: Zahar, 1976.

FORD, P. R., CARLING, C., GARCES, M., MARQUES, M., MIGUEL, C., FARRANT, A., SALMELA, J. H. The developmental activities of elite soccer players aged under-16 years from Brazil, England, France, Ghana, Mexico, Portugal and Sweden. Journal of sports sciences, 30(15), 1653-1663, 2012.

FERNANDES, M.G.; VASCONCELOS-RAPOSO, J.; FERNANDES, H.M. Propriedades psicométricas do CSAl-2 em atletas brasileiros. Psicologia: Reflexão e Crítica, v. 25, n. 4, p. 679-687, 2012.

FERREIRA, E. "O estado de ansiedade pré-competitiva e autoconfiança: estudo realizado com jogadores seniores de hóquei em patins.", 2006.

FOZA, V. O efeito da técnica de biofeedback na atenção visual seletiva de atletas juvenis de futebol de campo. Tese (Mestrado em Psicologia) - Universidade Federal de Santa Catarina, Centro de Filosofia e Ciências Humanas, Florianópolis: 2005.

FRANCO, G. S. Psicologia no Esporte e na Atividade Física. São Paulo: Manole, 2000.

FRANCO JÚNIOR, H. A dança dos deuses: futebol, cultura e sociedade. 1.ed. São Paulo: Companhia das Letras, 2007.

FRISCHNECHT, P. A influência da ansiedade no desempenho do atleta e do treinador. Treino Desportivo. Lisboa: II série, n. 15, p.21-28, 1990.

GREENLEES, I.; LEYLAND, A.; THELWELL, R.; FILBY, W. Soccer penalty takers' uniform color and pre-penalty kick gaze affect the impressions formed of them by opposing goalkeepers. Journal of Sports Sciences, 26, 569-576, 2008.

HARDY, L.; MAIDEN, D.; SHERRY, K. Goal-setting and Performance: The Effects of Performance Anxiety. Journal of Sports Sciences. (4), 233-234, 1986.

HARDY, L.; PARFITT, G.; PATES, J. Performance catastrophes in sport: A test of the hysteresis hypothesis. Journal of Sports Sciences, v. 12, n. 4, p. 327-334, 1994.

HATFIELD B.D.; HILLMAN C. The psychophysiology in sport: A mechanistic understanding of the psychology of superior performance. In: RN Singer, HA Hansenblas, CM Janelle (eds) Handbook of sport psychology, 5:243-259, 2001.

HERNANDEZ, J. A. E. João Carvalhaes, um psicólogo campeão do mundo de futebol. Estudos e pesquisas em psicologia, v. 11, n. 3, p. 1027-1049, 2011. 
HSIEH, T.; HUANG, C.; HUNG, T. Relationships between heart rate variability, attention, and athletic performance, International Journal of Sport and Exercise Psychology, 8:4, 473-475, 2010.

HUERTA, I.P._Structural changes during a century of the world's most popular sport. Statistical Methods and Applications, Volume 13, Number 2, September pg. 241-258, 2004.

JONES, G.; HANTON, S.; SWAIN, A. Intensity and interpretation of anxiety symptoms in elite and non-elite sports performers. Personality and Individual Differences, v. 17, n. 5, p. 657-663, 1994.

JORDET, G.; HARTMAN, E.; VISSCHER, C.; LEMMINK, K. A. P. M. Kicks from the penalty mark in soccer: The roles of stress, skill, and fatigue for kick outcomes. Journal of Sports Sciences, 25,121-12, 2007a.

JORDET, G.; ELFERINK-GEMSER, M. T.; LEMMINK, K. A. P. M.; VISSCHER, C. Emotions at the penalty mark: an analysis of elite players performing in an international penalty shootout. In T. Reilly,; A. M. Williams (Eds.), Science and Football VI (pp. 409-414). Oxford: Routledge, 2008.

JORDET, G. Why do English players fail in soccer penalty shootouts? A study of team status, self-regulation, and choking under pressure. Journal of sports sciences 27.2: 97-106, 2009.

JORDET, G., HARTMAN, E., SIGMUNDSTAD, E. Temporal links to performing under pressure in international soccer penalty shootouts. Psychology of Sport and Exercise, 10(6), 621-627, 2009.

JORDET, G.; HARTMAN, E.; VISSCHER, C.; LEMMINK, K. Kicks from the Penalty Mark in Soccer: The Roles of Stress, skill, and Fatigue for Kick Outcomes. Journal of Sports Sciences 25.2: 121-29, 2007b.

JORDET, G.; HARTMAN, E. Avoidance motivation and choking under pressure in soccer penalty shootouts. Journal of Sport; Exercise Psychology, 30, 452-459, 2008.

JORDET, G.; HARTMAN, E; VUJIK, P. J. Team history and choking under pressure in major soccer penalty shootouts. Journal Article: British Journal of Psychology. 05/2012; 103:268-83, 2012.

JÚNIOR, B. D. Um estudo sobre o nível de ansiedade estado précompetitiva em atletas de futsal. Dissertação de Mestrado em Educação Física da Universidade de Pato Branco, Pato Branco, 2004.

KNOBEL, M. Síndrome da adolescência normal. In: ABERASTURY, A. \& KNOBEL, M. Adolescência normal. 9a ed. Porto Alegre, Artes Médicas, 1981. p. 24- 62 
KUHN, W. Penalty-kick strategies for shooters and goalkeepers. Science and football, 1988.

LAGOS, L.; VASCHILLO, E.; VASCHILLO, B.; LEHRER, P.; BATES, M.; AND PANDINA, R. Heart rate variability biofeedback as a strategy for dealing with competitive anxiety: $A$ case study. Biofeedback, 36, (3), 109-115, 2008.

LANDERS, D. M.; HAN, M., SALAZAR, W.; PETRUZZELLO, S. J. Effects of learning on electroencephalographic and electrocardiographic patterns in novice archers. International Journal of Sport Psychology, 1994.

LANE, A. M.; SEWELL, D. F.; TERRY, P. C.; BARTRAM, D.; NESTI, M. S. Confirmatory factor analysis of the competitive state anxiety inventory-2. Journal of Sports Sciences, 17(6), 505-512, 1999.

LEHRER P.M.; WOOLFOLK R.L.; SIME, W.E. Principles and practice of stress management. 3rd ed. New York: Guilford Press, 2007.

LIPP M. E. N. Stress e suas Implicações. Estudos de Psicologia, v.1, n, 3-4, p.5-19, 1984. LUNDQVIST, C.; HASSMÉN, N. P. Competitive State Anxiety Inventory-2 (CSAI-2): Evaluating the Swedish version by confirmatory factor analyses. Journal of Sports Sciences, 23, 727-736, 2005.

MACHADO, A.A. (Org.). Psicologia do Esporte. Jundiaí: Ápice, 1997.

MACHADO, C., BRANCO, V., SOUSA, A. Adolescência: da vinculação à individuação. International Journal of Developmental and Educational Psychology, 211-216, 2008.

MIYAMOTO, N. T. Latência e acurácia de respostas motoras a estímulos visuais em situações de estresse (Tese de doutorado). Universidade de São Paulo, 2010.

MARTENS, R.; VEALEY, R.S.; BURTON, D. Competitive Anxiety in Sport. Champaign, IL: Human Kinetics Books, 1990.

MARTINENT, G.; FERRAND, C.; GUILLET, E.; GAUTHEUR, S. Validation of the French version of the Competitive State Anxiety Inventory-2 Revised (CSAl-2R) including frequency and direction scales. Psychology of Sport and exercise, 11(1), 51-57, 2010.

MASTERS R.S.W.; VAN DER KAMP J.; JACKSON R.C. Imperceptibly off-center goalkeepers influence penalty-kick direction in soccer. Psychological science. 18(3):222-3, 2007.

MCGRADY, A.V.; YONKEER, R.; TAN, S.Y.; FINE, T.H.; WOERNER, M. The Effect Of Biofeedbak Assisted Relaxation Training On Blood Pressure And Selected Biochemical Parameters In Patiens With Essential Hypertension. Biofeedback and Self Regulation, 6, 343-353, 1981. 
MILLER, C. He always puts it to the right: a history of the penalty kick. London: Victor Gollanez, 1998.

MOORE, N. C. A review of EEG biofeedback treatment of anxiety disorders. Clinical EEG and Neuroscience, 31(1), 1-6, 2000.

MOREIRA, M. B.; MEDEIROS, C. A. Princípios Básicos de Análise do Comportamento. Porto Alegre. Ed: Artmed, 2007.

MORELLI, C.D. Futebol de Campo: Histórico e Fundamento. Campinas: CD Morelli, 1986. MORRIS, L.; DAVIS, D.; HUTCHINGS, C. Cognitive and emotional components of anxiety: literature review and revised worry-emotionality scale. Journal of Educational Psychology, 75, 541-555, 1981.

MORYA, E.; BIGATAO, H.; LEES, A. RANVAUD, R. Evolving penalty kick strategies: World Cup and club matches 2000-2002. Science And Football Congress. 237-242, 2005.

MURRAY, B. Uma história do futebol. São Paulo: Hedra, 2000.

NONNEMACHER, G.; VOSER, R. C. Análise das Defesas dos Goleiros de Seleções nas Cobranças de Pênaltis. Lecturas Educación Física y Deportes (Buenos Aires), v. 16, p. 1 5, 2012.

OLATUNJI, B.O., CISLER J.M., DEACON, B. J. "Efficacy of Cognitive Behavioral Therapy for Anxiety Disorders: A Review of Meta-Analytic Findings." Psychiatric Clinics of North America 33.3, 2010.

PAUL, M.; GARG, K. The effect of heart rate variability biofeedback on performance psychology of basketball players. Applied Psychophysiology and Biofeedback, v. 37, n. 2, p. 131-144, 2012.

PELLETIER, M.H. Cognitive-behavioral Therapy Efficacy via Videoconferencing for Social (public Speaking) Anxiety Disorder Single Case Design. Ottawa: National Library of Canada: Bibliothèque Nationale Du Canada, 2003.

PEREIRA, M.M.B.; TRICOLI, V.A.C. A influência do meio ambiente e das práticas parentais na vulnerabilidade ao stress. In: Lipp, M.N. (Org.) Mecanismos neuropsicofisiológicos do stress: teoria e aplicações clínicas. São Paulo: Casa do Psicólogo, 67-70, 2003.

PERRY, F. D., SHAW, L., ZAICHKOWSKY, L. Biofeedback and neurofeedback in sports. Biofeedback 39.3: 95-100, 2011.

PIAGET, J. Desenvolvimento e aprendizagem. Studying teaching, 1972.

POP-JORDANOVA, N.; DEMERDZIEVA, A. Basic Science Biofeedback Training for Peak Performance in Sport - Case Study. Macedonian Journal of Medical Sciences. Jun 15; 3(2):113-118, 2010. 
POP-JORDANOVA N,; CAKALAROSKA I. Comparison of Biofeedback modalities for better achievement in high school students, Maced J Med Sci,1(2): 25-31, 2008.

POP-JORDANOVA, N.; DEMERDZIEVA, A. Biofeedback Training for Peak Performance in Sport - Case Study. In: Macedonian Journal of Medical Sciences. Jun 15; 3(2):113-118, 2010.

PUJALS, C.; VIEIRA, L. F. Análise dos fatores psicológicos que interferem no comportamento dos atletas de futebol de campo. Revista de Educação Física/UEM, v. 13, n. 1, p. 89-97, 2002.

PRAPAVESSIS, H., GROVE, J. R., MCNAIR, P. J., CABLE, N. T. Self-regulation training, state anxiety, and sport performance: A psychophysiological case study. The Sport Psychologist, 6(3), 213-229, 1992.

PYNE, J. M.; RICHARD GEVIRTZ, R. G. Psychophysiologic Assessment and Combat Post Traumatic Stress Disorder. Biofeedback: Spring 2009, Vol. 37, No. 1, pp. 18-23.

RANGÉ, B. Psicoterapias Cognitivo-Comportamentais: um diálogo com a psiquiatria. Porto Alegre: Artmed, 2001.

RAUDSEPP, L.; KAIS, K. "Confirmatory factor analysis of the Revised Competitive State Anxiety Inventory-2 among Estonian athletes." International Journal of Sports Science 23:727-736, 2005.

RAYMOND J.; SAJID I.; PARKINSON LA.; GRUZELIER J.H. Biofeedback and dance performance: a preliminary investigation. Applied Psychophysiological Biofeedback. 30(1):64-73, 2005.

REILLY, T.; GILBOURNE, D. Science and football: a review of applied research in the football codes. Journal of Sports Sciences. 21:693-705, 2003.

SALAZAR, W.; LANDERS, D. M.; PETRUZZELLO, S. J.; HAN, M.; CREWS, D. J.; KUBITZ, K. A. Hemispheric asymmetry, cardiac response, and performance in elite archers. Research quarterly for exercise and sport 61.4, 1990.

SAMULSKI, D. Psicologia do esporte. Barueri: Manole Ltda, 2002.

SANTOS, S. G.; PEREIRA, S. A. Perfil do nível de ansiedade traço pré-competitiva de atletas de esportes coletivos e individuais do Estado do Paraná. Revista Movimento, Porto Alegre, n. 6, ano 3, p. 3- 12, 1997.

SAPOLSKY, R. M. Why zebras don't get ulcers: The acclaimed guide to stress, stressrelated diseases, and coping-now revised and updated. Macmillan, 2004.

SELYE H. History and Present Status of the Stress Concept. In: Goldberger L, Breznitz S. Handbook of Stress - Theoretical and Clinical Aspects. New York: Free Press; 1986. p.720.

SEYLE, H. Stress without distress. Vie medicale au Canada francais (1975). 
SERASSUELO JUNIOR, H.; SIMÕES, A.C.; OLIVEIRA, S.R.S.; MANSANO, M.M. Futebol de campo: análise das tendências comportamentais em vencer, competir e estabelecer metas. In: XXVIII Simpósio Internacional de Ciências do Esporte, 2005, São Paulo. Anais, 2005. p. 193.

SILVEIRA, E. O medo do goleiro diante do pênalti. Jornal da UNESP. n.131, 1998, p.15. SINGER, R. N. Psychological testing of athletes. Journal of Physical Education and Recreation, v. 48, n. 5, p. 30-32, 1977.

SKINNER, B. F. Ciência e Comportamento Humano. São Paulo: Martins Fontes, 1953.

SKINNER, B. F. Tecnologia do Ensino. S. Paulo: Editora Pedagógica. 1972.

SKINNER, B. F.. Seleção por consequências. Rev. bras. ter. comport. cogn., São Paulo v. 9, n. 1, p. 129-137, jun. $2007 \quad$. Disponível em $<$ http://pepsic.bvsalud.org/scielo.php?script=sci_arttext\&pid=S1517-

55452007000100010\&lng=pt\&nrm=iso >. acesso em 05 dez. 2016.

SIMÕES, A. C. e Comportamento ideológico de liderança de professores técnicos de equipes escolares masculinas e femininas de basquetebol, handebol, futsal e voleibol.. 2005.

SPIELBERGER, C. D. Trait-state anxiety and motor behavior. Journal of Motor Behavior, 3, 265-279, 1971.

STEFANELLO, J. Ansiedade competitiva e os factores de personalidade de adolescentes que praticam voleibol: um estudo causal comparativo. Kinesis. Vol.6 (2), 203-204, 1990.

SCHWARTZ, M.S., Biofeedback a Pratictioner's Guide, 2nd Edition, The Guilford Press, New York, New York, 1995.

STRACK, B. W. Effect of heart rate variability (hrv) biofeedback on batting performance in baseball. Tese de Doutorado. ProQuest Information \& Learning, 2003.

TANIS, C. The effects of heart rhythm variability biofeedback with emotional regulation on the athletic performance of women collegiate volleyball players. Doctoral Dissertation, Capella University, Minnesota. Tattenbaum, 2008.

TODOROV, J. C. Quem tem medo de punição?. Rev. bras. ter. comport. cogn., São Paulo v. 3, n. 1, p. 37-40, abr. 2001. Disponível em $<$ http://pepsic.bvsalud.org/scielo.php?script=sci_arttext\&pid=S151755452001000100004\&lng=pt\&nrm=iso $>$. acessos em 05 dez. 2016.

TSORBATZOUDIS, H.; VARKOUKIS, V.; KAISSIDIS-RODAFINOS, A.; GROUIOS, G. A test of the reliability and factorial validity of the Greek version of the CSAI-2. Research Quarterly for Exercise and Sport, 69, 416-419, 1998. 
VALDÉS CASAL, H. M. Fatos e reflexões sobre a História da Psicologia do esporte. In: BRANDÃO, M. R. F.; MACHADO, A. A. (Eds.). Coleção Psicologia do Esporte: v. 1: teoria e aplicação. São Paulo: Atheneu, 1-29, 2007.

VALEY, R. Conceptualization of sport-confidence and competitive orientation: preliminar investigation and instrument development. Journal of Sport and Exercise Psychology. (8), 221-246, 1986.

VALLE, M. P. Atletas de alto rendimento: identidades em construção. Porto Alegre: PUCRS, 2003. Dissertação (Mestrado em Psicologia), Faculdade de Psicologia, Pontifícia Universidade Católica do Rio Grande do Sul. 2003.

VAN DER KAMP, J. A field simulation study of the effectiveness of penalty kick strategies in soccer: late alterations of kick direction increase errors and reduce accuracy. Journal of sports sciences, v. 24, n. 05, p. 467-477, 2006.

VAN DER KAMP, J.; MASTERS, R.S.W. "The human Müller-Lyer illusion in goalkeeping." Perception 37.6: 951-954, 2008.

VIANA, M. Competição, ansiedade e auto-confiança: implicações na preparação do jovem desportista para a competição. Treino Desportivo. Lisboa: II série, n. 13, p. 52-61, 1989.

VICKERS, J. N.; WILLIAMS, A. M. Performing under pressure: The effects of physiological arousal, cognitive anxiety, and gaze control in biathlon. Journal of Motor Behavior, v. 39, n. 5, p. 381-394, 2007.

VOSER, R. C.; GUIMARÃES, M. G. V.; RIBEIRO, E. R. Futebol: história, técnica e treino de goleiro. Porto Alegre: EDIPUCRS, 2006.

WEINBERG, R.S.; GOULD, D. Foundations of Sport \& Exercise Psychology. 4.ed. São Paulo: Artmed, 2008.

WILSON, M.R.; VINE, S.J.; WOOD, G. The influence of anxiety on visual attentional control in basketball free-throw shooting. Journal of Sport; Exercise Psychology,31,152168, 2009.

WILSON V. S.; PEPER, E., Athletes Are Different: Factors That Differentiate Biofeedback/Neurofeedback for Sport Versus Clinical Practice. Biofeedback: Spring 2011, Vol. 39, No. 1, pp. 27-30, 2011.

WISIAK, M. Análise temporal da antecipação do goleiro nas situações de cobranças de pênalti. 2001. 43f. Monografia (Graduação em Educação Física) - Instituto de Biociências, Universidade Estadual Paulista, Rio Claro, 2001.

WISIAK, M.; CUNHA, S. A. Análise da antecipação do goleiro em cobranças de pênaltis. Revista Motriz, 2004.

WITZIG, R. The Global Art of Soccer. New Orleans, LA, EUA: CusiBoy Publishing, 2006. 
WOOD, G. "Anxiety and attentional control in football penalty kicks: A mechanistic account of performance failure under pressure." 2010.

WOODMAN, T.; HARDY, L. The relative impact of cognitive anxiety and self-confidence upon sport performance: A meta-analysis. Journal of sports sciences, v. 21, n. 6, p. 443457, 2003.

WRIGHT, J. H.; BASCO, M. R.; THASE M. E. Learning Cognitive-behavior Therapy: An Illustrated Guide. Washington, DC: American Psychiatric Pub., 2006. 
ANEXOS 


\title{
ANEXO A: Aprovação do Projeto no Comitê de Ética
}

\author{
ESCOLA DE EDUCACÃO \\ FÍSICA E ESPORTE DA \\ UNIVERSIDADE DE SÃO
}

\section{DADOS DO PROJETO DE PESQUISA}

\section{PARECER CONSUBSTANCIADO DO CEP}

Título da Pesquisa: Biofeedback e psicologia cognitivo-comportamental: um estudo sobre a redução da ansiedade estado em atletas amadores de futebol de campo no momento da cobrança do pênalti. Pesquisador: Antônio Carlos Simões Área Temática:

Versão: 2

CAAE: 40688214.5 .0000 .5391

Instituição Proponente: UNIVERSIDADE DE SAO PAULO

Patrocinador Principal: Financiamento Próprio MINISTERIO DA EDUCACAO

\section{DADOS DO PARECER}

Número do Parecer: 1.034 .948

Data da Relatoria: 23/04/2015

\section{Apresentação do Projeto:}

Projeto relevante sobre os determinantes de desempenho em atletas. Focaliza aspectos psicológicos que influenciam no desempenho como a ansiedade. Apresenta articulação teórica e método adequados ao cumprimento dos objetivos do estudo.

\section{Objetivo da Pesquisa:}

Investigar se o método de biofeeback associado a psicologia cognitivo-comportamental é uma técnica útil na diminuição da ansiedade de atletas de futebol durante a cobrança de pênalti.

Avaliação dos Riscos e Benefícios:

O projeto produzirá benefícios para a área de conhecimento em questão e envolve risco mínimo para os participantes. Ademais, 16 participantes do estudo poderão ser beneficiados com a redução de ansiedade no momento da cobrança de penaltis, através de sessões de redução de pensamentos disfuncionais e técnicas de relaxamento e biofeedback que serão disponibilizadas pelo estud o.

Comentários e Considerações sobre a Pesquisa:

Trata-se de estudo descritivo exploratório com 32 atletas de futebol de 14 até 16 anos de diferentes classes sociais e equipes de futebol, dos quais 16 farão parte do grupo controle.

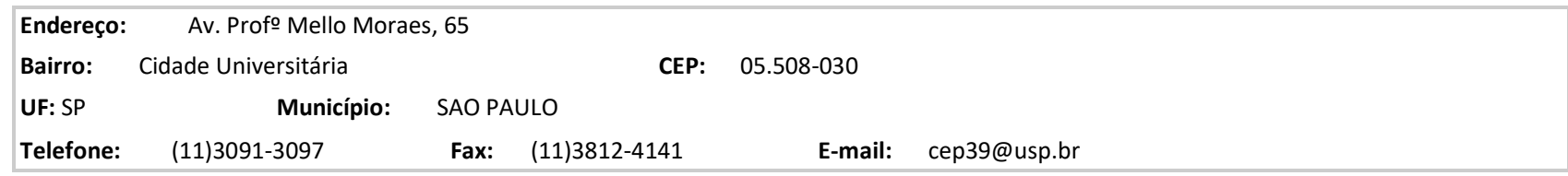




\section{ESCOLA DE EDUCAÇÃO \\ FÍSICA E ESPORTE DA \\ UNIVERSIDADE DE SÃO}

Continuação do Parecer: 1.034 .948

O pesquisador atendeu as recomendações feitas no parecer inicial sobre o TCLE: descreveu o risco mínimo em participar do estu do e também inclui no TCLE a informação de que os participantes do estudo não serão remunerados e que não haverá custos decorrentes de sua participação na pesquisa.

\section{Recomendações:}

O pesquisador atendeu as principais recomendações feitas no parecer inicial sobre o projeto: inclui na seção de método um item dedicado aos aspectos éticos do estudo; detalhou no método como serão feitas as sessões de redução de pensamentos disfuncionais e técnicas de relaxamento e biofeedback; incorporou no projeto e no TCLE a informação de que os resultados do estudo poderão ser apresentados aos clubes e aos jovens e pais envolvidos caso haja interesse por parte deles.

\section{Conclusões ou Pendências e Lista de Inadequações:}

Não há pendências em relação ao projeto e ao TCLE.

\section{Situação do Parecer:}

Aprovado

\section{Necessita Apreciação da CONEP:}

Não

Considerações Finais a critério do CEP:

\section{Assinado por:}

\section{Maria Augusta Peduti Dal'Molin Kiss}

(Coordenador)Endereço:Av. Profo Mello Moraes, 65

Bairro: Cidade Universitária

CEP: $\quad 05.508-030$

UF: SP

Município: SAO PAULO

Telefone:

(11)3091-3097

Fax: (11)3812-4141

E-mail: cep39@usp.br 


\section{ANEXO B: Versão Brasileira do CSAI-2R}

\section{Nome}

\section{Idade}

\section{CSAI-2R}

A seguir transcrevem-se algumas afirmações que os atletas usam para descrever os seus sentimentos antes da competição. Leia cada uma delas e assinale com um círculo, para cada afirmação, o número que melhor indicar como se sente agora - neste momento. Não há respostas certas nem erradas. Não dispense muito tempo em cada uma das afirmações.

Assinale o número que melhor indicar o que sente agora.

\begin{tabular}{|c|c|c|c|c|}
\hline \multirow[b]{2}{*}{ 1. Sinto-me agitado } & \multicolumn{2}{|c|}{ NADA } & \multicolumn{2}{|c|}{ MUITO } \\
\hline & 1 & 2 & 3 & 4 \\
\hline $\begin{array}{l}\text { 2. Estou preocupado porque posso não render tão bem como poderia nesta } \\
\text { competição. }\end{array}$ & 1 & 2 & 3 & 4 \\
\hline 3. Sinto-me autoconfiante. & 1 & 2 & 3 & 4 \\
\hline 4. Sinto o meu corpo tenso. & 1 & 2 & 3 & 4 \\
\hline 5. Estou preocupado pelo fato de poder perder. & 1 & 2 & 3 & 4 \\
\hline 6. Sinto tensão no meu estômago. & 1 & 2 & 3 & 4 \\
\hline $\begin{array}{l}\text { 7. Estou confiante de que posso corresponder ao desafio que me é } \\
\text { colocado. }\end{array}$ & 1 & 2 & 3 & 4 \\
\hline 8. Estou preocupado pelo fato de poder falhar sob pressão da competição. & 1 & 2 & 3 & 4 \\
\hline 9. O meu coração está a bater muito depressa & 1 & 2 & 3 & 4 \\
\hline 10. Estou confiante de que vou ter um bom rendimento & 1 & 2 & 3 & 4 \\
\hline 11. Estou preocupado pelo fato de poder ter um mau rendimento & 1 & 2 & 3 & 4 \\
\hline 12. Sinto o meu estômago "às voltas". & 1 & 2 & 3 & 4 \\
\hline $\begin{array}{l}\text { 13. Estou confiante porque me imagino, mentalmente, a atingir o meu } \\
\text { objetivo }\end{array}$ & 1 & 2 & 3 & 4 \\
\hline $\begin{array}{l}\text { 14. Estou preocupado pelo fato de os outros poderem ficar desapontados } \\
\text { com o meu rendimento. }\end{array}$ & 1 & 2 & 3 & 4 \\
\hline 15. As minhas mãos estão frias e húmidas. & 1 & 2 & 3 & 4 \\
\hline $\begin{array}{l}\text { 16. Estou confiante em conseguir ultrapassar os obstáculos sob a pressão } \\
\text { da competição }\end{array}$ & 1 & 2 & 3 & 4 \\
\hline 17. Sinto o meu corpo rígido. & 1 & 2 & 3 & 4 \\
\hline
\end{tabular}


APÊNDICES 
10.1 APÊNDICE $\mathrm{A}$ - Sintaxe e saídas das análises

> 1ibrary("n1me", 1ib.1oc="C:/Program Fi1es/R/R-3.3.1/1ibrary")

> 1ibrary("n1me", 1ib.1oc="C:/Program Files/R/R-3.3.1/1ibrary")

grupo0\$ava1: Ava1_1

median mean SE.mean CI.mean.0.95 var std.

dev

coef.var

648

0.2115121

grupo0\$aval: Ava1_2

median

29.6875000

1.5698162

3.3459840

39.4291667

6.2792

dev

coef.var

27.0000000

316

0.2696272

28.6875000

SE.mean CI.mean.0.95

var

std.

grupol <- subset (danie1, grupo != "0")

$>$ by (grupo1\$test, grupo1\$aval, stat.desc, basic = FALSE) grupo1 $\$$ ava1: Ava1_1
median

dev

mean

SE.mean CI.mean.0.95

4.1216541

59.8291667

7.7349

coef.var

454

29.0000000
0.2057264

29.7222222

1.4412358

3.0407416

37.3888889

std.

grupo1\$ava1: Ava1_2 median

mean

SE.mean CI.mean.0.95

var

6.1146

dev coef.var

24.0000000

24.5000000

1.0105651

2.1321060

18.3823529

std.

646 0.1749986

$>\mathrm{m} 0<-1 \mathrm{me}($ test $\sim 1$, random $=\sim 1 \mid \mathrm{id}$, data $=$ danie 1$)$

$>\operatorname{summary}(\mathrm{mO})$

Linear mixed-effects model fit by REML

Data: danie1

AIC BIC logLik

$439.0406 \quad 445.6547-216.5203$

Random effects:

Formula: $\sim 1 \mid$ id

StdDev: $\begin{array}{rr}\text { (Intercept) } & \text { Residua1 } \\ 4.640892 & 4.475423\end{array}$

Fixed effects: test $\sim 1$

Value Std.Error DF t-value p-value

$\begin{array}{lllll}\text { (Intercept) } 28.08824 & 0.9633365 & 34 & 29.15724 & 0\end{array}$

Standardized within-Group Residuals:
$-1.4178331$
Min Q1
Q1 Med
$-0.1480978$
0.5182240
$\operatorname{Max}$
1.9070995

Number of observations: 68

Number of Groups: 34 
$>\mathrm{m} 1<-1 \mathrm{me}($ test $\sim$ aval, random $=\sim 1 \mid \mathrm{id}$, data $=$ danie1)

$>\operatorname{summary}(\mathrm{m} 1)$

Linear mixed-effects model fit by REML

Data: danie1

$\begin{array}{lrr}\text { AIC } & \text { BIC } & \text { logLik }\end{array}$

$429.0297 \quad 437.7883-210.5148$

Random effects:

Formula: $\sim 1$ | id

(Intercept) Residual

StdDev: $\quad 4.8918793 .904383$

Fixed effects: test $\sim$ aval

Value Std.Error DF t-value p-value

$\begin{array}{lllllll}\text { (Intercept) } & 29.705882 & 1.073404 & 33 & 27.674459 & 0.0000\end{array}$

$\begin{array}{llllll}\text { avalAva1_2 } & -3.235294 & 0.946952 & 33 & -3.416535 & 0.0017\end{array}$

Correlation:

(Intr)

ava1Ava1_2 -0.441

Standardized Within-Group Residuals:
Min
Q1 Med
0.5815631
Q3 Max

$-1.1967803-0.5378926-0.1213666$

Number of observations: 68

Number of Groups: 34

$>\mathrm{m} 2<-1 \mathrm{me}($ test $\sim$ aval + grupo, random $=\sim 1 \mid \mathrm{id}$, data $=$ danie1)

$>\operatorname{summary}(\mathrm{m} 2)$

Linear mixed-effects model fit by REML

Data: danie1

AIC BIC logLik

$426.7189437 .5909-208.3595$

Random effects:

Formula: $\sim 1$ id

(Intercept) Residual

StdDev: $\quad 4.875987 \quad 3.904383$

Fixed effects: test $\sim$ aval + grupo

Value std.Error DF t-value p-value

$\begin{array}{lllllll}\text { (Intercept) } 30.805147 & 1.478687 & 33 & 20.832776 & 0.0000\end{array}$

$\begin{array}{llllll}\text { ava1Ava1_2 } & -3.235294 & 0.946952 & 33 & -3.416534 & 0.0017\end{array}$

$\begin{array}{llllll}\text { grupo } & -2.076389 & 1.925261 & 32 & -1.078497 & 0.2889\end{array}$

Correlation:

(Intr) av1A_2

avalAva1_2 -0.320

$\begin{array}{lll}\text { grupo } & -0.689 & 0.000\end{array}$

Standardized Within-Group Residuals:

$\begin{array}{crrrr}\text { Min } & \text { Q1 } & \text { Med } & \text { Q3 } & \text { Max } \\ -1.26393264 & -0.57296450 & -0.08240001 & 0.53534007 & 1.70989857\end{array}$

Number of observations: 68

Number of Groups: 34

$>\mathrm{m} 3<-1 \mathrm{me}($ test $\sim$ aval $*$ grupo, random $=\sim 1 \mid \mathrm{id}$, data $=$ danie 1$)$ 


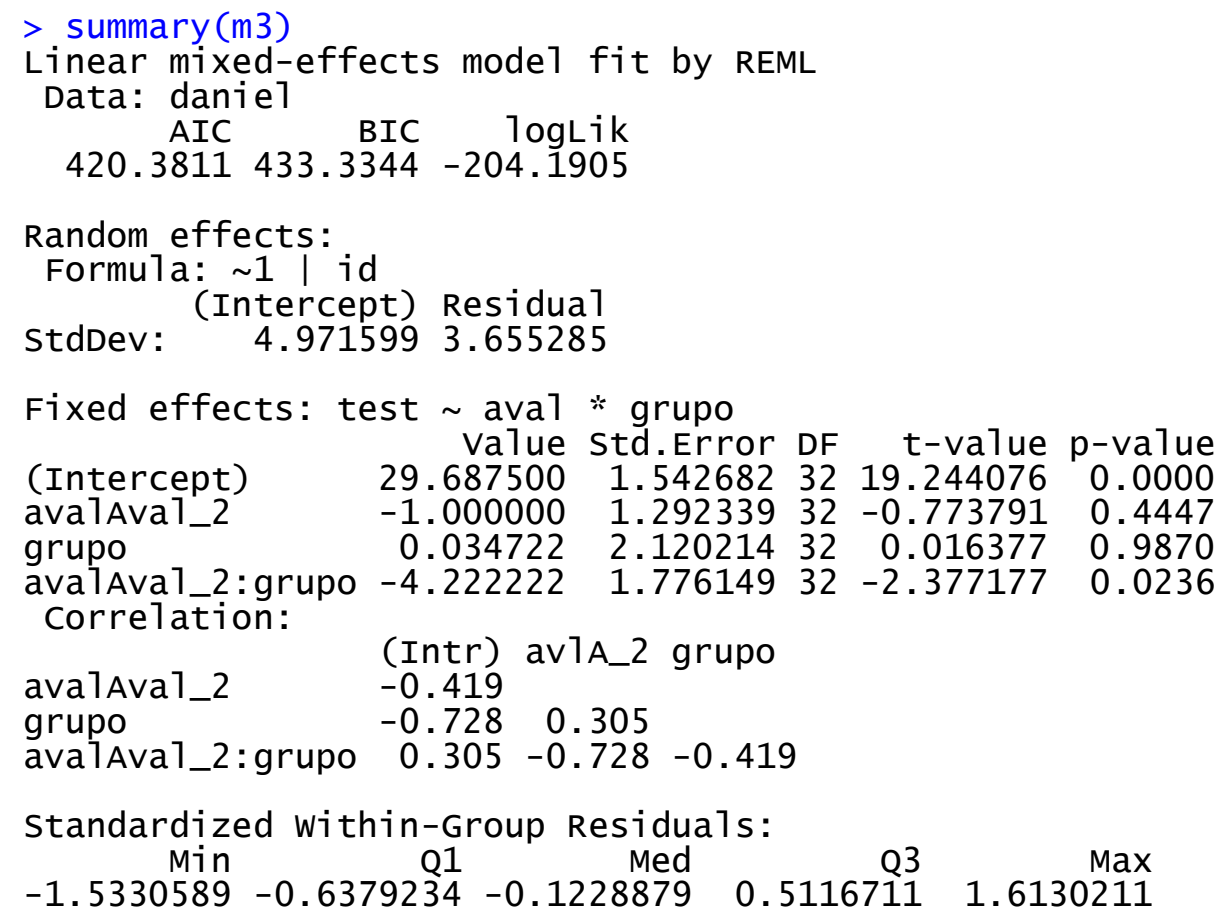

Number of observations: 68

Number of Groups: 34

$>$ danie1\$grupo <- as.factor(danie1\$grupo)

$>$ danie1\$avagrupo <- interaction(danie1\$grupo, danie1\$ava1)

$>\mathrm{m} 4<-1 \mathrm{me}($ test $\sim$ avagrupo, random $=\sim 1 \mid \mathrm{id}$, data $=$ daniel)

> 1ibrary ("mu1tcomp", 1ib. 1oc=" /R/win-1ibrary/3.3")

Carregando pacotes exigidos: mvtnorm

Carregando pacotes exigidos: surviva1

Carregando pacotes exigidos: TH.data

Carregando pacotes exigidos: MASS

Attaching package: 'TH.data'

The following object is masked from 'package:MASS':

geyser

$>\operatorname{summary}(\mathrm{g} 1 \mathrm{ht}(\mathrm{m} 4,1 \mathrm{infct}=\operatorname{mcp}($ avagrupo $=$ "Tukey" $))$

Simultaneous Tests for General Linear Hypotheses

Multiple Comparisons of Means: Tukey Contrasts

Fit: $7 \mathrm{me}$. formula(fixed $=$ test $\sim$ avagrupo, data $=$ daniel, random $=\sim 1$ । id)

Linear Hypotheses:

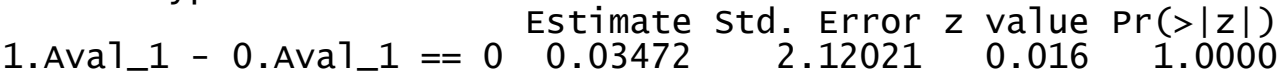




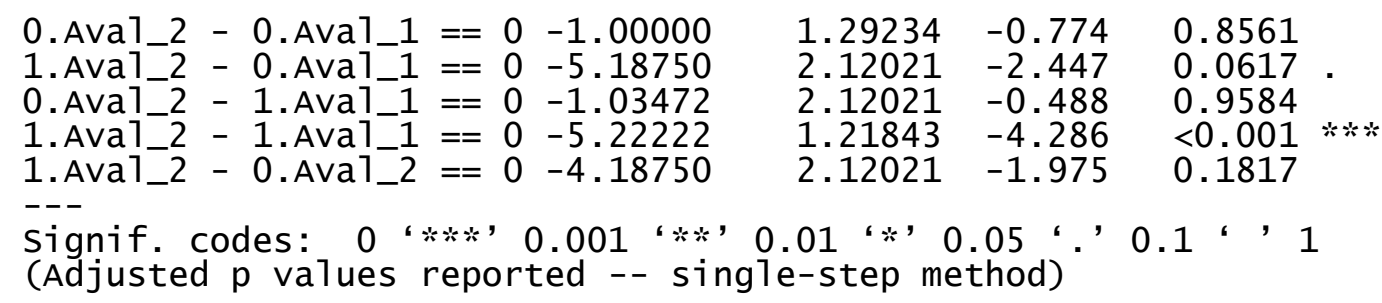

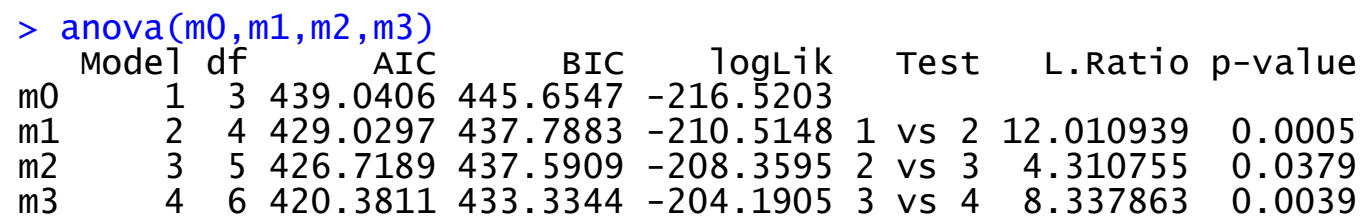

$>\operatorname{plot}(\mathrm{m} 3)$

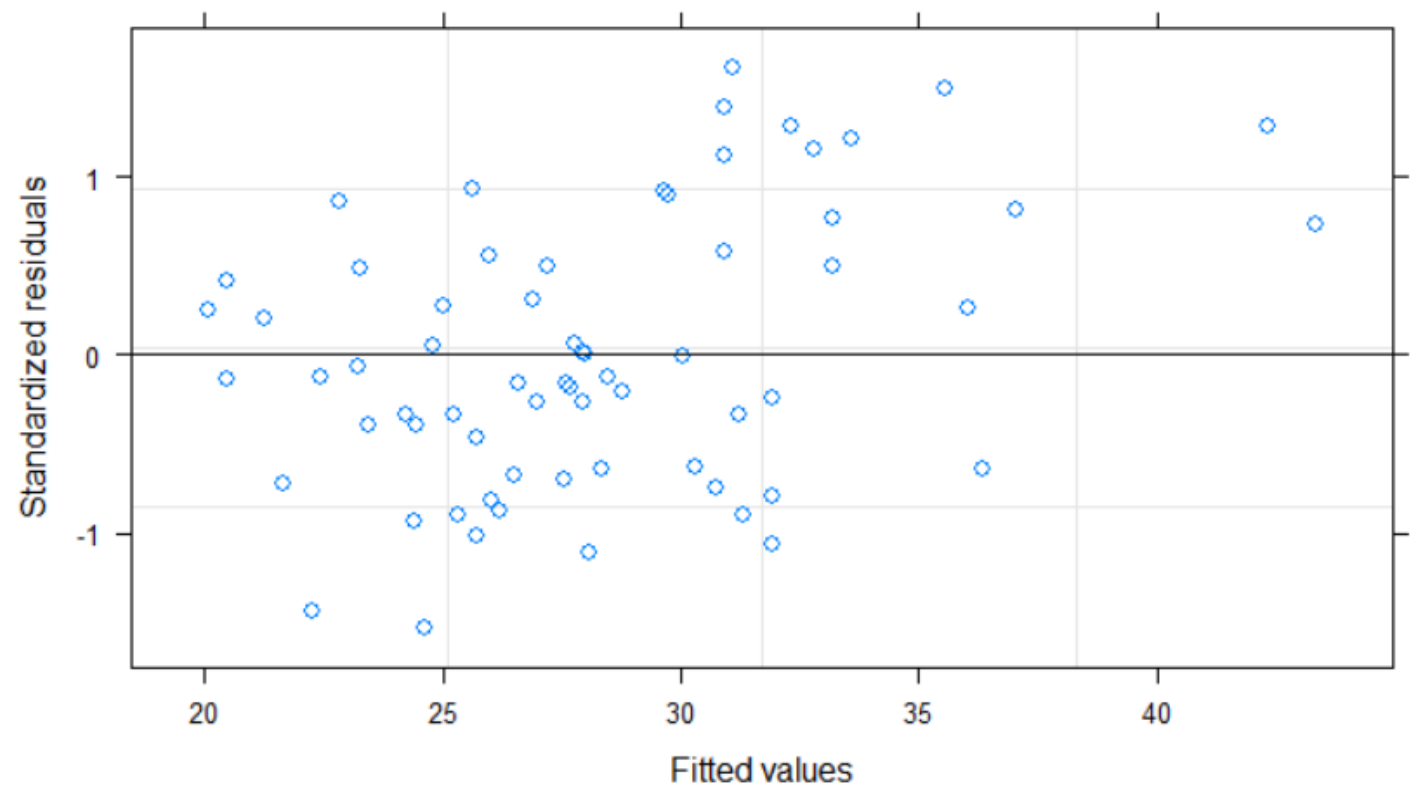

$>$ by (grupo0\$som, grupo0\$ava1, stat.desc, basic $=$ FALSE)

\begin{tabular}{|c|c|c|c|c|c|}
\hline median & mean & SE.mean & CI.mean.0.95 & var & std.dev \\
\hline $\begin{array}{l}9.0000000 \\
0.3012302\end{array}$ & 10.2500000 & 0.7719024 & 1.6452710 & 9.5333333 & 3.0876096 \\
\hline
\end{tabular}

\begin{tabular}{|c|c|c|c|c|c|}
\hline median & mean & SE.mean & CI.mean.0.95 & var & std.dev \\
\hline $\begin{array}{l}9.0000000 \\
3024537\end{array}$ & 10.0625000 & 0.7608589 & 1.6217323 & 9.2625000 & 3.0434356 \\
\hline
\end{tabular}
0.3024532 $>$ by (grupo1\$som, grupo1\$ava1, stat.desc, basic $=$ FALSE) grupo1\$ava1: Ava1_1 median

mean SE.mean CI.mean.0.95

var std.dev coef.var

$10.5000000 \quad 10.8888889$

0.7707432

1.6261259

10.6928105

3.2699863 0.3003049

grupo1\$aval: Aval_2 median mean

SE.mean CI.mean.0.95

var std. dev coef.var 

8.0000000
9.2222222
0.6980625
1.4727831
8.7712418
2.9616282
0.3211404

$>$ som_model $<-1 \mathrm{me}(\mathrm{som} \sim 1$, random $=\sim 1 \mid i \mathrm{~d}$, data $=$ danie1_1ong)

$>$ summary (som_mode1)

Linear mixed-effects model fit by REML

Data: danie1_long

AIC BIC logLik

$328.4606 \quad 335.0747-161.2303$

Random effects:

Formu1a: $\sim 1$ | id

(Intercept) Residual

StdDev: $\quad 2.5999711 .693409$

Fixed effects: som $~ 1$

Value Std.Error DF t-value p-value

(Intercept) $10.102940 .49090763420 .58013 \quad 0$

Standardized within-Group Residuals:

$\begin{array}{rrrrr}\text { Min } & \text { Q1 } & \text { Med } & \text { Q3 } & \text { Max } \\ -1.6788758 & -0.4609046 & -0.1139740 & 0.3362931 & 1.8642735\end{array}$

Number of observations: 68

Number of Groups: 34

$>$ som_mode $1<-1 \mathrm{me}(\mathrm{som} \sim \mathrm{ava} 1$, random $=\sim 1 \mid \mathrm{id}$, data $=$ danie1_long)

$>$ summary (som_model)

Linear mixed-effects model fit by REML

Data: danie1_long

AIC BIC logLik

$324.4664333 .225-158.2332$

Random effects:

Formula: $\sim 1$ id

(Intercept) Residua1

StdDev: $\quad 2.6379951 .571384$

Fixed effects: som $\sim$ aval

Value Std.Error DF t-value p-value

$\begin{array}{lllllll}\text { (Intercept) } & 10.588235 & 0.5265947 & 33 & 20.106993 & 0.0000\end{array}$

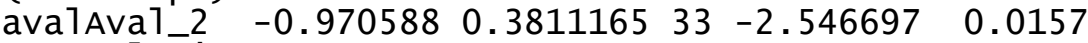

Correlation:

(Intr)

ava1Ava1_2 -0.362

Standardized within-Group Residuals:

$\begin{array}{rrrrr}\text { Min } & \text { Q1 } & \text { Med } & \text { Q3 } & \text { Max } \\ -1.5142937 & -0.5397819 & -0.1537067 & 0.3774261 & 2.1470674\end{array}$

Number of observations: 68

Number of Groups: 34

$>$ som_mode1 $<-1 \mathrm{me}$ (som $\sim$ aval $\%$ grupo, random $=\sim 1 \mid \mathrm{id}$, data $=$ danie1_1ong)

$>$ summary (som_mode1)

Linear mixed-effects model fit by REML

Data: danie1_long

AIC BIC logLik

$321.4595 \quad 334.4128-154.7298$

Random effects:

Formula: $\sim 1$ | id

(Intercept) Residual

StdDev: $\quad 2.7052881 .502276$

Fixed effects: som $\sim$ aval * grupo

Value Std.Error DF t-value $p$-value

$\begin{array}{lllllll}\text { (Intercept) } \quad 10.250000 & 0.7736043 & 32 & 13.249668 & 0.0000\end{array}$

$\begin{array}{lllllll}\text { ava1Ava1_2 } & -0.187500 & 0.5311349 & 32 & -0.353018 & 0.7264\end{array}$ 
$\begin{array}{lrrrrr}\text { grupo1 } & 0.638889 & 1.0632174 & 32 & 0.600901 & 0.5521 \\ \text { avalAva1_2:grupo1 } & -1.479167 & 0.7299751 & 32 & -2.026325 & 0.0511\end{array}$

Correlation:

ava1Ava1_2

$\begin{array}{lrrr}\text { grupo1 } & -0.728 & 0.250 & \\ \text { ava1Ava1_2:grupo1 } & 0.250 & -0.728 & -0.343\end{array}$

(Intr) av1A_2 grupo1

Standardized within-Group Residuals:
$-1.3582722$
Q1
Med
Q3
Max

Number of observations: 68

Number of Groups: 34

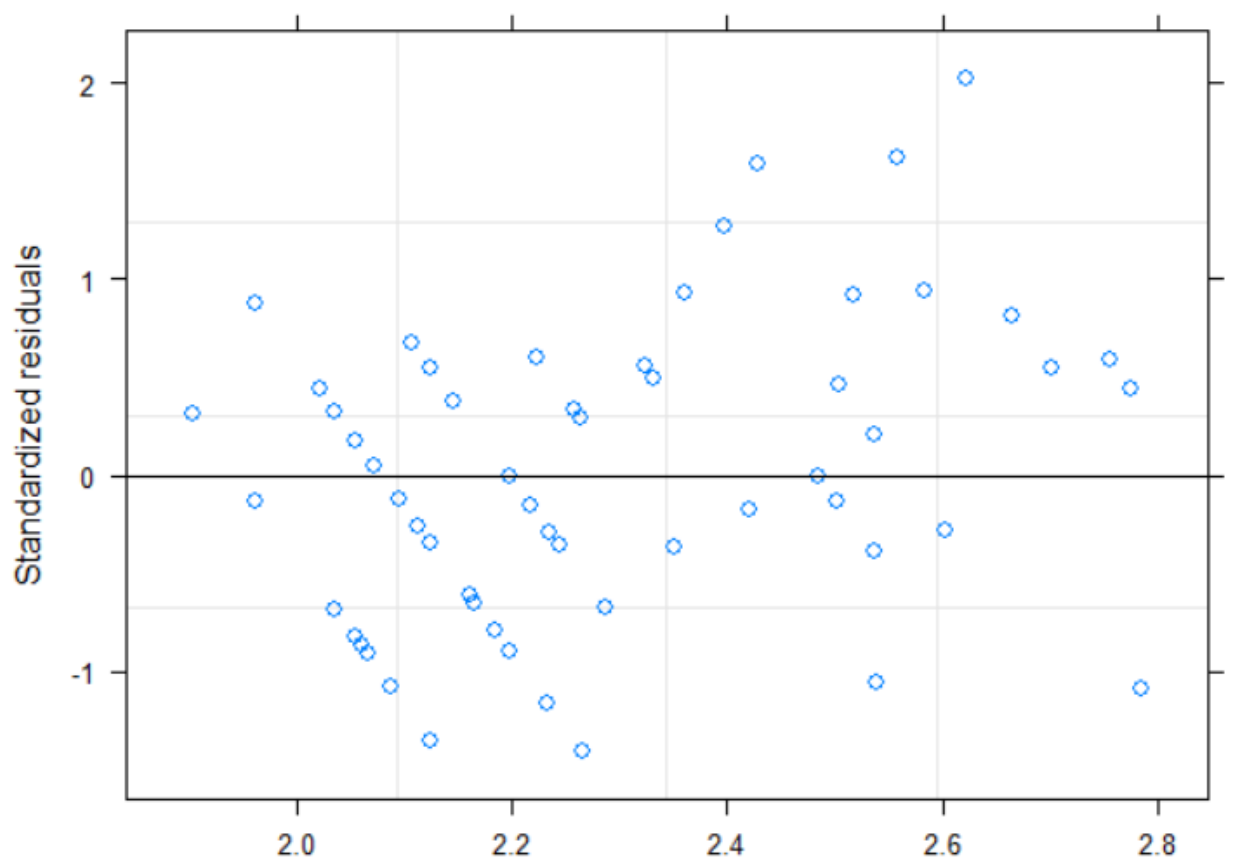

Fitted values

$>$ cog_model $<-1 \mathrm{me}(\operatorname{cog} \sim 1$, random $=\sim 1 \mid i d$, data $=$ danie1_1ong $)$

$>$ summary (cog_mode1)

Linear mixed-effects model fit by REML

Data: danie1_long

$$
\text { AIC BIC logLik }
$$

$339.8241346 .4381-166.912$

Random effects:

Formula: 1 | id

(Intercept) Residual

stdDev: $\quad 2.2258812 .128241$

Fixed effects: $\operatorname{cog} \sim 1$

Value Std.Error DF t-value $p$-value
$5882350.460793834 \quad 18.63791$

(Intercept) $8.588235 \quad 0.460793834 \quad 18.63791$

Standardized within-Group Residuals:

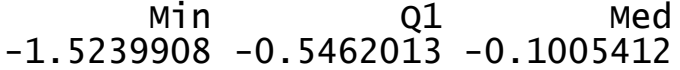
$\begin{array}{rr}\text { Q3 } & \text { Max } \\ 0.7056364 & 2.2349811\end{array}$

Number of observations: 68

Number of Groups: 34

$>$ cog_mode1 $<-1 \mathrm{me}(\operatorname{cog} \sim$ aval, random $=\sim 1 \mid \mathrm{id}$, data = danie1_1ong)

$>$ summary (cog_mode1)

Linear mixed-effects model fit by REML 
Data: danie1_long

$336.9342345 .6928-164.4671$

Random effects:

Formula: $\sim 1$ id

$\begin{array}{lrr} & \text { (Intercept) } & \text { Residual } \\ \text { StdDev: } & 2.274794 & 2.022159\end{array}$

Fixed effects: $\operatorname{cog} \sim$ aval

Value Std.Error DF t-value p-value

$\begin{array}{lllllll}\text { (Intercept) } & 9.117647 & 0.5219819 & 33 & 17.467361 & 0.0000\end{array}$

$\begin{array}{llllll}\text { avalAva1_2 } & -1.058824 & 0.4904456 & 33 & -2.158901 & 0.0382\end{array}$

Correlation:

(Intr)

ava1Ava1_2 -0.47

Standardized Within-Group Residuals:
$\begin{array}{rrr}\text { Min } & \text { Q1 } & \text { Med } \\ -1.9021137 & -0.6335911 & -0.1338205\end{array}$
0.5797863
$\operatorname{Max}$
2.5776646

Number of observations: 68

Number of Groups: 34

$>$ cog_model $<-1 \mathrm{me}(\operatorname{cog} \sim$ aval + grupo, random $=\sim 1 \mid i d$, data $=$ danie1_long $)$

$>$ summary (cog_mode1)

Linear mixed-effects model fit by REML

Data: danie1_long

AIC BIC logLik

$336.6476347 .5195-163.3238$

Random effects:

Formula: $\sim 1$ | id

(Intercept) Residual

StdDev: $\quad 2.2942412 .022159$

Fixed effects: $\operatorname{cog} \sim$ aval + grupo

value Std.Error DF $t$-value $p$-value

$\begin{array}{llllllll}\text { (Intercept) } & 9.498162 & 0.7189512 & 33 & 13.211136 & 0.0000\end{array}$

$\begin{array}{llllll}\text { avalAva1_2 } & -1.058824 & 0.4904456 & 33 & -2.158901 & 0.0382\end{array}$

$\begin{array}{llllll}\text { grupo1 } & -0.718750 & 0.9288501 & 32 & -0.773806 & 0.4447\end{array}$

Correlation:

(Intr) av1A_2

ava1Ava1_2 -0.341

$\begin{array}{lll}\text { grupo1 } & -0.684 & 0.000\end{array}$

Standardized within-Group Residuals:
Min
Q1 Med
Q3
$-1.9588649-0.6483849-0.1733499$
$0.5613651 \quad 2.5209134$

Number of observations: 68

Number of Groups: 34

$>$ cog_mode $1<-1 \mathrm{me}(\operatorname{cog} \sim$ aval $*$ grupo, random $=\sim 1 \mid \mathrm{id}$, data $=$ danie1_1ong $)$

$>$ summary (cog_mode1)

Linear mixed-effects model fit by REML

Data: danie1_long

AIC BIC logLik

$333.9863346 .9396-160.9932$

Random effects:

Formula: $\sim 1 \mid$ id

StdDev: (Intercept) Residual

Fixed effects: $\operatorname{cog} \sim$ aval * grupo

Value Std.Error DF t-value p-value

$\begin{array}{llllll}\text { (Intercept) } \quad 9.062500 & 0.7598234 & 32 & 11.927114 & 0.0000\end{array}$

avalAva1_2 $\quad-0.187500 \quad 0.694478132 \quad-0.269987 \quad 0.7889$

$\begin{array}{llllll}\text { grupo1 } & 0.104167 & 1.0442773 & 32 & 0.099750 & 0.9212\end{array}$

ava1Ava1_2:grupo1 $-1.645833 \quad 0.9544688 \quad 32 \quad-1.724345 \quad 0.0943$ 
Correlation:

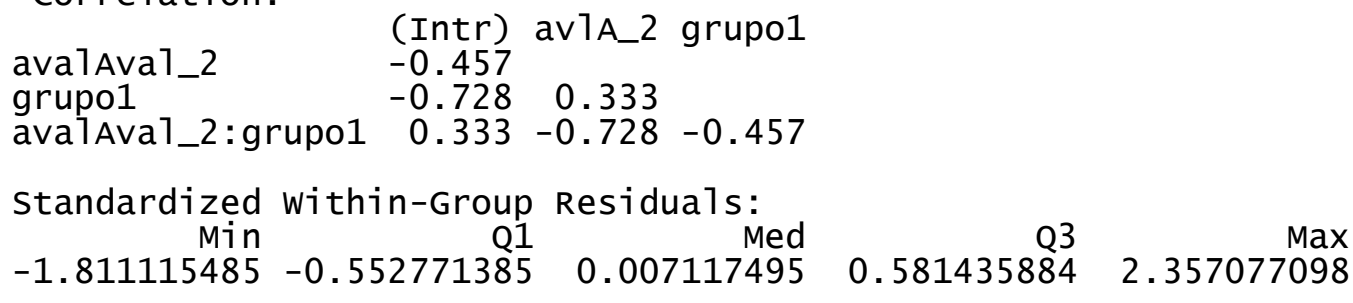

Number of observations: 68

Number of Groups: 34

$>$ by (grupo0\$cog, grupo0\$aval, stat.desc, basic $=$ FALSE)

grupo0\$ava1: Ava1_1 median

mean

SE.mean CI.mean.0.95

var

std.dev coef.var
8.0000000
9.0625000
0.7717337
1.6449115
9.5291667
3.0869348

0.3406273

grupo0\$aval: Ava1_2 median

mean

SE.mean CI.mean.0.95

var

std. dev

coef.var

8.0000000

8.8750000

0.9168560

1.9542324

13.4500000

3.6674242

0.4132309

$>$ by $($ grupo $1 \$ c o g$, grupo $1 \$ a v a 1$, stat.desc, basic $=$ FALSE)

grupo1\$ava1: Ava1_1 median

mean

SE.mean CI.mean.0.95

var

std.dev

coef.var

9.0000000

9.1666667

0.7197040

1.5184427

9.3235294

3.0534455

$$
-
$$

grupo1\$ava1: Ava1_2 median coef.var

7.0000000

7.3333333

mean

SE.mean CI.mean.0.95

var

std.dev

0.3102526

$0.5362664 \quad 1.1314233 \quad 5.1764706$

2.2751858

$>$ auto_mode $1<-1 \mathrm{me}$ (auto $\sim 1$, random $=\sim 1 \mid \mathrm{id}$, data $=$ danie1_1ong)

$>$ summary (auto_mode1)

Linear mixed-effects model fit by REML

Data: danie1_long AIC BIC logLik

$319.326 \quad 325.9401-156.663$

Random effects:

Formu1a: $\sim 1$ | id

(Intercept) Residual

StdDev: $\quad 1.5056342 .021938$

Fixed effects: auto $\sim 1$

value std.Error DF t-value p-value

$\begin{array}{llllll}\text { (Intercept) } & 9.352941 & 0.3560838 & 34 & 26.26613 & 0\end{array}$

Standardized within-Group Residuals:

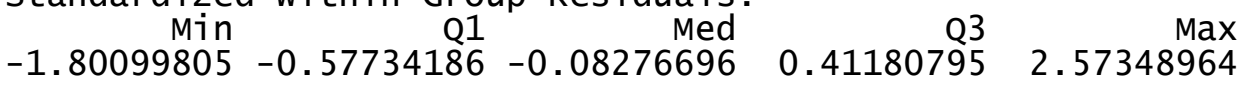

Number of observations: 68

Number of Groups: 34

$>\operatorname{var}$ (auto_mode1)

Error: is.atomic $(x)$ is not TRUE

$>$ auto_mode1 <- 1me (auto $\sim$ ava1, random $=\sim 1 \mid$ id, data $=$ danie1_1ong)

$>$ summary (auto_mode 1 )

Linear mixed-effects model fit by REML

Data: danie1_long

$$
\text { AIC BIC logLik }
$$

$313.335 \quad 322.0936-152.6675$ 


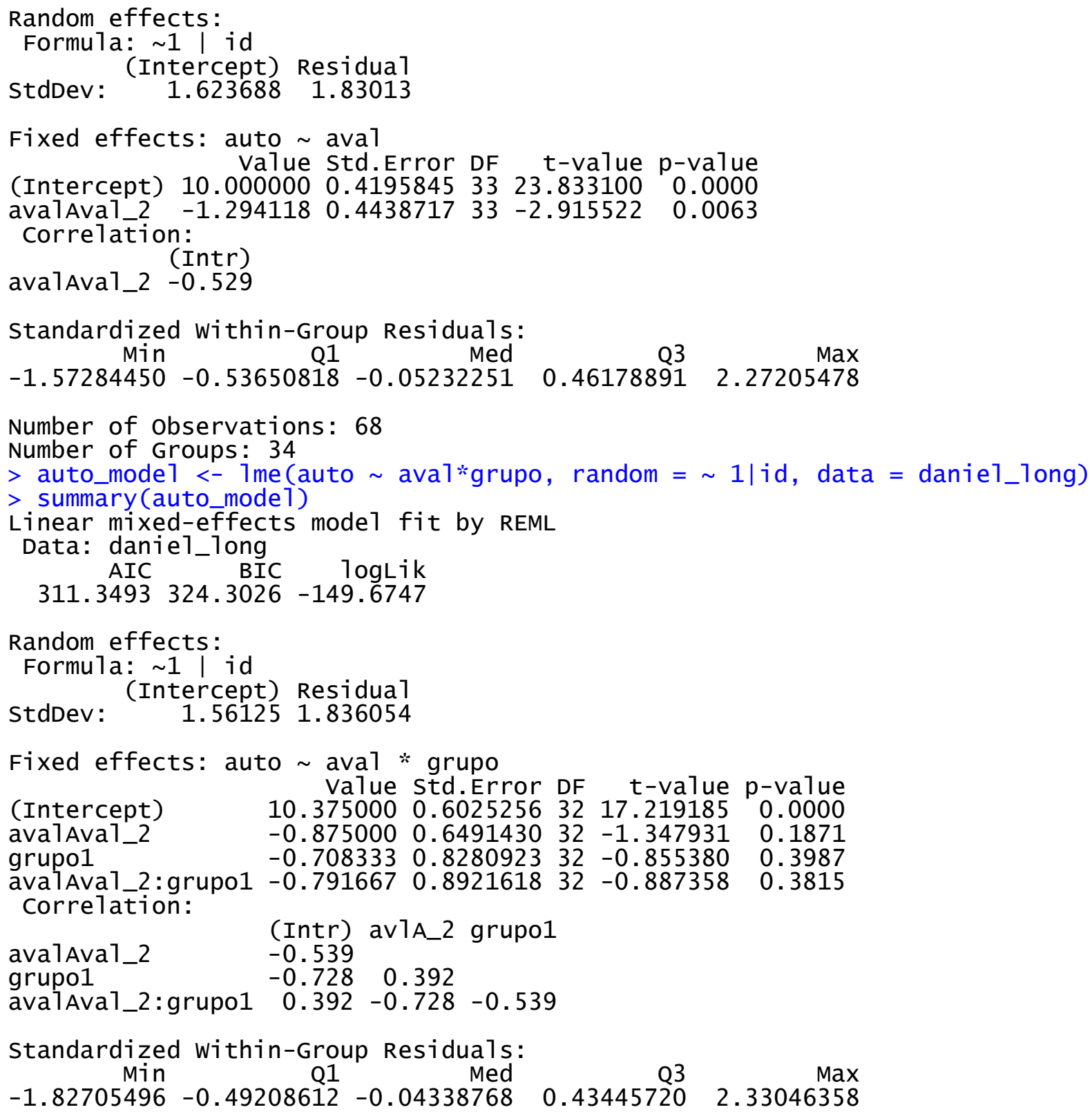

Number of observations: 68

Number of Groups: 34

$>$ by (grupo0\$auto, grupo0\$ava1, stat.desc, basic = FALSE)

grupo0\$aval: Ava1_1 median mean SE.mean CI.mean.0.95 var std.dev coef. var

$\begin{array}{llllll}10.5000000 & 10.3750000 & 0.4819665 & 1.0272872 & 3.7166667 & 1.9278658\end{array}$
0.1858184

grupo0\$aval: Ava1_2 median mean SE.mean CI.mean.0.95 var std.dev coef.var
9.0000000
9.5000000
0.6454972
1.3758448
6.6666667
2.5819889

> by (grupo1\$auto, grupo1\$aval, stat.desc, basic = FALSE) grupo1\$ava1: Ava1_1 median

mean

SE.mean CI.mean.0.95

var std.dev coef.var 9.0000000 9.6666667

0.7497276

1. 5817870

10.1176471

3.1808249 


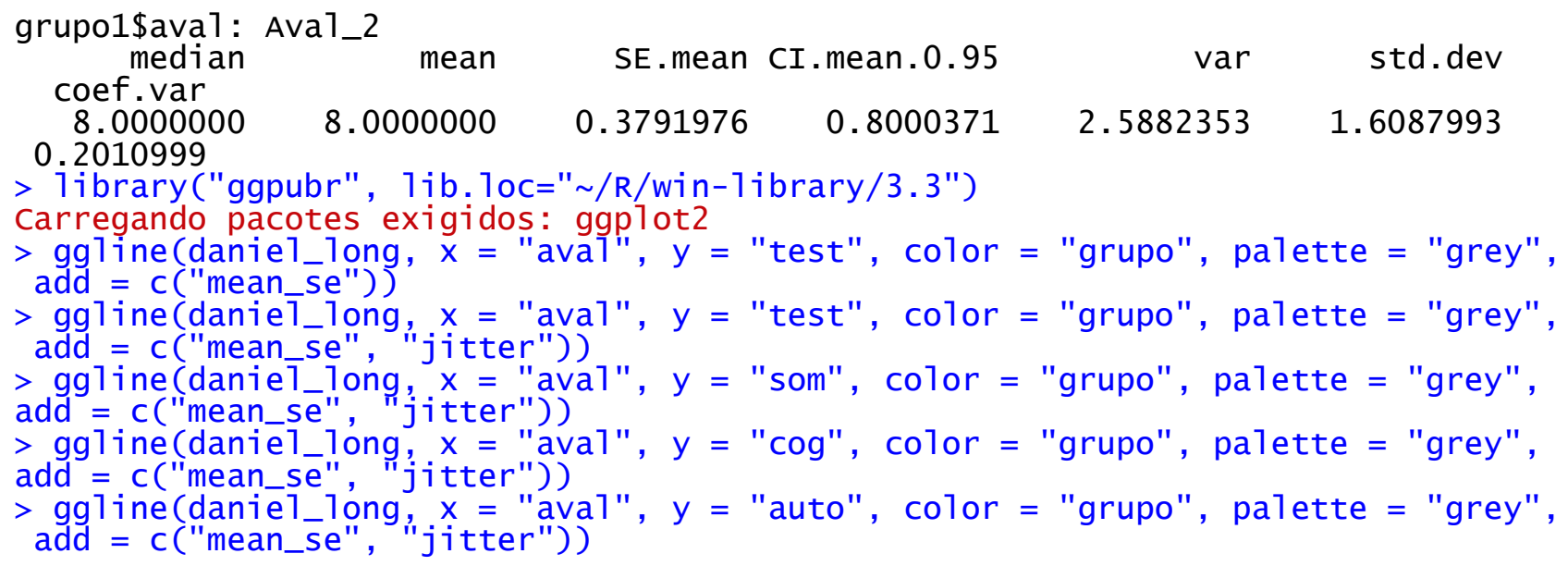
0.2010999

> 1ibrary ("ggpubr", 1ib.1oc=" /R/win-1ibrary/3.3")

\section{Carregando pacotes exigidos: ggplot2}

$>$ ggline(danie1_long, $x=$ "ava1", $y=$ "test", color = "grupo", palette = "grey", add = c ("mean_se") )

> ggline(danie $\overline{1}$ long, $x=$ "aval", y = "test", color = "grupo", palette = "grey", add = c("mean_se", "jitter")) $>$ ggline(danie $\overline{1}_{\text {_long, }} x=$ "aval", $y=$ "som", color = "grupo", palette = "grey", add = c("mean_se", "jitter")) add gline(daniel_long, $x=$ "aval", $y=$ "cog", color = "grupo", palette = "grey",

$>$ ggline(danie1_long, $x=$ "aval", $y=$ "auto", color = "grupo", palette = "grey", add = c("mean_se", "jitter")) 


\section{APÊNDICE B - Parecer de Mérito do Departamento de Esporte}

São Paulo, 20 de maio de 2013.

IImo. Sr. Prof. Dr. Valmor A.A. Tricoli

MD. Chefe do Departamento de Esporte

Escola de Educação Física e Esporte (EEFE)

Universidade de São Paulo.

Parecer de mérito sobre trabalho acadêmico

Após análise do projeto intitulado "Biofeedback e psicologia cognitivocomportamental: um estudo sobre a redução de ansiedade estado em atletas amadores de futebol de campo no momento da cobrança de pênalti?", sob a responsabilidade do Prof. Dr. Antônio Carlos Simões, aprovo o seu encaminhamento ao Comitê de Ética em Pesquisa, pelos seguintes motivos: 1. Clareza na descrição do projeto, 2. Conhecimento dos procedimentos técnicos a serem utilizados na coleta e análise de dados, 3. Falta de informações sobre o tema a ser abordado no projeto e, 4. Relevância do trabalho para as áreas do Esporte e Psicologia.

Sem mais para o momento,

Brudito Vuria Prof. Dr. Benedito Pereira.

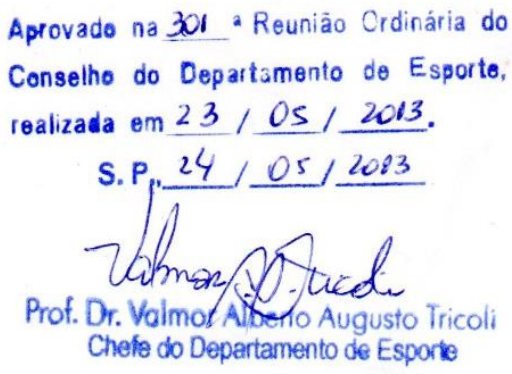


APÊNDICE C - Termo de Consentimento Livre e Esclarecido

\section{TERMO DE CONSENTIMENTO LIVRE E ESCLARECIDO}

\section{I - DADOS DE IDENTIFICAÇÃO DO SUJEITO DA PESQUISA OU RESPONSÁVEL LEGAL}

1. DADOS DO INDIVÍDUO

Nome completo

Sexo

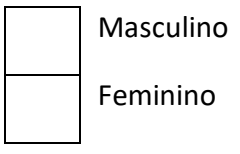

RG

Data de nascimento

Endereço completo

CEP

Fone

e-mail

2. RESPONSÁVEL LEGAL

Nome completo

Natureza (grau de parentesco, tutor, curador, etc.)

Sexo

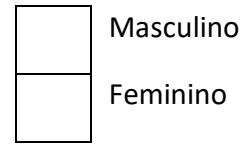

RG

Data de nascimento

Endereço completo

CEP

Fone

e-mail 


\section{II - DADOS SOBRE A PESQUISA CIENTÍFICA}

1. Título do Projeto de Pesquisa

Biofeedback e Psicologia Cognitivo-Comportamental: Um estudo sobre a redução da Ansiedade Estado em Jogadores Profissionais de Futebol no momento da cobrança de pênaltis.

2. Pesquisador Responsável

Prof. Dr. Antonio Carlos Simões

3. Cargo/Função

Professor Coordenador e responsável pelo projeto de pesquisa

4. Avaliação do risco da pesquisa:

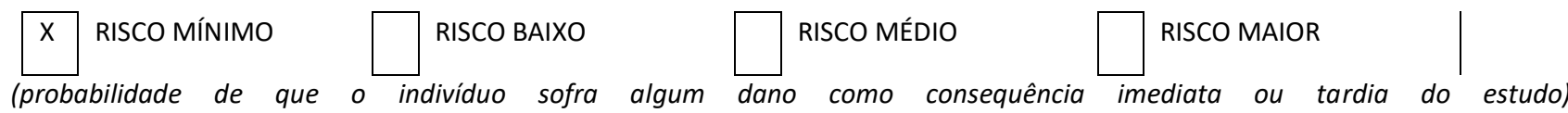
Obs. A participação no estudo envolve risco mínimo. Os temas tratados na presente pesquisa podem causar incômodos ou desconfortos. Entretanto, o pesquisador tem experiência na aplicação dos instrumentos e na abordagem dos temas. Para os casos de persistência ou baixa resolutividade do incômodo ou desconforto, será imediatamente retomado com o participante todos os seus direitos conforme o TCLE assinado e ele será conduzido imediatamente ou logo após a finalização da atividade, como lhe convier, para atendimento/acolhimento pelo pesquisador para o pronto atendimento das demandas que surgiram e providência dos encaminhamentos que se fizerem necessários.

5. Duração da Pesquisa

A pesquisa será realizada durante 2 anos.

6. Remuneração dos participantes

Os participantes não serão remunerados e nem haverá custos decorrentes de suas participações na pesquisa.

\section{III - EXPLICAÇÕES DO PESQUISADOR AO INDIVÍDUO OU SEU REPRESENTANTE LEGAL SOBRE A PESQUISA, DE FORMA CLARA E SIMPLES, CONSIGNANDO:}

\section{JUSTIFICATIVA}

O estresse pode afetar diretamente o desempenho de jogadores de futebol na cobrança de pênaltis.

Diversos estudos frequentemente exploram como a cobrança de pênalti se altera quando o batedor está ansioso, estressado ou tranquilo, porém há necessidade de estudos que explorem o modo como esse estresse pode ser reduzido. 
Investigar se método de biofeedback associado a psicologia cognitivo-comportamental é uma técnica eficiente e eficaz para diminuir o estado de ansiedade do seu filho no momento da cobrança de um pênalti.

\section{PROCEDIMENTO}

- Em um primeiro momento, o seu filho responderá questionários para avaliar sua ansiedade, e logo após irá participar de uma competição de pênaltis, onde será filmado.

- Em uma segunda fase, os jogadores serão divididos em 2 turmas. Seu filho poderá participar de um trabalho de redução de pensamentos disfuncionais e ansiedade no momento do pênalti, junto com técnicas de relaxamento e biofeedback, ou poderá ser colocado no outro grupo, que irá servir de comparação.

- Em um terceiro momento será criado novamente o ambiente de cobrança de pênalti, e seu filho responderá novamente os questionários, antes da nova cobrança de pênaltis, que também será filmada.

\section{DESCONFORTOS E RISCOS ESPERADOS}

O estudo tem como objetivo reestruturar pensamentos que gerem sintomas de ansiedade, assim como reduzir esses sintomas através do biofeedback. Não existe nenhum tipo de risco para a saúde física e mental do seu filho.

\section{BENEFÍCIOS QUE PODERÃO SER OBTIDOS}

Seu filho poderá ser beneficiado com a redução de sua ansiedade no momento da cobrança de pênalti, e também da redução de ansiedade em geral.

\section{PROCEDIMENTOS ALTERNATIVOS QUE POSSAM SER VANTAJOSOS PARA O INDIVÍDUO:}

Os resultados esperados através do presente estudo podem fornecer informações relevantes e auxiliar o seu filho a alcançar seus ideais esportivos, superar obstáculos e dificuldades, além de aprimorar o autoconhecimento e equilíbrio emocional, social, es portivo e psicológico.

\section{IV - ESCLARECIMENTOS DADOS PELO PESQUISADOR SOBRE GARANTIAS DO SUJEITO DA PESQUISA:}

1.O(a) senhor(a) poderá solicitar informações, esclarecer dúvidas pessoais sobre os possíveis riscos e dos benefícios que o es tudo poderá trazer para os mesmos.

2. O(a) senhor(a) terá liberdade de retirar seu consentimento a qualquer momento e de deixar de participar do estudo, sem que isto lhe traga qualquer prejuízo.

3. O tratamento dos dados coletados garante e garantirá sigilo absoluto e privacidade ao seu filho.

4. O resultado desta pesquisa poderá ser apresentado ao clube, aos atletas e ao senhor, caso haja interesse.

5. O filho(s) do(a) Senhor(a) terão disponíveis a assistência no HU ou HCFMUSP, por eventuais danos à saúde, decorrentes da presente pesquisa

6. Garantimos ao Senhor(a) a salvaguarda da confidencialidade, sigilo e privacidade de todas as informações coletadas. 
V - INFORMAÇÕES DE NOMES, ENDEREÇOS E TELEFONES DOS RESPONSÁVEIS PELO ACOMPANHAMENTO DA PESQUISA, PARA CONTATO EM CASO DE INTERCORRÊNCIAS CLÍNICAS E REAÇÕES ADVERSAS.

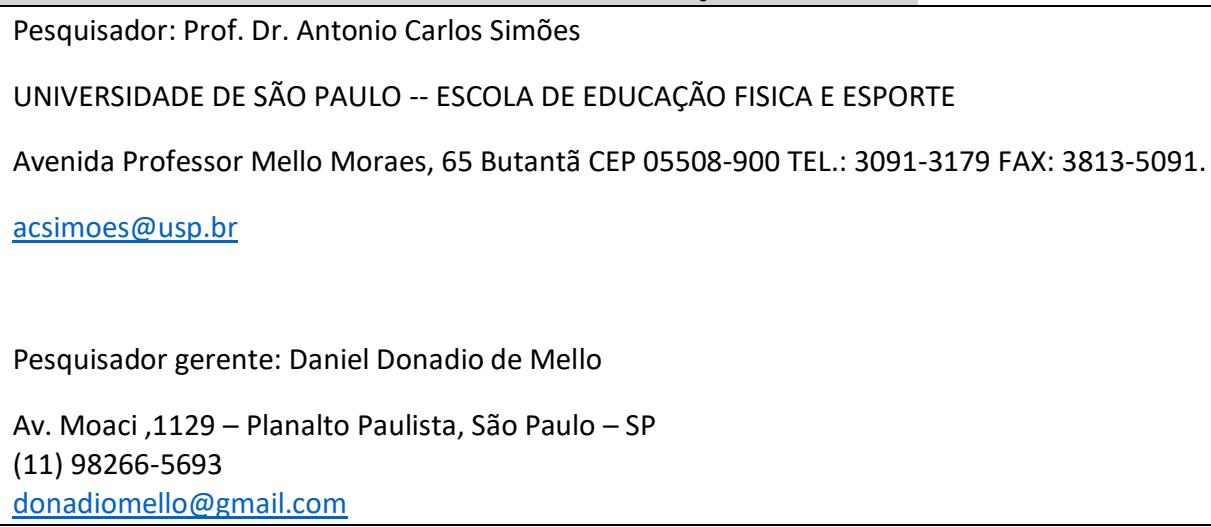

\section{VI. - OBSERVAÇÕES COMPLEMENTARES}

\section{VII - CONSENTIMENTO PÓS-ESCLARECIDO}

Declaro que, após convenientemente esclarecido pelo pesquisador e ter entendido o que me foi explicado, consinto em participar do presente Projeto de Pesquisa.

São Paulo,

assinatura do sujeito da pesquisa

ou responsável legal assinatura do pesquisador

(carimbo ou nome legível) 


\section{APÊNDICE D - Projeto Piloto}

Com o objetivo de testar a eficiência dos instrumentos bem como o método, realizou-se um estudo piloto com atletas entre quatorze e dezesseis anos pertencentes a uma equipe de futebol de um clube de relevância na cidade de São Paulo. Os procedimentos de coleta e os resultados serão apresentados abaixo.

\subsection{Delineamento do Estudo}

Os dados foram coletados durante as fases de treinamento programados pela equipe pesquisada, durante dois meses, em 2015. As coletas consistiram na variável ansiedade estado pelo questionário Revised Competitive State Anxiety Inventorie (CSAI-2R) após o aviso de que ocorreria uma competição por pênaltis em que eles seriam filmados e avaliados. Nas semanas sequentes, os fizeram 4 sessões de biofeedback e psicologia cognitivo-comportamental. Após isso, realizou-se novamente a competição, aplicando pela segunda vez o questionário CSAI-2R.

\subsection{Casuística}

O projeto piloto contou com a participação de 5 atletas amadores de futebol de campo, do sexo masculino, de 14 a 16 anos, pertencentes a um clube da cidade de São Paulo.

\subsection{Coleta de dados}

Todos os atletas participantes do estudo piloto assinaram o Termo de Consentimento Livre e Esclarecido, assim como seus responsáveis. O projeto foi aprovado pelo comitê de ética da Escola de Educação Física e Esporte da Universidade de São Paulo e obteve autorização do clube selecionado.

As coletas de dados de ansiedade consistiram em um encontro para preenchimento do questionário de ansiedade-estado, aproximadamente 10 minutos antes das cobranças de pênalti, e após o aviso de que seriam filmados e avaliados.

\subsection{Material e Método}

O método utilizado caracteriza-se por um delineamento experimental do tipo de pesquisa exploratória descritiva, no qual teve como finalidade comparar a ansiedade antes de competições com pênaltis anterior e posterior ao treinamento de biofeedback e psicologia cognitivocomportamental. O instrumento utilizado para avaliar a ansiedade estado foi o questionário Revised Competitive State Anxiety Inventory - 2 (CSAI-2R) validado para Português (FERNANDES e col 2012). O CSAI-2R foi utilizado com sua pontuação geral, e nos seus subitens (ansiedade somática, ansiedade cognitiva e autoconfiança).

\subsection{Resultados e Discussão}


Os resultados em relação as características da amostra, valores de estado de ansiedade-estado comparativa entre os sujeitos antes e depois do treinamento com biofeedback e psicologia cognitivocomportamental, respectivamente. Como é esperado que o treinamento tenha algum efeito, foi realizado o teste $t$ pareado unicaldal à direita para testar se a média dos resultados do CSAI-2R prétreino é maior que o pós-treino.

Tabela 1 - teste t pareado itens e subitens $(n=5)$

\begin{tabular}{|c|c|c|c|c|c|c|c|c|c|}
\hline & & \multicolumn{5}{|c|}{ Paired Differences } & \multirow[t]{3}{*}{$\mathrm{t}$} & \multirow[t]{3}{*}{ df } & \multirow{3}{*}{$\begin{array}{l}\text { Sig. (2- } \\
\text { tailed) }\end{array}$} \\
\hline & & \multirow[t]{2}{*}{ Mean } & \multirow[t]{2}{*}{$\begin{array}{c}\text { Std. } \\
\text { Deviation }\end{array}$} & \multirow{2}{*}{$\begin{array}{c}\text { Std. } \\
\text { Error } \\
\text { Mean }\end{array}$} & \multicolumn{2}{|c|}{$\begin{array}{l}90 \% \text { Confidence Interval of } \\
\text { the Difference }\end{array}$} & & & \\
\hline & & & & & Lower & Upper & & & \\
\hline Pair 1 & $\begin{array}{l}\text { Medida pré treino - Medida } \\
\text { pós treino }\end{array}$ & 6.600 & 4.393 & 1.965 & 2.412 & 10.788 & .359 & & .028 \\
\hline Pair 2 & Somatica1 - Somatica2 & 2.200 & 1.095 & .490 & 1.156 & 3.244 & .491 & & .011 \\
\hline Pair 3 & Cognitiva1 - Cognitiva2 & 3.000 & 2.236 & 1.000 & .868 & 5.132 & 3.000 & & .040 \\
\hline Pair 4 & Confianca1 - Confiança2 & 1.400 & 2.966 & 1.327 & -1.428 & 4.228 & .055 & & .351 \\
\hline
\end{tabular}

A ansiedade-estado dos jogadores de futebol amadores frente às cobranças de pênalti após o treinamento com biofeedback e psicologia cognitiva foi significativamente menor $(p=0.028)$ do que a mensurada antes do treinamento, rejeitando a hipótese nula. Ou seja, existem evidências de que a diferença entre as médias é diferente de zero. O índice de confiabilidade é de $95 \%$, em termos de confiança de que o treinamento com o uso do biofeedback e psicologia cognitiva é eficiente na redução da ansiedade-estado em jogadores de futebol para o momento da cobrança do pênalti.

O gráfico 1 e a tabela 2 mostram as médias de cada subtipo de ansiedade-estado: somática, cognitiva e autoconfiança (invertido). 


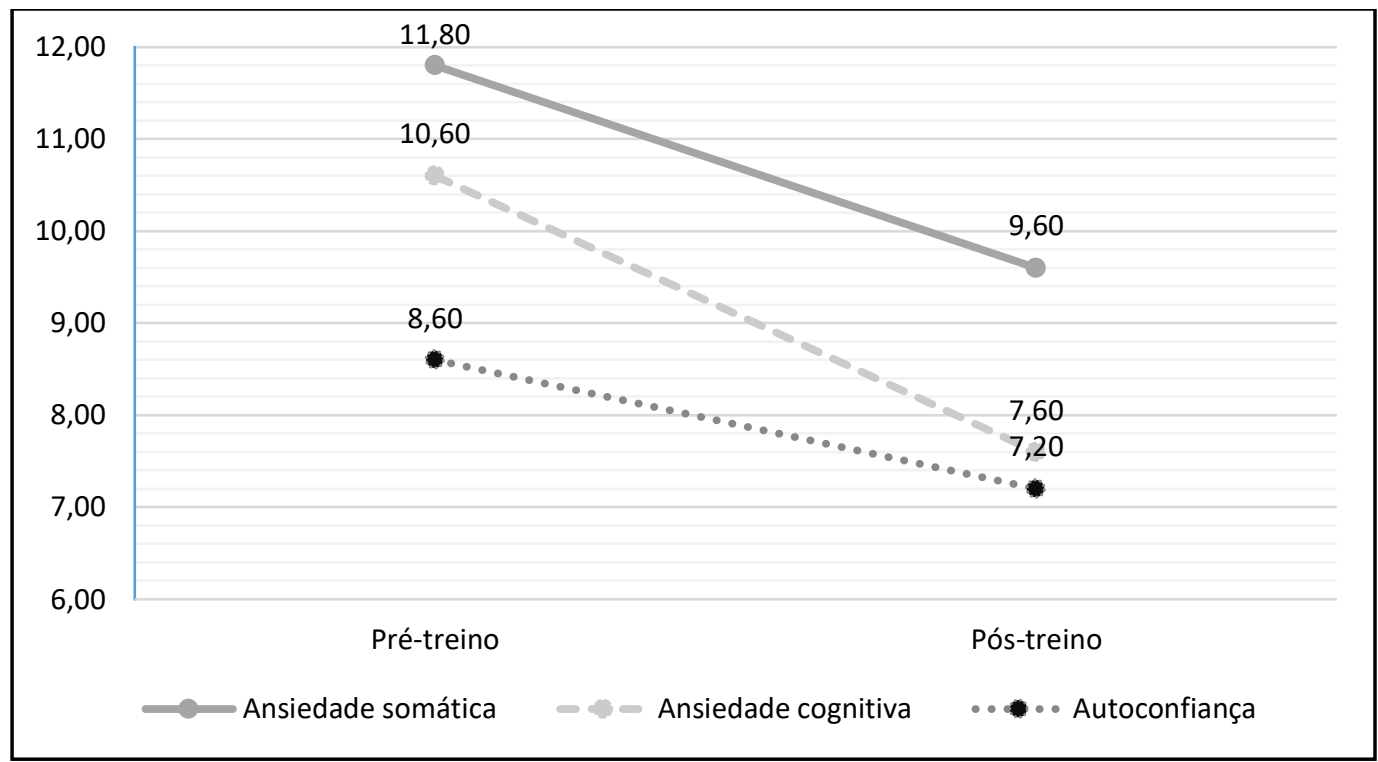

Gráfico 2 - Sub-itens CSAI-2R

\begin{tabular}{|l|r|r|r|}
\hline & Pré-treino & Pós-treino & Redução \% \\
\hline Ansiedade somática & 11,80 & 9,60 & $18,64 \%$ \\
\hline Ansiedade cognitiva & 10,60 & 7,60 & $28,30 \%$ \\
\hline Autoconfiança & 8,60 & 7,20 & $16,28 \%$ \\
\hline
\end{tabular}

Tabela 2 - Redução dos subitens CSAI-2R

Diante dos dados é possível notar uma considerável redução nas médias de ansiedade cognitiva $(28,30 \%$ do valor pré-treino), ansiedade somática $(18,64 \%)$ e influência negativa na autoconfiança $(16,28 \%)$.

Nessas observações, ressalta-se o fato da ansiedade cognitiva ter diminuído de maneira mais expressiva do que a ansiedade somática. Essa diminuição da ansiedade cognitiva nos leva a duas hipóteses: a primeira supondo que se o treinamento cognitivo com redução dos pensamentos automáticos disfuncionais foi um marcador responsável pela redução da ansiedade cognitiva, e; a segunda sugerindo que com a redução dos níveis de ansiedade somática alcançado pelo treinamento respiratório e biofeedback os pensamentos automáticos intrusos, geradores de ansiedade, diminuíram por consequência, abaixando os níveis de ansiedade cognitiva mensurados no CSAI-2R. 